Aus dem Institut für Pathologie

(Univ.-Prof. Dr. med. L. Füzesi)

der Medizinischen Fakultät der Universität Göttingen

\title{
Das Einwachsverhalten von zylindrischen Implantaten aus einer porösen Ti-6Al-4V-Legierung in die Femurkondyle des Kaninchens
}

\author{
INAUGURAL-DISSERTATION \\ zur Erlangung des Doktorgrades \\ der Medizinischen Fakultät der \\ Georg-August-Universität zu Göttingen
}

vorgelegt von

Alice Frosch geb. Sackmann

aus

Dschiginka (Russland)

Göttingen 2020 
Dekan:

Prof. Dr. med. W. Brück

Referent:

Prof. Dr. med. L. Füzesi

Ko-Referent:

Prof. Dr. Dr. Schliephake

Drittreferent:

Prof. Dr. R. Mausberg

Datum der mündlichen Prüfung: 10.12.2020 
Hiermit erkläre ich, die Dissertation mit dem Titel „Das Einwachsverhalten von zylindrischen Implantaten aus einer porösen Ti-6Al-4V-Legierung in die Femurkondyle des Kaninchens" eigenständig angefertigt und keine anderen als die von mir angegebenen Quellen und Hilfsmittel verwendet zu haben.

Göttingen, den...................

Alice Frosch 


\section{Inhaltsverzeichnis}

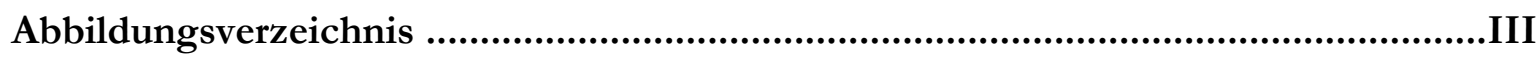

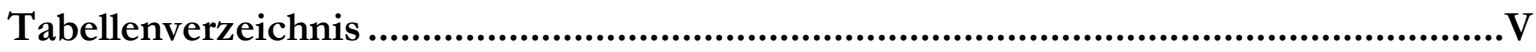

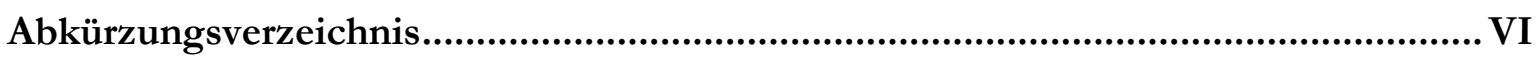

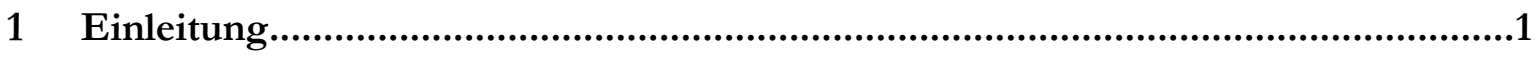

1.1 Implantatmaterialien zum Ersatz und zur Verstärkung von Knochengeweben ........ 1

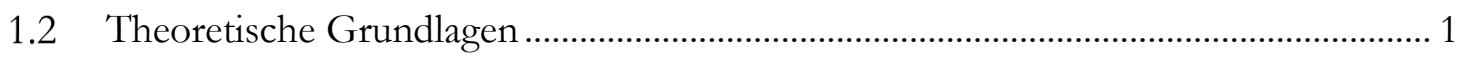

1.2.1 Anforderung an das Implantatlager............................................................. 1

1.2.2 Anforderungen an die Knochenersatzmaterialien............................................ 2

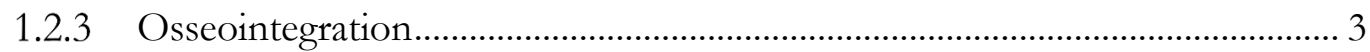

1.2.4 Einfluss mechanischer Belastung auf die Osseointegration............................... 4

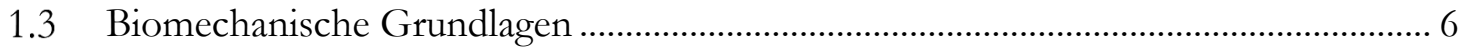

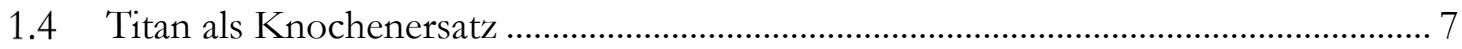

1.5 Titanschaum, das neue Knochenersatzmaterial .........................................................

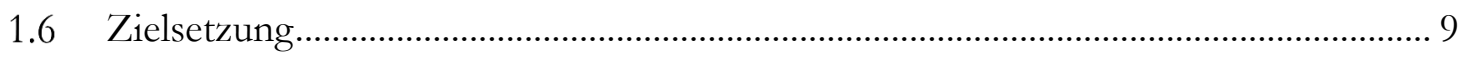

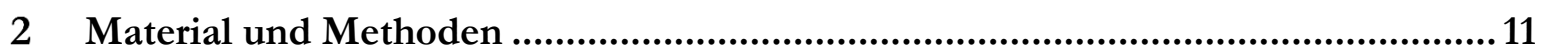

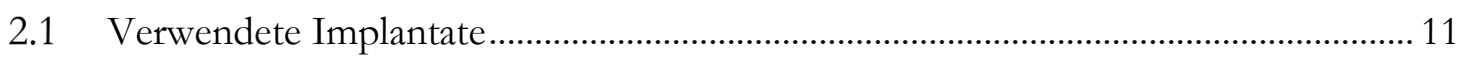

2.1.1 Poröse Implantate (Gruppe P) ……………….............................................. 11

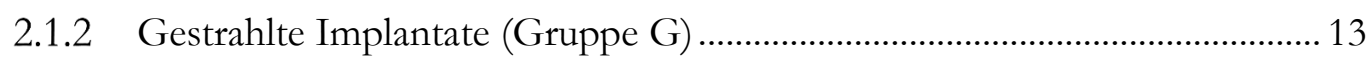

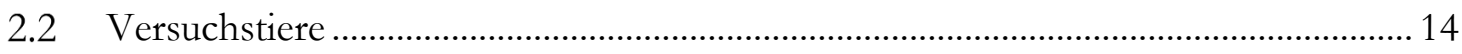

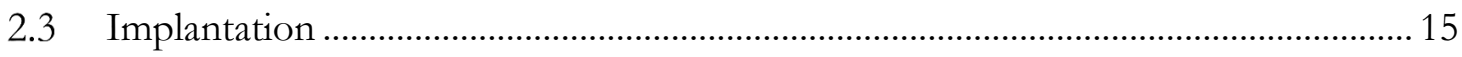

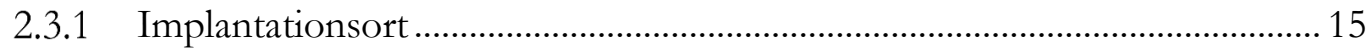

2.3.2 Implantationsvorbereitung und Medikation...................................................... 16

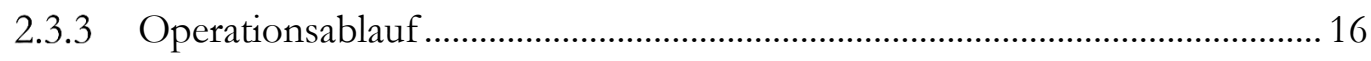

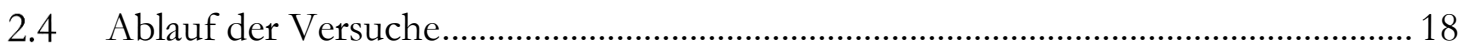

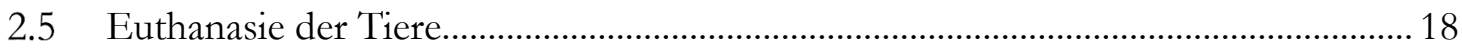

2.6 Eignung der Proben für Histologie........................................................................... 19

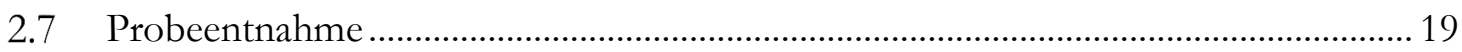

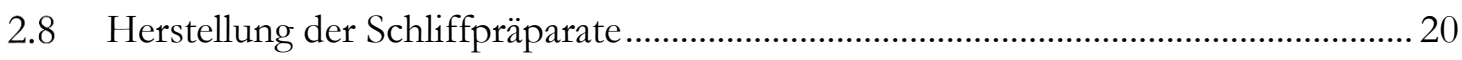

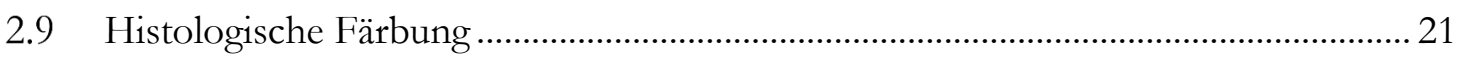

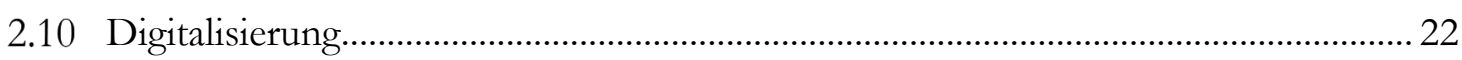

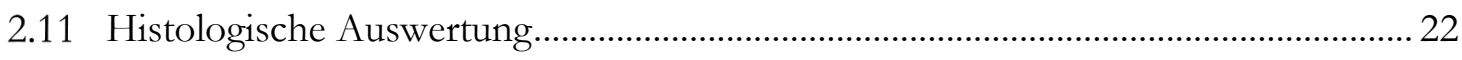




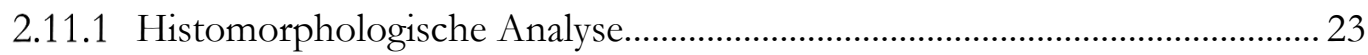

2.11.2 Histomorphometrische Analyse....................................................................... 24

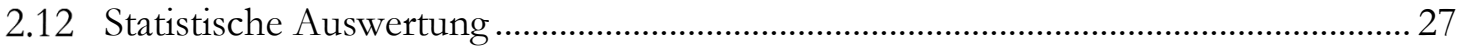

$3 \quad$ Ergebnisse

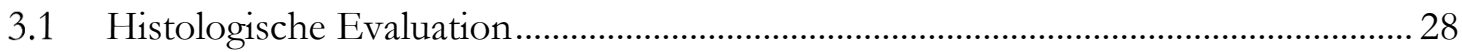

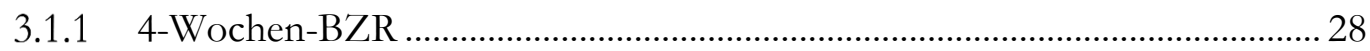

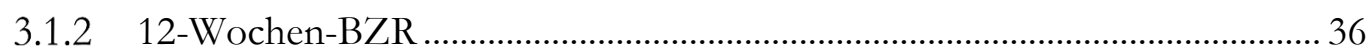

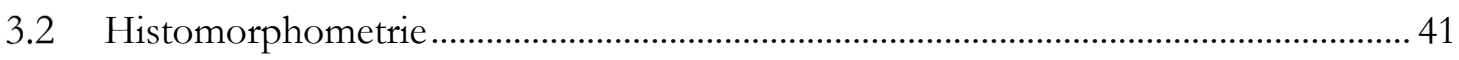

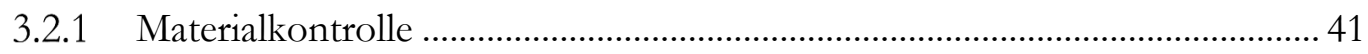

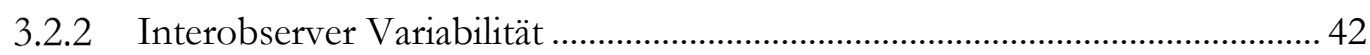

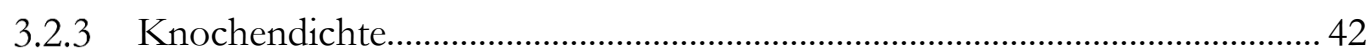

3.2.4 Bone to Implant Contact (BIC) ………...................................................... 49

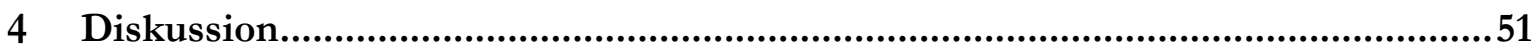

4.1 Studiendesign....................................................................................................... 51

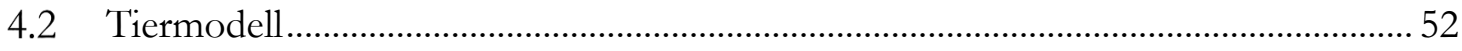

4.3 Untersuchungsmethoden............................................................................................ 54

4.4 Interobserver-Unterschiede......................................................................................... 55

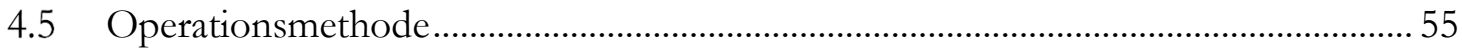

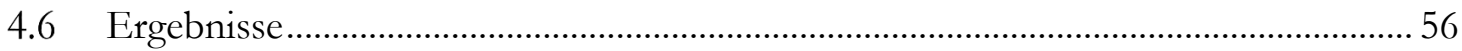

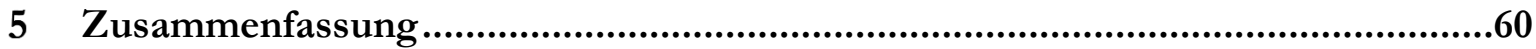

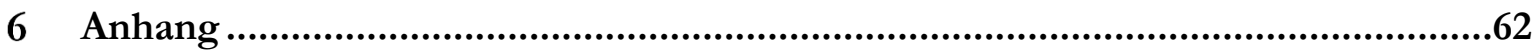

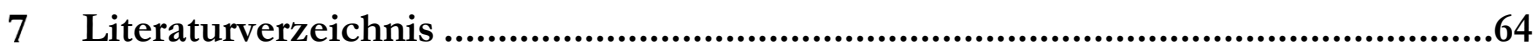




\section{Abbildungsverzeichnis}

Abbildung 2.1.1-1 Gesintertes, poröses Material aus Ti-6Al-4V-Legierung................................. 12

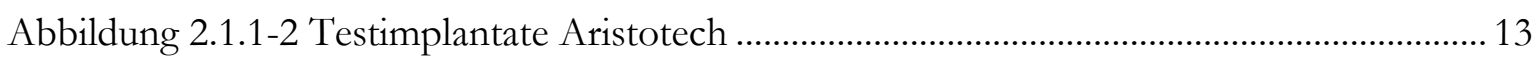

Abbildung 2.1.1-3 Schematische Darstellung der Implantate......................................................... 13

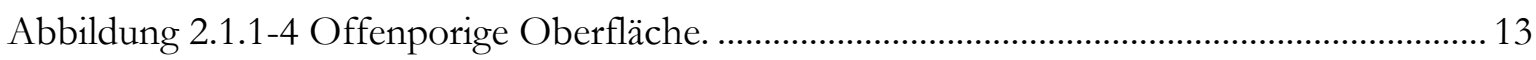

Abbildung 2.1.2-1 Testimplantate Aristotech für Implantationsversuche am Kaninchen........ 14

Abbildung 2.3.1-1 Schematische Darstellung des Kaninchenskeletts ........................................... 15

Abbildung 2.3.3-1 Implantationsort laterale Femurkondyle ........................................................ 16

Abbildung 2.3.3-2 Aufsicht auf die mediale Seite des Implantats nach Osteotomie................... 18

Abbildung 2.7-1 Ausrichtung des Femurpräparats.......................................................................... 20

Abbildung 2.8-1 Schematische Darstellung des Zuschnitts .......................................................... 21

Abbildung 2.9-1 Histologisch gefärbtes Trenn-Dünnschliffpräparat.......................................... 22

Abbildung 2.11.1-1 Poröses Implantat und die Implantattiefe..................................................... 23

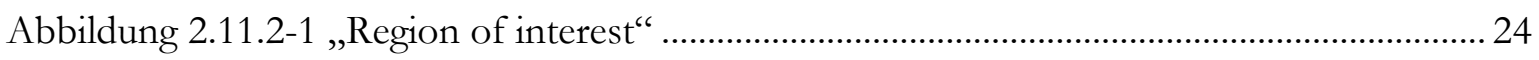

Abbildung 3.1-1 Laterale Femurkondyle des Kaninchens mit Titanimplantat ........................... 28

Abbildung 3.1.1-1 Poröses (P) und gestrahltes (G) Implantat........................................................ 29

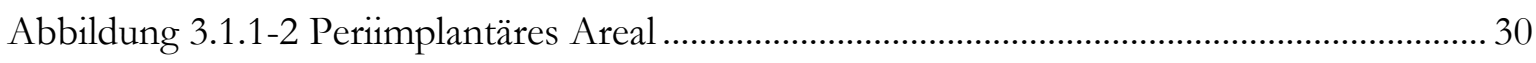

Abbildung 3.1.1-3 Poröses Implantat mit mineralisiertem Knochen und Osteoid ..................... 30

Abbildung 3.1.1-4 Poröses (P) und gestrahltes (G) Implantat nach 4-Wochen-BZR................. 31

Abbildung 3.1.1-5 Gestrahltes Implantat (1). Periimplantäre Region............................................. 32

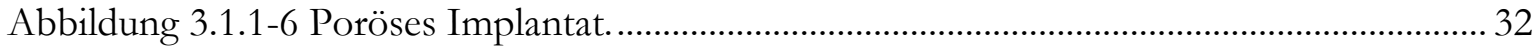

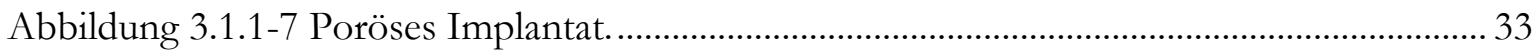

Abbildung 3.1.1-8 Poröses Implantat. Neugebildetes Spongiosabälkchen intraporös. .............. 33

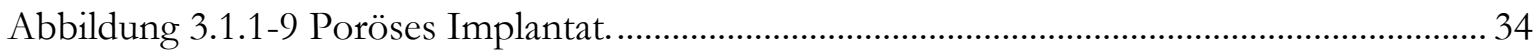

Abbildung 3.1.1-10 Poröses $(P)$ und gestrahltes Implantat $(G)$ nach 4-Wochen-BZR. ............ 35

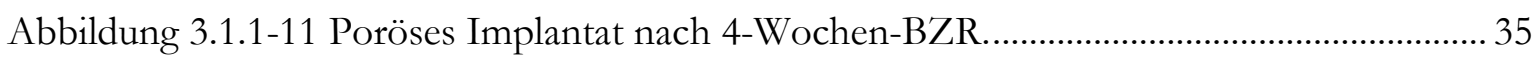

Abbildung 3.1.1-12 Ein neugebildetes Spongiosabälkchen intraporös in ROI 6........................ 36

Abbildung 3.1.2-1 Titanimplantat nach 12-Wochen-BZR mit kortikaler Lage............................ 37

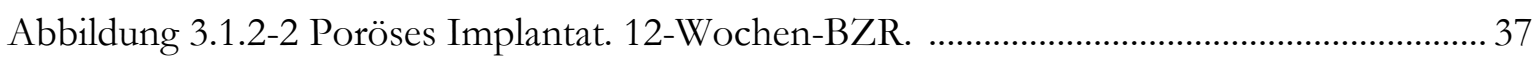

Abbildung 3.1.2-3 Poröses Implantat nach 12-Wochen-BZR....................................................... 38

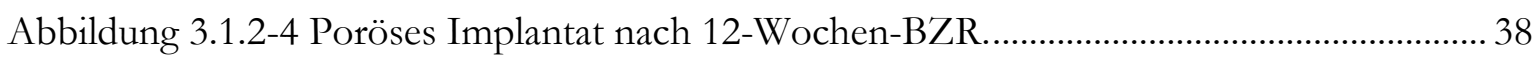

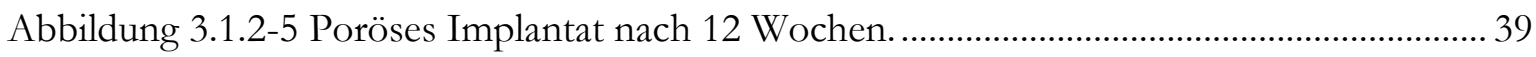

Abbildung 3.1.2-6 Poröses Implantat nach 12-wöchigem BZR..................................................... 40

Abbildung 3.2.1-1 Umfänge für Implantate G und P im zeitlichen Verlauf ............................... 41 


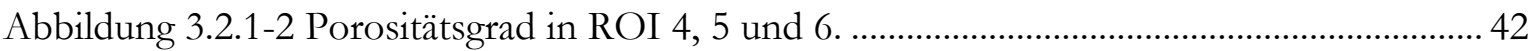

Abbildung 3.2.3-1 Periimplantäre Knochendichte (ROI 1) nach 4 und 12 Wochen .................. 45

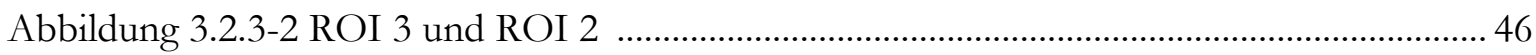

Abbildung 3.2.3-3 Knochendichte (\%) in ROI 5 (A) und ROI 6 (B) ......................................... 49

Abbildung 3.2.4-1 Verteilung des Parameters Knochenanlagerung (mm)................................... 50 


\section{Tabellenverzeichnis}

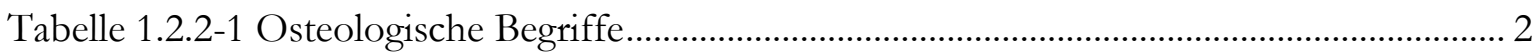

Tabelle 1.2.4-1 Elastizitätsmodul (Gigapascal) im Vergleich ........................................................... 8

Tabelle 2.1.1-1 Größe der verwendeten Titan-und Paraformaldehydperlen................................. 11

Tabelle 2.11.2-1 Einteilung der ,region of interest“ 1-6 peri- und intraimplantär ...................... 25

Tabelle 3.2.3-1 Mittelwert und Standardabweichung für Knochendichte (\%) in ROI 1 ............ 42

Tabelle 3.2.3-2 Mittelwert und Standardabweichung für Knochendichte (\%) und Implantattiefe in ROI 1 nach 4-wöchigem BZR......................................... 43

Tabelle 3.2.3-3 Mittelwert und Standardabweichung für Knochendichte (\%) in ROI 2-3 ........ 43

Tabelle 3.2.3-4 Mittelwert und Standardabweichung für Knochendichte (\%) periimplantär ... 43

Tabelle 3.2.3-5 Mittelwert und Standardabweichung für Knochendichte (\%) in ROI 1 ........... 44

Tabelle 3.2.3-6 Mittelwert und Standardabweichung für die Knochendichte (\%) in ROI 1 nach der Implantattiefe.

Tabelle 3.2.3-7 Mittelwert und Standardabweichung für die Knochendichte (\%) in ROI 2-3. 44

Tabelle 3.2.3-8 Mittelwert und Standardabweichung für Knochendichte in ROI 2-3

Tabelle 3.2.3-9 Mittelwert und Standardabweichung für Knochendichte in ROI 1 zur Implantattiefe in den Implantaten $\mathrm{G}$ und $\mathrm{P}$ 46

Tabelle 3.2.3-10 Mittelwert und Standardabweichung für Knochendichte (\%) in ROI 2 und 3 für die Implantate $G$ und $P$ 47

Tabelle 3.2.3-11 Mittelwert und Standardabweichung für Knochendichte in ROI 2-3 zur Implantattiefe 47

Tabelle 3.2.3-12 Mittelwert und Standardabweichung für Knochendichte (\%) in ROI 4-6 zur Implantattiefe 48

Tabelle 3.2.4-1 Mittelwert und Standardabweichung für Knochenanlagerung (mm) 49 


\section{Abkürzungsverzeichnis}

$\begin{array}{ll}\text { BIC } & \text { bone-implant-contact } \\ \text { BMP } & \text { bone morphogenetic proteins } \\ \text { BZR } & \text { Beobachtungszeitraum } \\ \text { D } & \text { Diameter } \\ \text { dest. } & \text { destillata } \\ \text { E-Modul } & \text { Elastizitätsmodul } \\ \text { Ek } & \text { Edelkorund } \\ \text { Fa } & \text { Firma } \\ \text { GPa } & \text { Gigapascal } \\ \text { G } & \text { gestrahltes Implantat } \\ \text { H } & \text { Stunde } \\ \text { i.v. } & \text { intravenös } \\ \text { P } & \text { poröses Implantat } \\ \text { PMMA } & \text { Polymethymethacrylat } \\ \text { ROI } & \text { region of interest } \\ \text { UMG } & \text { Universitätsmedizin Göttingen }\end{array}$




\section{Einleitung}

\subsection{Implantatmaterialien zum Ersatz und zur Verstärkung von Knochengeweben}

In den letzten sechzig Jahren führte die Optimierung und Standardisierung chirurgischer Operationstechniken und des Implantationsmaterials zu verbesserten Ergebnissen auf dem Gebiet chirurgischer und orthopädischer Implantologie. Auf dem Gebiet der Biomaterialforschung sind ebenfalls ständig Fortschritte zu verzeichnen. Die Entwicklung neuer Implantationsmaterialien spielt eine entscheidende Rolle für Heilungsprozesse und die Dauerfestigkeit der Implantate. Dabei ist das wichtigste Ziel, die mechanische Funktion des zu ersetzenden Knochens so schnell wie möglich wiederherzustellen und eine funktionsstabile Beweglichkeit zu erreichen.

\subsection{Theoretische Grundlagen}

\subsubsection{Anforderung an das Implantatlager}

Die Anforderungen an das Implantationsmaterial und das Implantatlager im Knochen sind hoch. Unabhängig vom verwendeten Implantationsmaterial spielt die Qualität des Implantatlagers im Knochen bei Einheilungsprozessen eine wichtige Rolle. Lexer befasste sich bereits 1924 mit den biologischen und biomechanischen Verhältnissen des Knochens und unterschied drei Arten von Transplantatlager (Lexer 1924): ersatzstarkes Lager, ersatzschwaches Lager und ersatzunfähiges Lager.

Das ersatzstarke Lager zeichnet sich durch vitalen Knochen mit guter Vaskularisation aus, während das ersatzunfähige Lager aus avitalen Knochen besteht und mit schlechten Durchblutungsverhältnissen und Instabilität vergesellschaftet ist. Daraus ergeben sich die Anforderungen an das Knochenersatzmaterial. Die biologische Potenz des zu verwendenden Materials ist umso höher zu wählen, je schlechter die lokalen Bedingungen im Knochenlager sind. Andererseits kann ein optimales Transplantat wegen der ausbleibenden biologischen Antwort kaum in ein ersatzunfähiges Lager integriert werden (Lexer 1924). 


\subsubsection{Anforderungen an die Knochenersatzmaterialien}

Die Implantationsmaterialien müssen zahlreiche werkstofftechnische und biologische Anforderungen erfüllen (Albrektsson und Johansson 2001) .

Die idealen Eigenschaften eines Knochenersatzmaterials sind: osteogenetische Wirkung durch Knocheneigensynthese, hohe biologische Potenz keine immunologischen Abstoßungsreaktionen, Freiheit von toxischen oder mutagenen Nebenwirkungen, Sterilität, vollständiger knöcherner Einund Umbau, osteoinduktive Wirkung durch Anregung zur Differenzierung pluripotenter Stammzellen zu Osteoblasten, osteokonduktive Wirkung durch Leitschienenfunktion.

Die letzten genannten Eigenschaften haben Albrektsson und Johansson genauer untersucht und erklärt (Albrektsson und Johansson 2001) (Tabelle 1.2.2-1).

Tabelle 1.2.2-1 Osteologische Begriffe (Albrektsson und Johansson 2001)

\begin{tabular}{|l|l|l|}
\hline Begriff & Definition & Beispiel \\
\hline $\begin{array}{l}\text { Osteoin- } \\
\text { duktiv }\end{array}$ & $\begin{array}{l}\text { Osteoinduktive Substanzen begünstigen die Knochenneubil- } \\
\text { dung durch Freisetzung von Knochenwachstumsfaktoren }\end{array}$ & $\begin{array}{l}\text { bone morphogenetic protein } \\
\text { (BMP) }\end{array}$ \\
\hline $\begin{array}{l}\text { osteo- } \\
\text { konduktiv }\end{array}$ & $\begin{array}{l}\text { Osteokonduktive Substanzen begünstigen das Anwachsen } \\
\text { von Knochen, dienen als Leitschiene }\end{array}$ & $\begin{array}{l}\text { Synthetische und allogene Kno- } \\
\text { chenersatzmaterialien }\end{array}$ \\
\hline osteogen & $\begin{array}{l}\text { Osteogene Substanzen enthalten Zellen, die fähig sind Kno- } \\
\text { chen zu bilden oder selbst zu Knochenzellen auszudifferen- } \\
\text { zieren. }\end{array}$ & $\begin{array}{l}\text { Autogenes Transplantat: Kno- } \\
\text { chenspäne aus dem Beckenkamm }\end{array}$ \\
\hline
\end{tabular}

Das moderne Konzept der Biokompatibilität umfasst sowohl die Verträglichkeit des implantierten Materials mit dem umliegenden Gewebe als auch die Fähigkeit, spezifische Funktionen vor Ort zu übernehmen (Remes und Williams 1992).

Die wichtigste Voraussetzung für Biokompatibilität in der langzeitmedizinischen Anwendung ist die Schadenfreiheit des verwendeten Materials und die Fähigkeit einer biologischen und chemischen Inertheit. Einige Faktoren beeinflussen die Biokompatibilität: chemische Zusammensetzung, mechanische Eigenschaften, elektrische Leitfähigkeit und Oberflächenbeschaffenheit.

Dabei zählen nicht nur die zelluläre und biomechanische Verträglichkeit mit dem Implantatlager (z. B. Knochen), sondern auch mit dem umliegenden Gewebe (z. B. Knochenmark oder Knorpel) (Tengvall und Lundstrom 1992).

Die Biokompatibilität ist unter anderem abhängig von der Materialtoxizität und der Korrosionsund Degradationsrate (Elias 2011). Mineralische, metallische oder polymere Werkstoffe kommen 
je nach Zusammensetzung entweder als inerte oder abbaubare Materialien zum Einsatz. Die Korrosionsresistenz ist ein wichtiger Punkt bei der Auswahl eines langzeitverankerten Knochenersatzes.

Das Verständnis der Interaktionen zwischen Implantat und Implantatlager spielt ebenfalls eine wichtige Rolle in der Osseointegration. Die primäre Befestigung der Implantate im Knochen erfolgt durch eine mechanische Verankerung. Die Faktoren, die diesen ersten Schritt beeinflussen, sind die Oberflächenbeschaffenheit des Implantats wie Oberflächenrauigkeit oder Oberflächenstrukturierung. Die Rauigkeit der Implantatoberfläche erhöht die Zelladhäsion und Zelldifferenzierung (Aparicio et al. 2003). Auch Hilfsimplantate (u. a. Schrauben und Schellen) können die Primärstabilität verbessern. Ein weiterer entscheidender Schritt in der dauerhaften Implantatverankerung ist die ossäre Integration des Implantats.

\subsubsection{Osseointegration}

Die Langzeitergebnisse der erfolgreichen ossären Integration eines Implantats hängen von mehreren Parametern ab, da dabei ein Zusammenspiel ineinandergreifender biologischer und mechanischer Faktoren stattfindet. Das Verständnis der Osseointegration erfordert Kenntnisse über die Biologie und Physiologie des Knochens, über Materialeigenschaften und chirurgische Operationstechniken sowie über die Pathophysiologie der Frakturheilung (Albrektsson T und Albrektsson B 1987; Albrektsson T et al. 1981). Branemark definierte den Begriff Osseointegration als strukturellen und funktionellen direkten Kontakt zwischen vitalen Knochen und Implantatoberfläche (Branemark 1983).

Albrektsson beschreibt das Phänomen der Osseointegration auf der Grundlage lichtmikroskopischer Untersuchungen als Kontakt zwischen Knochen und Implantatoberfläche (Albrektsson et al. 1981). Dabei ist die Abwesenheit einer bindegewebigen Trennschicht zwischen Implantatoberfläche und Knochen entscheidend.

Der Begriff „Osseointegration“ wurde im Verlauf der Zeit modifiziert und den modernen Forschungsergebnissen angepasst. Die wichtigsten Anforderungen an eine erfolgreiche Osseointegration sind das Vorhandensein einer biokompatiblen Implantatoberfläche und die Präsenz eines vitalen Implantatlagers. Eine Reihe von Faktoren ist entscheidend für erfolgreiche Langzeitergebnisse: die Auswahl des Metalls für den Knochenersatz, das Design und die Oberflächenbeschaf- 
fenheit des Implantats, die anatomische Lokalisation des Implantationsortes, die Vitalität des Knochens, chirurgische Operationstechniken, aber auch die Compliance des Patienten (Albrektsson und Zarb 1993).

Die Osseointegration als biologisches Konzept beschreibt die Inkorporation eines Fremdkörpers in vitalen Knochen mit daraus resultierender Fixation und Stabilität während funktioneller Belastung (Boyan et al. 1996). Histologisch gesehen bedeutet dies eine Zelldifferenzierung und ein Zellwachstum mit direkter Anlagerung von Knochenzellen an die Implantatoberfläche.

\subsubsection{Einfluss mechanischer Belastung auf die Osseointegration}

Die Formation und Stabilität des neugebildeten Knochens am Implantat entsteht durch eine Kombination aus Knochenanlagerung und -resorption. Die Balance zwischen diesen Prozessen ist abhängig von verschiedenen Stimuli wie mechanische Belastung, biomechanische Kraftflüsse sowie das Auftreten von Entzündungsreaktionen. Dementsprechend beschreibt der Begriff Osseointegration einen dynamischen Prozess mit ständigen An- und Umbauvorgängen des Knochens in Abhängigkeit der auftretenden Stimuli.

Die mechanische Belastung ist ein integraler Bestandteil der Knochenphysiologie und beeinflusst Regulationsvorgänge der Homöostase sowie Remodeling- und Reparaturvorgänge des Knochens. Julius Wolff, ein deutscher Anatom und Chirurg, beschrieb als Erster den Einfluss der mechanischen Belastung auf die Umbau- und Reparaturvorgänge des Knochens (Wolff 1892). Das Wolffsche Transformationsgesetz besagt, dass der Knochen unter mechanischer Belastung tendenziell aufgebaut wird und an Festigkeit zunimmt, während es bei fehlender mechanischer Belastung eher zu einem Knochenabbau kommt. Diese biologischen Vorgänge werden als Mechanotransduktion bezeichnet (Allori et al. 2008). Die Mechanotransduktion beschreibt den Einfluss komplexer zellulärer und molekularer Mechanismen auf Knochenmorphologie und Architektur. Dabei wird physische Belastung übersetzt in korrespondierende zelluläre Signalwege. Deformationskräfte lösen Druckschwankungen im lakunokanalikulären Netzwerk des Knochens aus. Über den veränderten Fluss kann so die mechanische Belastung an Osteozyten weitergeleitet werden. Mechonorezeptoren der Osteozyten werden auf diese Weise aktiviert und setzen so komplexe intrazelluläre mechanotransduktive Kaskaden in Gang (Allori et al. 2008; Burr et al. 2002). Hochfrequente Beanspruchung beeinflusst die Knochenmasse und fehlende Aktivität führt zum Knochenabbau. Die Zunahme der Festigkeit des Knochens bei Belastung lässt sich mit der Beobachtung von Rubin und seiner Arbeitsgruppe erklären (Rubin und Lanyon 1985). Sie untersuchten den Einfluss mechani- 
scher Stimulation auf den Knochen der hinteren Extremitäten des Schafes. Dabei führte hochfrequente Anstrengung der Tiere bei niedriger Amplitude zu einem signifikanten Anstieg der spongiösen Knochenmasse (Rubin et al. 2001).

Die Primärstabilität spielt eine wichtige Rolle in der Osseointegration, da sich gezeigt hat, dass eine übermäßige Bewegung des Implantats im Implantatlager zu einer schlechteren knöchernen Integration des Implantats führen kann (Schmit-Neuenburg und Stuermer 1987). Zu große Verschiebebewegungen zwischen Implantatoberfläche und Knochenlager führen zur bindegewebigen Abkapselung des Implantats bei fehlendem direktem Implantat-Knochen-Kontakt. Dies gilt insbesondere für rigide Werkstoffe wie rostfreier Stahl, Aluminiumoxid, Zirkoniumoxid und cpTitan (solides Titan) als Implantationsmaterial (Elias 2011).

Unter dem Begriff „Implantatstabilität“ wird die Fähigkeit des Implantatlagers verstanden, unter mechanischer Beanspruchung seine Struktur und biologische Funktion zu erhalten und die Übertragung von Kräften und Drehmomenten vom Implantat in das angrenzende Gewebe zu gewährleisten (Elias 2011). Ein direkter Kontakt zwischen Implantatoberfläche und Knochen ohne interponiertes Bindegewebe verbessert die primäre Implantatstabilität und erhöht damit die Wahrscheinlichkeit einer dauerhaft stabilen sekundären und tertiären Implantatstabilität (Elias 2011). Die primäre Stabilität unmittelbar nach der Implantation ist somit ein entscheidender Baustein für eine erfolgreiche Osseointegration.

Die sekundäre Stabilität beschreibt die Situation des Implantats im Knochen nach primärer Osseointegration in der Remodelingphase des Knochens. In diesem Stadium ist der primäre Heilungsprozess abgeschlossen und reife Knochenzellen charakterisieren das „Interface“. Die Aufrechterhaltung der Osseointegration im weiteren Verlauf wird als tertiäre Stabilität bezeichnet. Dieses ist die Dauerform der Grenzschicht und wird regulären Anpassungsvorgängen unterworfen (Elias 2011).

Biokompatible Werkstoffe und ein optimierter mechanischer Kraftfluss fördern entsprechend die Osseointegration. Fremdkörperreaktionen (z. B. auf PMMA-Knochenzement) oder mechanische Fehlbelastungen begünstigen die Ausbildung einer bindegewebigen Grenzschicht, verringern damit die knöcherne primäre Implantatstabilität und können letztendlich zum Knochenabbau und dauerhafter mechanischer Instabilität eines Implantats führen (Elias 2011). 


\subsection{Biomechanische Grundlagen}

Eine Grundvoraussetzung für gute Langzeitergebnisse in der Implantologie bzw. Endoprothetik ist die stabile knöcherne Integration der Implantate. Um dies zu gewährleisten, muss eine gute primäre Implantatstabilität mit einem entsprechenden Dauerdruck des Knochengewebes auf die Implantatoberfläche bestehen und übermäßige Mikrobewegungen des Implantats im Implantatlager sollten möglichst vermieden werden. Dies kann erreicht werden, indem das Implantatlager gegenüber dem Implantat geringfügig unterdimensioniert wird. Beim Einbringen des Implantats kommt es somit zu einem leichten „Aufdehnen“ des Implantatlagers, wodurch eine Press-Fit-Situation mit direktem Implantat-Knochen-Kontakt erzielt wird. Der Vorteil ist eine gleichbleibende Kraft- und Druckverteilung vom Implantat auf den Knochen. Unter dieser Dauerdruckbedingung kann die funktionelle Anpassung des Knochens stattfinden (Pauwels 1973). Bewegungen oder Scherkräfte unmittelbar nach der Implantation werden durch die Press-Fit-Situation verringert, wodurch die Primärstabilität ohne bindegewebige Abkapselung des Implantats und die Osseointegration begünstigt werden (Carter und Giori 1991).

Unterliegt der Kraftfluss im zeitlichen Verlauf einer qualitativen und quantitativen Veränderung, kann es zu periimplantären Umbauvorgängen des Knochens kommen. Eine Minderbelastung des Knochens führt zu atrophen Abbauvorgängen, während aus einer Überbelastung eine periprothetische Fraktur resultieren kann. Jedoch entsprechen solche Umbauprozesse im Rahmen der Osseointegration zunächst einer physiologischen Anpassung und werden Remodeling genannt. Die Remodelingprozesse sind während der primären und sekundären Osseointegration zum Teil erheblich, jedoch ist das Remodeling darüber hinaus ein fortwährender Prozess (Knoch 1990). Voraussetzung für eine gute Langzeitprognose ist ein möglichst wenig veränderter, tragfähiger Knochen, weshalb übermäßige Remodelingvorgänge (z. B. Knochenresorption) nach abgeschlossener Osseointegration vermieden werden sollten.

Neben der Implantationstechnik (z. B. Press-Fit-Verfahren) beeinflusst auch die Elastizität des verwendeten Implantatmaterials den Kraftfluss (sog. Stress-Shielding) und damit die Langzeitstabilität. Große Unterschiede in der Elastizität zwischen Implantatmaterial und Knochen führen zu mehr Stress-Shielding als kleinere. So führen Titanlegierungen aufgrund der geringeren Steifigkeit im Vergleich zu steiferen Materialen (geringere Elastizität) wie z. B. Stahl zur gleichmäßigeren Kraftübertragung am Implantat-Kochen-Interface des Materials. Werkstoffe mit geringerer Steifigkeit als die der Kortikalis führen zu einer Überbelastung der implantattragenden Strukturen und somit zu Resorptionsvorgängen und Implantatlockerung (Versagen des ,iso-elastischen“ Prinzips) (Long und Rack 1998). 


\subsection{Titan als Knochenersatz}

Titan und seine Legierungen sind in der medizinischen Implantologie seit den siebziger Jahren weit verbreitet. Gründe dafür sind deren optimale Eigenschaften. Titan weist eine gute Biokompatibilität, eine hohe Festigkeit bei relativ geringem Gewicht, ein relativ niedriges Elastizitätsmodul und eine hohe Korrosionsbeständigkeit im Vergleich mit anderen metallischen Biomaterialien auf (Long und Rack 1998).

Sowohl die Biokompatibilität als auch die Korrosionsresistenz werden durch $\mathrm{O}_{2}$-Atome an der Oberfläche des Titans erreicht. Die Sauerstoffatome bilden eine Schicht von 5 bis $10 \mathrm{~nm}$ Dicke und schützen so das darunterliegende Metall vor Korrosion. Diese Oxidschicht verleiht der Oberläche des Metalls seinen neutralen Charakter und lässt das implantierte Material vom umgebenden Gewebe nicht als Fremdkörper erkennen (Elias 2011). Somit wird die Fremdkörperreaktion wesentlich geringer ausfallen oder sogar ausbleiben. Titan erlaubt mit diesen Eigenschaften einer Vielzahl von Molekülen sich an dessen Oberfläche zu binden und somit die Integration in das umliegende Gewebe zu verbessern. Dieser Bindungsvorgang wird unter anderem durch Entzündungsreaktionen, wie zum Beispiel im Rahmen des Einheilungsprozesses gefördert (Schmidt 1992). Weitere Gründe für das weite Anwendungsgebiet von Titanimplantaten sind eine gute Festigkeit trotz geringen Gewichts und ein relativ niedriges Elastizitätsmodul (Long und Rack 1998).

\subsection{Titanschaum, das neue Knochenersatzmaterial}

Seit tausenden Jahren versuchen die Menschen, sich die positiven Eigenschaften von natürlichen Strukturen zu Nutze zu machen. „Lernen von der Natur als Anregung für eigenständiges technisches Weiterarbeiten“ - diese Formulierung hat einer der bedeutendsten Wissenschaftler unserer Zeit, ein Pionier der Bionik in Deutschland, Prof. Werner Nachtigall aufgestellt (Nachtigall 2002). Bionik beschäftigt sich mit dem Erkennen und Übertragen von Lösungen aus der belebten Natur auf Technik. Vom Verpackungsmaterial über Schall- oder Wärmedämmmaterialien bis hin zur Automobilindustrie oder Raumfahrttechnik findet das bionische Prinzip in der heutigen Zeit häufig Anwendung.

Auf der Suche nach einem optimalen Verhältnis zwischen dem Gewicht und der Festigkeit eines Implantats hat die Medizintechnik ebenfalls ein Beispiel aus der belebten Natur herangezogen. Der spongiöse Knochen weist eine interessante Struktur aus miteinander verbundenen Stegen auf. Die 
dabei entstandenen Zwischenräume sind ebenfalls untereinander verbunden. Die Knochensubstanz weist herausragende physikalische und mechanische Eigenschaften auf und bleibt trotz eines relativ geringen Gewichts stabil.

Obwohl Titan und seine Legierungen exzellente Eigenschaften aufweisen, werden Probleme beschrieben, die überwiegend darauf zurückzuführen sind, dass die auf herkömmliche Weise hergestellten Titanimplantate aus festen Schmiedelegierungen gefertigt werden. Die eingesetzten Implantate weisen eine höhere Festigkeit und geringere Elastizität im Vergleich mit dem umliegenden Knochengewebe auf (Tabelle 1.2.4-1).

Tabelle 1.2.4-1 Elastizitätsmodul (Gigapascal) im Vergleich: Knochen vs. solides Titanimplantat.

\begin{tabular}{|l|l|}
\hline Material & Gigapascal \\
\hline Titan & 110 \\
\hline Kortikaler Knochen & $12-20$ \\
\hline Spongiöser Knochen & $0,02-3$ \\
\hline
\end{tabular}

Ein Knochen-Implantat-Verbund mit solchen Unterschieden im Elastizitätsmodul macht sich vor allem im Bereich der Kraftübertragung bemerkbar. Aufgrund der höheren Festigkeit wird der Kraftfluss unter Belastung zugunsten des Implantates umgeleitet. Der umliegende Knochen wird so im natürlichen Bewegungsablauf von der Belastung abgeschirmt und unterliegt in einem geringen Masse dem Abbau im Rahmen des Remodeling (sog. Stress-Shielding). Der Prozess des StressShielding basiert auf dem Wolffschen Gesetz und beschreibt die Reduktion der Knochendichte in Abwesenheit physischer Belastung. So kommt es im zeitlichen Verlauf zur nicht ausreichenden Verankerung der Implantate im Gewebe und zur Implantatlockerung. Eine Balance zwischen Implantatdauerbelastbarkeit und Festigkeit/Steifigkeit des Materials musste gefunden werden.

Bereits 1943 wurde die Herstellung eines porösen metallischen Materials dokumentiert. Sosnik versuchte mithilfe von Schmelzen von Quecksilber im Aluminium Poren zu erzeugen (Simancik 2002). White und Weber waren die ersten Beschreiber einer verbesserten Osseointegration im porösen Material (White et al. 1972). Zu Beginn wurden durch eine thermale Vorbehandlung aus Kalziumkarbonatexoskeletten von Korallen Knochenersatzmaterialien hergestellt, die ebenfalls exzellente Korrosionseigenschaften aufwiesen. Der Herstellungsprozess wurde als „replamineform process" bezeichnet. Aufgrund einer geringen mechanischen Belastbarkeit fanden jedoch diese Materialien keine dauerhafte Anwendung in der Orthopädie (Ryan et al. 2006).

Die Verwendung poröser Materialien für orthopädische rekonstruktive Chirurgie als Ersatz für Autografs ist auf gesteigertes Interesse gestoßen und hatte eine hohe Zahl von wissenschaftlichen 
Arbeiten zur Folge. Für die lasttragende orthopädische Anwendung haben Metalle bisher als Basis für poröse Beschichtungen das beste Potential gezeigt. Dies führte zur Herstellung poröser Titanimplantate (Ryan et al. 2006).

In der Literatur wird beschrieben, dass die Verankerung des neuen, offenporigen Materials durch seine Architektur begünstigt wird (Bobyn et al. 1982; Murray und Semple 1981). Um die Unterschiede in der Festigkeit und Elastizität des eingebauten Materials zu verringern, wurde ein Implantat nach dem Vorbild der Natur gefertigt. Es gleicht dem spongiösen Knochen (Hartmann 2012).

Diese neuartigen offenporigen Titanimplantate werden nach einem Prinzip, welches als Sintern bezeichnet wird, hergestellt. Die knochenähnliche Schwammstruktur der Testobjekte entsteht durch Versetzen des Titanpulvers mit Polyoxymethylen-Perlen, sodass sich die wesentlich kleineren Titanpulverperlen um die Polyoxymethylenpartikel anlagern, welche nach einer Wärmebehandlung unter Vakuumbedingungen verdampfen, wodurch an deren Stelle gleichgroße Poren entstehen (Bram 2013). Die zusammengesinterten Titanperlen formen die Begrenzungen der Poren und bilden ein Gerüst aus Stegen und Platten der konkav geformten zwischen den Polymerkugeln befindlichen Schichten. Die Poren sind im gesamten Implantat verteilt und weisen eine sehr variable Größe und Verteilung entsprechend der gewählten Siebung auf.

Es handelt sich hierbei jeweils um gasverdüste, kugelige Pulverperlen. Durch gezielte Variation der Platzhalterpulverperlengröße ist es bei diesem Herstellungsverfahren möglich, das Elastizitätsmodul des Titanschaums dem des Knochens anzupassen und so das Risiko der Spannungsabschirmung deutlich zu minimieren.

Des Weiteren berühren sich die meisten Polymerkugeln untereinander, weshalb nahezu alle Poren Verbindungen untereinander und zur Oberfläche aufweisen. Die Interkonnektivität der Poren ist unabdingbar für das Einwandern osteoblastärer Stammzellen in das Innere des Implantats, um so die Osseointegration zu triggern (Cameron et al. 1978).

\subsection{Zielsetzung}

Die vorliegende Dissertation beschäftigte sich mit histologischen und histomorphometrischen Untersuchungen von Implantaten und deren umliegendem Knochengewebe. Dazu wurden zu Vergleichszwecken zwei morphologisch unterschiedliche Implantatmaterialien bei gleicher chemischer 
Zusammensetzung und gleichen äußeren Abmaßen verwendet. Für die neuartigen, offenporigen Implantate, gefertigt aus Titanschaum, dienten die herkömmlichen Titanimplantate aus homogener Schmiedelegierung mit sandgestrahlter Oberfläche als Kontrollgruppe. Hierfür wurde eine zweiteilige Versuchsreihe konzipiert, nach der der implantattragende Knochen von Kaninchen in gleicher Weise mit Implantaten versorgt und nach 4 bzw. 12 Wochen untersucht wurde.

Das Ziel dieser Untersuchung war sowohl für die neuen offenporigen Titanimplantate als auch für die Kontrollgruppe mit sandgestrahlter Oberfläche:

- die Charakterisierung der Biokompatibilität und Osseointegration der Ti-6Al-4V-Implantate im Verlauf der Verweildauer,

- die morphologische Beschreibung des Kontaktgewebes und seine Ausrichtung unter dem biomechanischen Einfluss des Fremdkörpers,

- die qualitative Beschreibung der Implantat-Verankerung anhand der Morphometrie des neugebildeten Knochens und

- die besondere Erörterung der Implantat-Porosität und die Besonderheiten der Gewebereaktionen. 


\section{Material und Methoden}

\subsection{Verwendete Implantate}

\subsubsection{Poröse Implantate (Gruppe P)}

Die im Rahmen der Studie Anthrocells zu untersuchende Titanschaumimplantate wurden im Platzhalterverfahren nach Bram im Fraunhofer-Institut in Bremen hergestellt (Bram 2013).

Der erste Schritt des Herstellungsprozesses war die Fertigung einer Titanpulver-Platzhalter-Mischung. Verwendet wurden Granulate aus einer Ti-6Al-4V-Legierung der Fa. TLS (Bitterfeld-Wolfen, Deutschland) mit einer Perlengröße von durchschnittlich $35 \mu \mathrm{m}$ sowie Paraformaldehydperlen (Fa. ACROS Organics, Schwerte, Deutschland) mit einer Reinheit $>90 \%$. Um eine mittlere Porengröße mit einem Durchmesser von bis zu $400 \mu \mathrm{m}$ zu erreichen, wurden zunächst die Paraformaldehydperlen mit einem Durchmesser unter $500 \mu \mathrm{m}$ mit einer Analysensiebmaschine (AS 2000 control g, Fa. Retsch, Haan, Deutschland) abgesiebt. Die Paraformaldehydperlen unterliegen während des Sinterungsprozesses einer Schrumpfung. So konnte die in der Literatur beschriebene Porengröße von ca. $400 \mu \mathrm{m}$ erreicht werden. Die Größenangaben der Platzhalterperlen (Tabelle 2.1.1-1) wurde in Anlehnung an die Arbeit von Bobyn gewählt (Bobyn et al. 1980).

Tabelle 2.1.1-1 Größe der verwendeten Titan-und Paraformaldehydperlen

\begin{tabular}{|l|l|}
\hline Material & Pulverperlengröße $(\mu \mathrm{m})$ \\
\hline Titan & $22-45$ \\
\hline Platzhalter (Paraformaldehyd) & 500 \\
\hline
\end{tabular}

Bobyn und seine Arbeitsgruppe beschrieben eine positive Auswirkung der Porengröße zwischen 50 und $400 \mu \mathrm{m}$ auf das Einwachsverhalten des Knochens. Das Mischungsverhältnis des Titangranulats zur Platzhalterperlenmenge musste 498,38 g zu 189,75 g betragen, um eine Porosität von 29 $\% \mathrm{zu}$ erreichen. Es folgte eine Homogenisierung des Gemisches mittels $26 \mathrm{~g}$ Paraffin in $200 \mathrm{ml}$ Hexanfraktion (Fa. Merck KGaA Darmstadt, Deutschland) in einem Taumelmischer (BIOMATION Wissenschaftliche Geräte GmbH, Mainz, Deutschland). Nach Abdampfen des Hexans konnten mithilfe einer hydraulischen Presse Vorformen der Prüfkörper in gewünschter Größe gefertigt werden (Abbildung 2.1.1-1). Zum Entfernen der Platzhalter wurden die gefertigten Presslinge in einem Kendro-Umluftofen (Typ VT6060 MU/2, Fa. Heraeus, Villingen-Schwenningen, Deutschland) mit einer Kronlab-Dosierpumpe Typ VP120 (Fa. Labexchange, Burlandingen, Deutschland) im Stickstoffstrom auf $110^{\circ} \mathrm{C}$ erhitzt und mit Salpertersäuredampf versetzt, um so 
die Paraformaldehydperlen vollständig katalytisch zu polymerisieren. Die Säure wurde anschlieBend mit Stickstoff ausgespült. Der Sintervorgang fand in einem Entbinder- und Sinterofen ELNIK 3002 (Fa. THERMCONCEPT GmbH, Bremen, Deutschland) statt. Die Prüfkörper wurden mit Argon-Atmosphäre für eine Stunde bei $1300{ }^{\circ} \mathrm{C}$ gesintert.

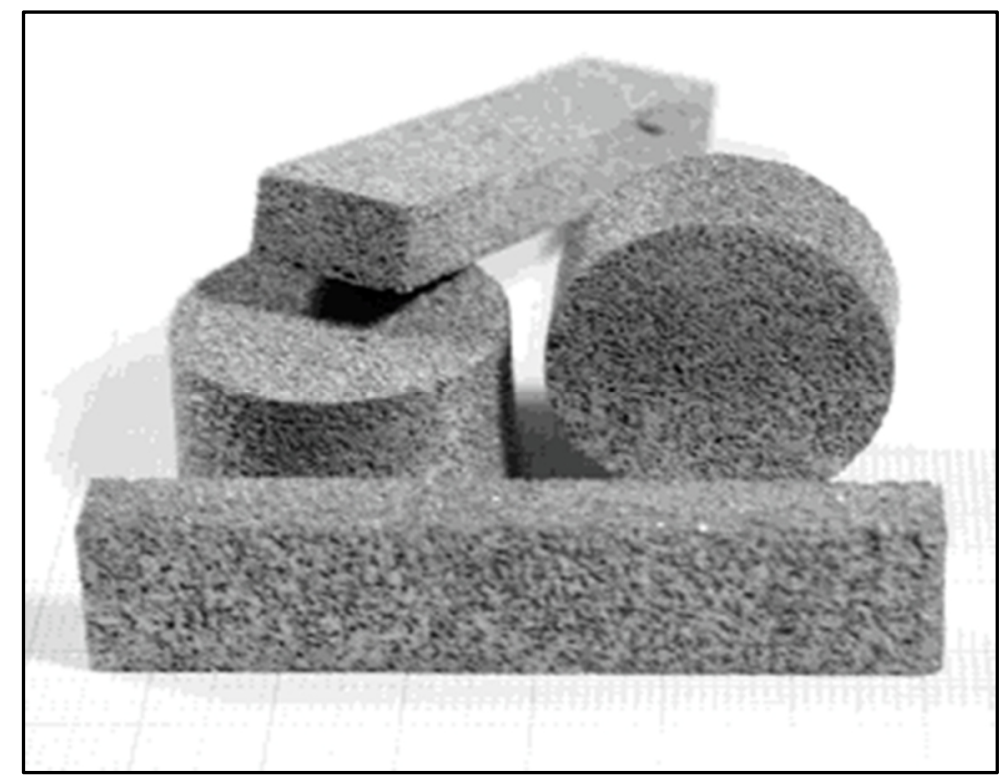

Abbildung 2.1.1-1 Gesintertes, poröses Material aus Ti-6Al-4V-Legierung (ISO 5832-3, ASTM F136, (C) Aristotec).

Die Sinterkörper wurden anschließend auf einer Drehbank abgedreht. Die fertigen Implantate wiesen eine Länge von $7 \mathrm{~mm}$ und einen Durchmesser von 5,6 $\mathrm{mm}$ auf. Zentral waren die Implantate mit einer Bohrung von 1,6 mm Durchmesser versehen (Abbildung 2.1.1-2). Diese diente einerseits intraoperativ der Aufnahme eines Setzinstrumentes, andererseits nach Explantation der Aufnahme eines Spickdrahtes (Durchmesser 1,5 mm) zur achsgerechten Ausrichtung beim Trimmen zur Herstellung der histologischen Schnitte. Die Kanten der Implantate waren abgerundet, um das Einführen in die Bohrkanäle zu erleichtern (Abbildung 2.1.1-3). Um eine optimale Press-Fit-Situation herzustellen, waren die Implantate im Radius um 0,1 mm größer als eine diamantbesetzte Hohlschleife (Articomed, Jörg Giessler e. K., Schlüchtern, Deutschland), mit Hilfe derer der Knochenzylinder entnommen wurde. Die Implantate wiesen eine nach außen offenporige Struktur auf (Abbildung 2.1.1-4), um die sofortige Durchblutung nach der Implantation und somit das Einwachsen des Knochens zu erleichtern. Die Poren wiesen eine Interkonnektivität im Implantatinneren auf. 


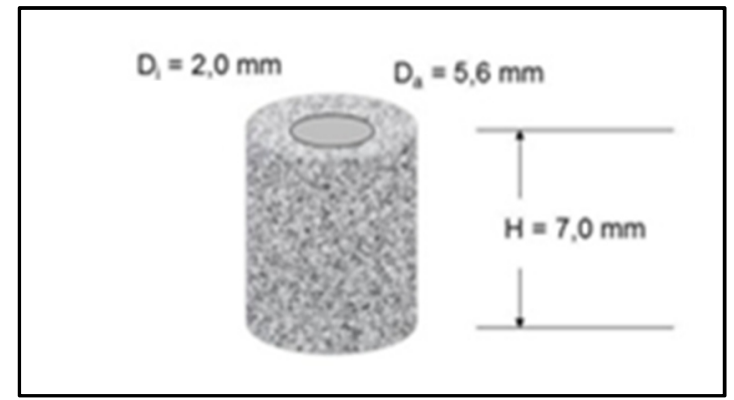

Abbildung 2.1.1-2 Testimplantate Aristotech für Implantationsversuche am Kaninchen (C Aristotec).

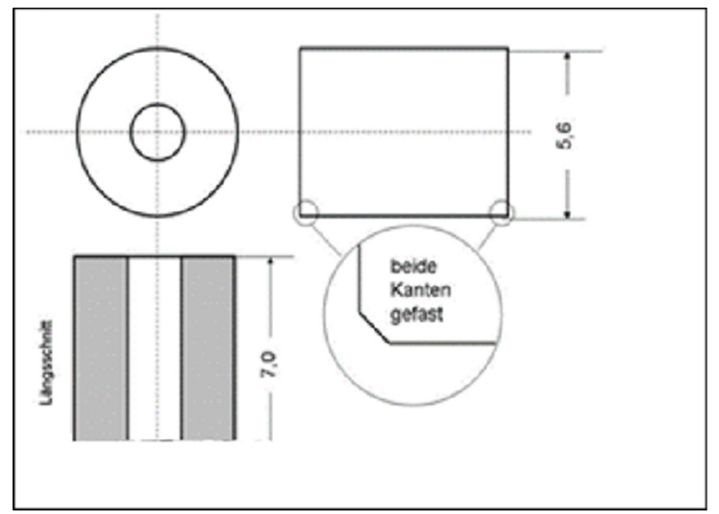

Abbildung 2.1.1-3 Schematische Darstellung der Form und Maße der Implantate mit den abgerundeten Kanten (C) Aristotec).

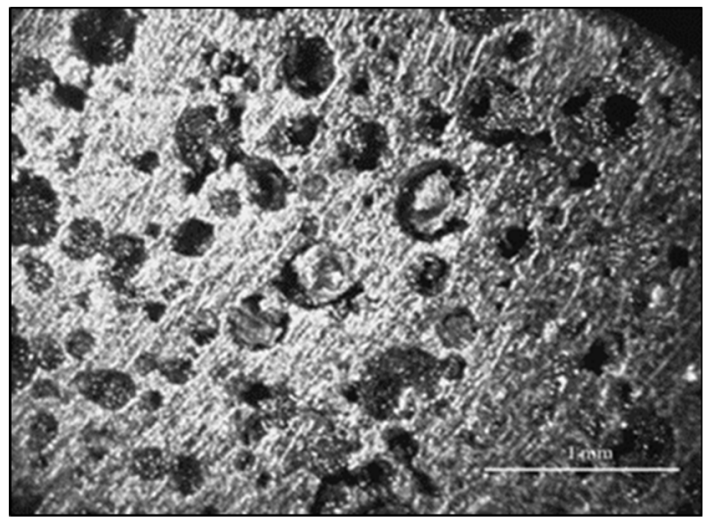

Abbildung 2.1.1-4 Offenporige Oberfläche des porösen Implantats (C Aristotec).

\subsubsection{Gestrahlte Implantate (Gruppe G)}

Bei der Kontrollgruppe handelte es sich um zylindrische Implantate gleicher Gestalt und Dimensionierung, welche durch Drehen aus einer homogenen Titanschmiedelegierung Ti-6Al-4V hergestellt wurden. Um die Oberfläche biokonduktiv zu gestalten, wurde diese durch Korundstrahlen 
grob aufgeraut (Abbildung 2.1.2-1). Als Strahlmittel wurde Edelkorund (EK = 99,7 Aluminiumoxid) mit einer Körnergröße von $1000 \mu \mathrm{m}$ (P20) (Fa. Merete Medical GmbH, Berlin, Deutschland) verwendet. Die verwendeten Implantate hatten dasselbe Implantatdesign. Der Außendurchmesser der Implantate $\mathrm{D}=5,6 \mathrm{~mm}$ basierte auf einem Übermaß von 0,2 $\mathrm{mm}$ gegenüber dem Außendurchmesser der Hohlschleife, die für die Erzeugung des Implantatlagers (Articomed, Jörg Giessler e. K., Schlüchtern, Deutschland) benutzt wurde (Soldner 1999).

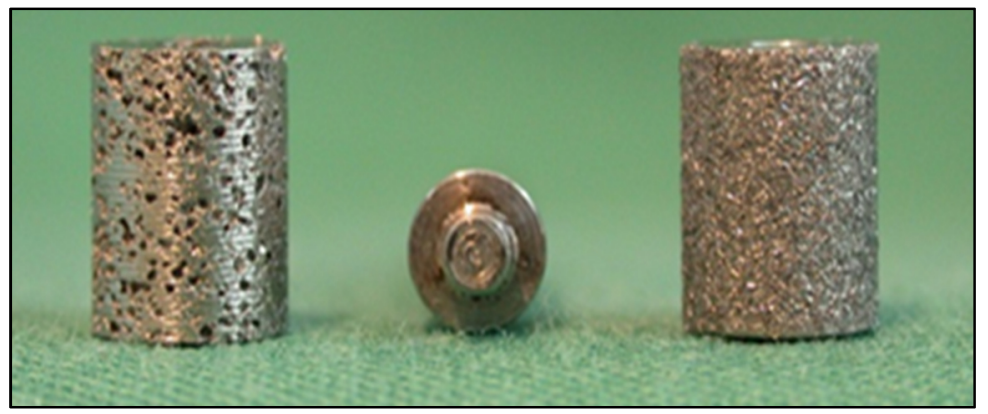

Abbildung 2.1.2-1 Testimplantate Aristotech für Implantationsversuche am Kaninchen. Poröses (links) und gestrahltes (rechts) Ti-6Al-4V-Implantat.

\subsection{Versuchstiere}

Die vorliegende Studie wurde im Rahmen eines Drittmittelprojekts UMG/Orthopädie und der Fa. Aristotech GmbH durchgeführt (Förderung ZIM KA2002302MD8). Auf Basis des deutschen Tierschutzgesetzes erfolgte die Genehmigung von der Bezirksregierung Braunschweig als Tierversuchsvorhaben unter der Nr. 33.14-42502-04-10/0059 am 30.04.2010. Hierzu wurden 16 Chinchilla-Bastard-Kaninchen (Charles River Laboratories) mit einem Gewicht von ca. 3 kg, was einem Lebensalter zwischen 12 und 14 Wochen entspricht, eingesetzt. In diesem Alter gelten die Kaninchen als ausgewachsen.

Die Unterbringung der Tiere erfolgte artgerecht. Als Nahrung wurden ein kommerziell erhältliches Kaninchenfutter und Trinkwasser ad libitum herangezogen. Nach einer wöchentlichen Eingewöhnungsphase wurden die Operationen durchgeführt. Ein Tier musste aufgrund schwerer Bissverletzungen aus der Versuchsreihe herausgenommen werden. 


\subsection{Implantation}

\subsubsection{Implantationsort}

Als Implantationsort wurde die laterale Femurkondyle gewählt (Abbildung 2.3.1-1). Einerseits war hier eine gute Zugänglichkeit auf den Knochen gegeben, andererseits eigneten sich die Größenverhältnisse der lateralen Femurkondyle für die Implantation. Um den potenziellen Effekt der Ortsabhängigkeit zu nutzen, wurden die Implantate nahezu vollständig im Bereich der Metaphyse positioniert. Die Implantate hatten somit Kontakt mit der Kortikalis, der Spongiosa und dem Markraum.

Die beidseitigen Implantationen erfolgten einzeitig. Am Implantationsort wurden die Implantate parallel zur Kondylenachse und mittig im lateralen Kondylus positioniert, sodass das Einwachsverhalten unter gleichen Bedingungen, abhängig von der Lage im Präparat, ermittelt werden konnte (Abbildung 2.3.1-1). Jedes Tier wurde mit einem Implantat im Bereich der linken und der rechten Kondyle des distalen Femurs mit jeweils einer neuartigen gesinterten Ti-6Al-4V-Legierung (P-Implantat) und einem Modell aus homogenem Vollmaterial der gleichen Legierung mit grob gestrahlter Oberfläche (G-Implantat) als Kontrollgruppe versehen. Die Auswahl der Seiten geschah intraoperativ randomisiert.

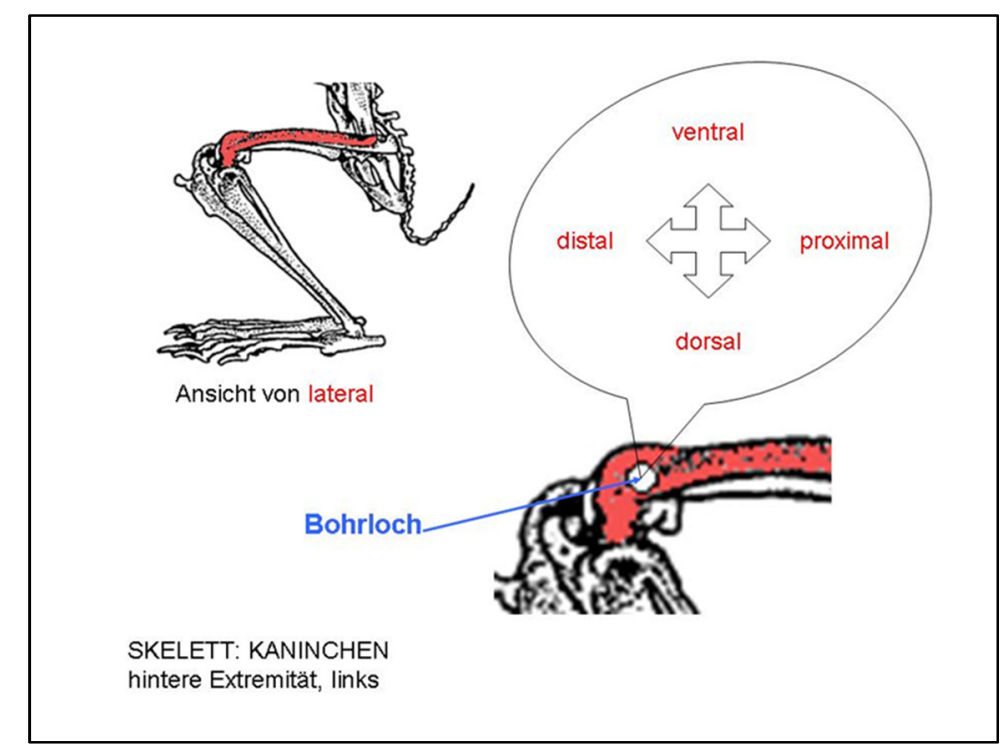

Abbildung 2.3.1-1 Schematische Darstellung des Kaninchenskeletts und der angestrebten Bohrlochposition am lateralen Femurkondylus 


\subsubsection{Implantationsvorbereitung und Medikation}

Zur Identifizierung der Tiere wurde eine Tätowierung der Tiernummer in der Innenseite eines Ohres vorgenommen. Jedes Versuchstier wurde vom Versuchsbeginn bis zum Einschläfern beobachtet, um sämtliche Vorfälle, die das Wohlbefinden des Tieres beeinträchtigten, zu vermerken. Jedes Tier wurde unmittelbar präoperativ gewogen und untersucht. Die Sedation erfolgte mit einer intramuskulären Injektion von $0,3 \mathrm{ml}(10 \mathrm{mg})$ Xylazin $+0,5 \mathrm{ml}(50 \mathrm{mg})$ Ketanest pro kg Körpergewicht. Zur Aufrechterhaltung der Narkose wurde ein intravenöser Zugang in die große Ohrvene gelegt und mit einem Perfusor (B. Braun, Melsungen Deutschland) verbunden. Darüber konnte eine konstante Konzentration von $5 \mathrm{ml}$ Xylazin und $5 \mathrm{ml}$ Ketanest zusammen mit $40 \mathrm{ml} \mathrm{NaCl}$ $1,7 \mathrm{ml} / \mathrm{kg} / \mathrm{h}$ verabreicht werden.

\subsubsection{Operationsablauf}

Die Rasur erfolgte am Kniegelenk mit ausreichender Freilegung der Innenseite der Hinterläufe, ergänzt mit einer Sprühdesinfektion durch eine alkoholische Lösung (Hautdesinfektionsmittel, B.Braun Softasept ${ }^{\circledR}$ N, Melsungen, Deutschland). Anschließend folgten die Seitlagerung des Tieres und das sterile Abdecken des Operationsgebiets.

Die Identifikation der Implantationsstelle erfolge durch Tasten des Übergangs der durchbauten Wachstumsfuge zur Diaphyse. An dieser Stelle wurde der Hautschnitt gesetzt. Durch eine atraumatische Präparationsmethode wurde der laterale Kondylus des Femurs freigelegt. Der Operationssitus konnte mittels eingesetzter Haken dargestellt und offengehalten werden (Abbildung 2.3.3-1).

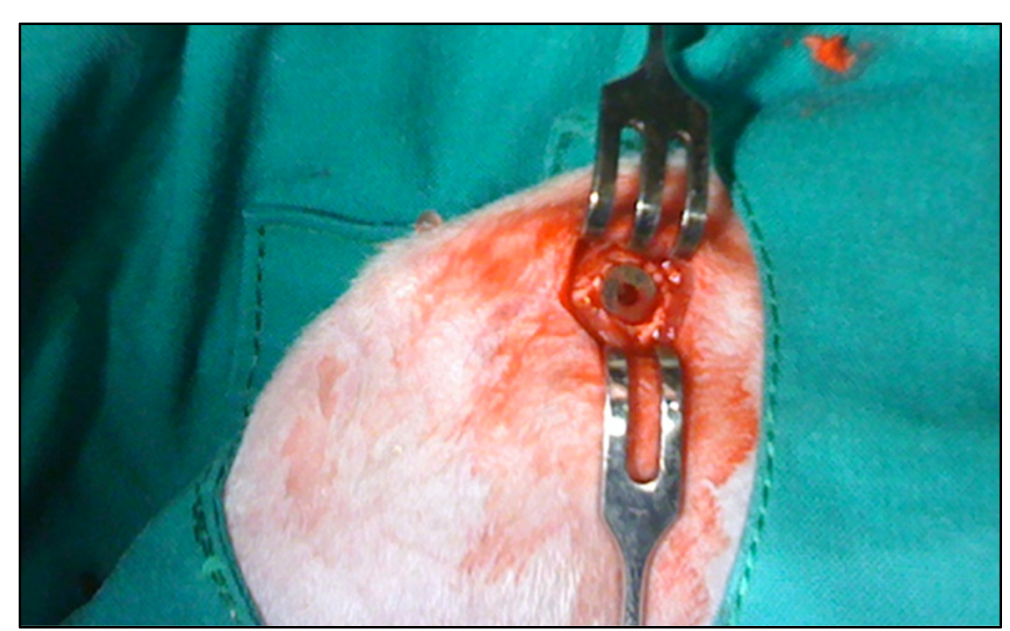

Abbildung 2.3.3-1 Implantationsort laterale Femurkondyle. 
Zum Erstellen des Implantatbettes in Form eines Zylinders wurde eine mit Diamant beschichtete Hohlschleife (Articomed, Jörg Giessler e. K., Schlüchtern, Deutschland) mit einem äußeren Durchmesser von 5,4 mm verwendet. Diese durfte nur unter Rotation angesetzt und bei fortwährender Kühlung mit physiologischer Kochsalzlösung in Betrieb genommen werden. Anschließend erfolgte die Entnahme des Knochenzylinders, ggf. mit angepasstem Extractor. Die vorgefertigten Bohrlöcher wurden nochmals kontrolliert und gegebenenfalls von Knochenresten im Bohrloch durch Curettage befreit. Die erreichte Bohrtiefe durfte anschließend nicht mehr als 5,5 bis 6,0 mm betragen. Die Eingangsebene im Bereich des kortikalen Knochens wurde zum Erleichtern des Einführens der Prüfkörper mit Hilfe einer Kugelfräse mit einem Durchmesser von 5,6 mm erweitert. Damit konnte eine reproduzierbare Press-Fit-Situation gewährleistet werden. Die Implantation des Titanzylinders erfolgte mit leichten Hammerschlägen unter Zuhilfenahme einer Einsetzhilfe. Eine mögliche Fissurbildung bei der Einführung der Implantate musste unbedingt vermieden werden. Die Eindringtiefe wurde genauestens kontrolliert. Bei der schrägen Knochenoberfläche musste ein Kompromiss zwischen Überstand und einer zu tiefen Positionierung gefunden werden. Eine Positionierung unterhalb der Kortikalis und ein Verkippen des Implantats musste grundsätzlich vermieden werden. Das Ziel war die optimale Lage des Implantats überwiegend im spongiösen Knochengewebe der lateralen Femurkondyle (Abbildung 2.3.3-2). Der OP-Bereich wurde nach abgeschlossener Implantation gründlich gespült (Cutasept F Lösung, HARTMANN AG, Heidenheim, Deutschland). Der Wundverschluss erfolgte mittels Subkutannaht in Einzelknopftechnik mit einem 4.0-Vicryl-Faden und anschließender intrakutaner Hautnaht in fortlaufender Technik mit dem 4.0-Monocryl-Faden. Unmittelbar postoperativ erhielten die Versuchstiere eine einmalige Injektion von Antibiotikum (0,5 ml Langzeit Penstrep) und über 3 Tage ein Analgetikum (Rimadyl 0,1 $\mathrm{ml} / \mathrm{kg})$. 


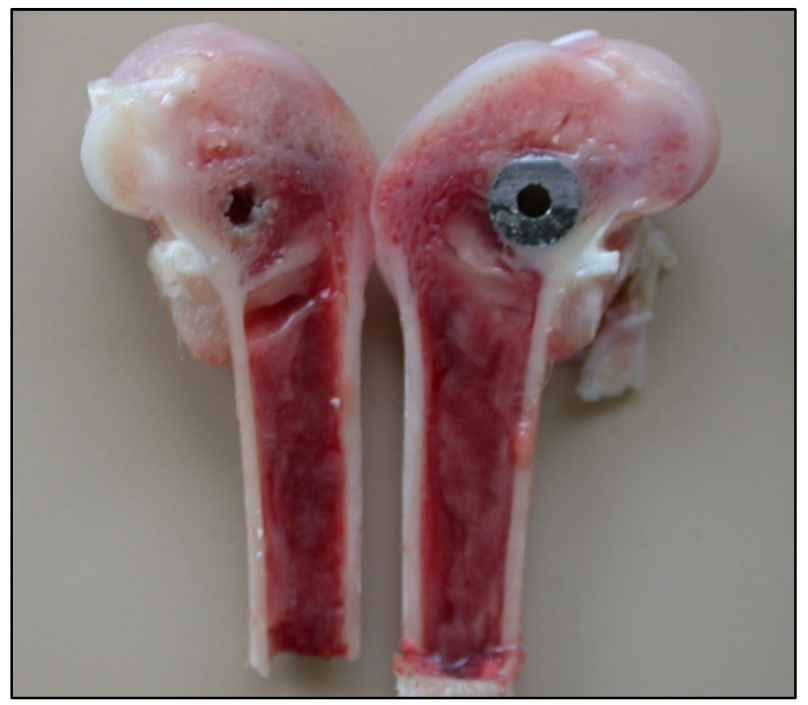

Abbildung 2.3.3-2 Aufsicht auf die mediale Seite des Implantats nach Osteotomie (Tier 29).

Die postoperative Unterbringung der Tiere fand in Einzelkäfigen unter Verwendung von dort angebrachten Rotlichtlampen statt. Die Aufwachphase wurde durch Tierpfleger beobachtet und dokumentiert. Die ärztliche Kontrolle erfolgte in der ersten postoperativen Woche täglich und danach wöchentlich.

Die Bewegung im Stall war jederzeit erlaubt. Dabei wurde auf symmetrische Belastung der Hinterläufe geachtet. Die Fadenentfernung erfolgte am 12. postoperativen Tag.

\subsection{Ablauf der Versuche}

Die Aufteilung der Tiere des histologischen Teils der Studie erfolgte randomisiert in zwei Überlebenszeitfraktionen, um den zeitlichen Verlauf der Osseointegration zu ermitteln: Sieben Tieren mit einem vier Wochen Beobachtungzeitraum von (4-Wochen-BZR); acht Tiere mit einem 12-Wochen-BZR. Die Auswahl der zeitlichen Aufteilung erfolgte, da die primäre Knochenheilung bei einem Kaninchen nach vier Wochen und das knöcherne Remodeling nach 12 Wochen abgeschlossen sind (Knoch 1990).

\subsection{Euthanasie der Tiere}

Nach Ablauf des jeweiligen 4- oder 12-Wochen-BZR wurden die Tiere mittels Ketamin/Xylazin in eine Allgemeinnarkose versetzt und anschließend unter tierärztlicher Kontrolle durch die Gabe 
von T61® (Fa. Intervet, Köln, Deutschland - Wirkstoff Embutramid) mit einer Dosierung von 0,3 $\mathrm{ml}$ pro kg Körpergewicht i.v. euthanasiert.

\subsection{Eignung der Proben für Histologie}

Vor der Entnahme der Präparate wurde eine makroskopische Untersuchung der Tiere und der Operationsnarbe durchgeführt, um eine mögliche Infektion des Operationsgebiets auszuschließen. Die einliegenden Implantate wurden zunächst makroskopisch auf die Richtigkeit der Lage des Implantats in der lateralen Femurkondyle, eventuelle neu entstandene Frakturen periimplantär oder weitere Zeichen einer mechanischen Schädigung wie zum Beispiel Dislokation des Implantats, Gewebeeinblutungen, Schwellungen sowie Veränderungen an der Gelenkkapsel untersucht. AnschlieBend wurde die Festigkeit des Implantantsitzes im Knochen manuell überprüft, um somit eine eventuelle Implantatlockerung auszuschließen.

\subsection{Probeentnahme}

Die Implantate wurden im Knochenlager belassen und mit dem gesamten Femur entnommen. Das anhängende Weichgewebe wurde sorgfältig abpräpariert. Dazu wurden die Oberschenkelmuskulatur in der Mitte des Femurs durchtrennt und die Muskelstränge und Kapselgewebe abpräpariert. Die präparierten Femora wurden in gepufferter 4\%iger Formalinlösung eingelagert.

Nach mindestens vier Wochen Fixierung folgten eine Waschung der Präparate in 0,1 M Phosphatpufferlösung sowie die Dehydration in aufsteigender Alkoholreihe. Danach wurde das Trimmen der Femora durchgeführt. Im Bereich der lateralen Kondyle wurde das zentrale Bohrloch des Implantats aufgesucht und bis zur medialen Kortikalis durchbohrt. Es folgte eine zwischenzeitliche Einbettung in einer Sägelehre nach Ausrichten des Femurs mit Hilfe eines Spickdrahtes durch das zentrale Bohrloch des Implantats (Abbildung 2.3.3-1). Die Sägeschnitte erfolgten deshalb ohne Winkelabweichung rechtwinklig zur Implantatachse entlang der Seitenflächen der Zylinder (Exact Sectioning System, Fa. Messner, Oststeinbek, Deutschland). Dadurch entstand eine planparallele Knochen-Implantat-Scheibe, in der das Implantat senkrecht zu den Begrenzungsseiten ausgerichtet war. 


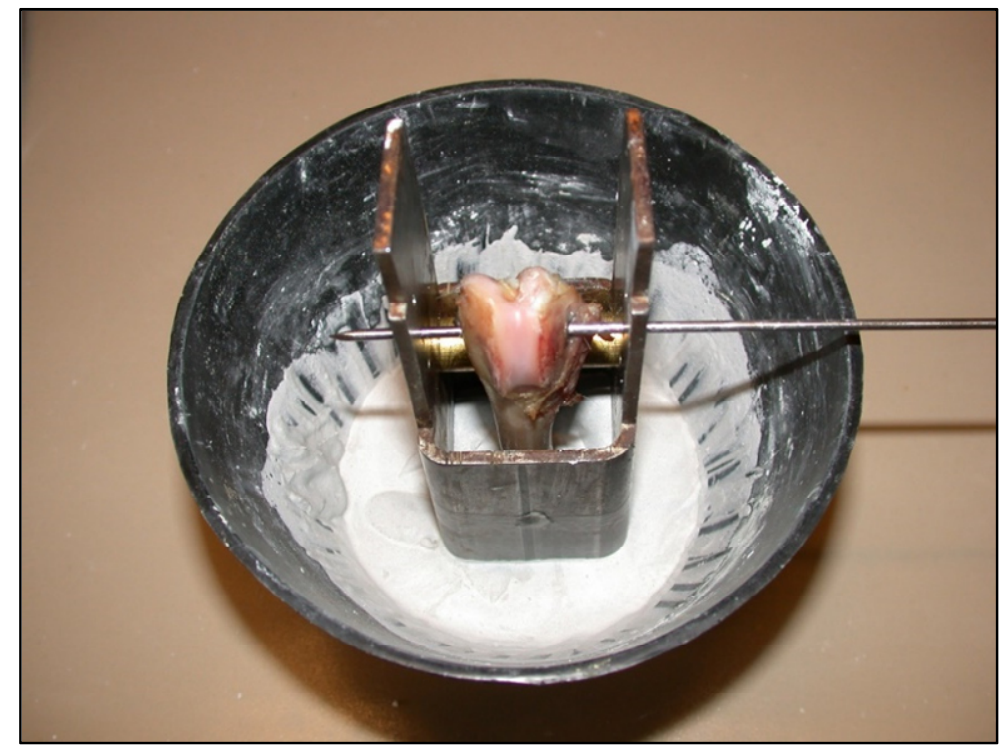

Abbildung 2.3.3-1 Ausrichtung des Femurpräparats mit Hilfe eines Spickdrahts durch das zentrale Bohrloch des Implantats.

\subsection{Herstellung der Schliffpräparate}

Aufgrund der Materialhärte der in den Knochen eingebrachten Titanimplantate war die Anfertigung von konventionellen Paraffin- oder Gefrierschnitten nicht möglich. Insbesondere zur Darstellung und Beurteilung der Grenzfläche zwischen dem Metallimplantat und dem umliegenden Gewebe war eine kombinierte Trenn-Dünnschliff-Technik und Hartschnitt-Technik notwendig. Die exakte Schnittuntersuchung der Femora konnte letztendlich mit dem kalthärtenden Polymethylmethacrylat-Einbettungsmedium „Technovit ${ }^{\circledR}$ 9100“ (Fa. Heraeus Kulzer, Wehrheim, Deutschland) ermöglicht werden. Das Kunststoffeinbettsystem auf Basis von Methylmethacrylat wurde u. a. speziell für die Einbettung von mineralisiertem Gewebe entwickelt. Die Polymerisation fand unter Ausschluss von Sauerstoff und bei Temperaturen um den Gefrierpunkt zur Ableitung der Polymerisationswärme statt. Die Dauer der Einbettung betrug 24 Stunden.

Zum Zuschneiden der Präparate wurde die Innenlochsäge SP1600 (Fa. Leica Mikrosysteme Vertrieb GmbH, Bensheim, Deutschland) verwendet. Der Zuschnitt der fixierten Gewebeblöcke erfolgte rechtwinklig zur Symmetrieachse des Implantats in der Frontaleben von lateral nach medial (Abbildung 2.3.3-1) Die Präparatdicke betrug zunächst $250 \mu \mathrm{m}$. Um das Ausmaß der knöchernen Integration der Implantate zu beurteilen, wurden entlang des Implantats mindestens drei Sägeschnitte pro Femurpräparat hergestellt: ,kortikal“, ,,spongiös“, „,medullär“.

In den nachfolgenden Kapiteln werden die einzelnen Sägeschnitte als Implantattiefe bezeichnet. Die Sägeschnitte wurden mithilfe von Sekundenkleber „Loctite 420“ (Fa. Henkel, Garching, 
Deutschland) auf Polymerobjektträgern befestigt. Danach folgte die Reduktion der Schliffe auf 150 $\mu \mathrm{m}$. Anschließen wurden die Präparate auf eine Stärke von ca. 20 bis $30 \mu \mathrm{m}$ geschliffen und poliert.

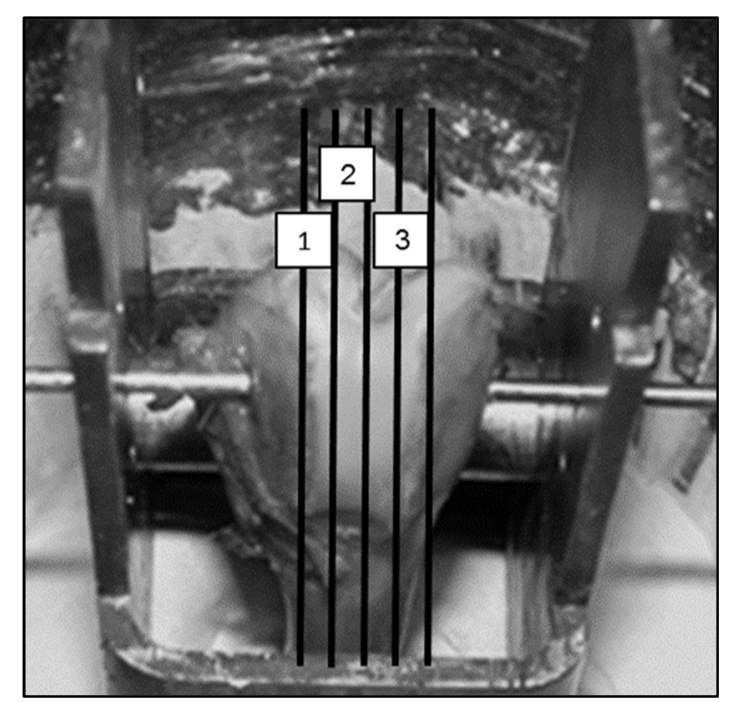

Abbildung 2.3.3-1 Schematische Darstellung des Zuschnitts rechtwinkelig zur Symmetrieachse von lateral nach medial entlang des implantierten Prüfkörpers. 1: Lage des Implantates „kortikal“, 2: Lage des Implantates „spongiös“, 3: Lage des Implantates „medullär“.

\subsection{Histologische Färbung}

Die histologische Färbung erfolgte nach der Methode von Smith und Karadgianes (Smith und Karadgianes 1974). Die polierten Präparate wurden zunächst, wie von Dahl beschrieben, mit Methylenblau vorbehandelt und anschließend mit Alizarin rot gefärbt (Dahl 1952). Für den Färbevorgang wurden die Schnittpräparate für 30 Sekunden in die zuvor auf $80^{\circ} \mathrm{C}$ erwärmte Methylenblaulösung getaucht und anschließend mit Aqua dest. gründlich abgespült. Die Trocknung erfolgte für drei bis vier Stunden bei Raumtemperatur. Als letzter Färbeschritt wurden die vorbehandelten Präparate 40 Sekunden lang in Alizarinrot-Lösung eingelegt und danach gründlich mit Aqua dest. abgespült. Anschließend wurden die Präparate für 24 Stunden bei Raumtemperatur getrocknet. Das Ergebnis der histologischen Färbung erlaubte eine Diskriminierung zwischen mineralisierten (braun) und nicht mineralisierten (blau) Knochenanteilen (Abbildung 2.3.3-1). 


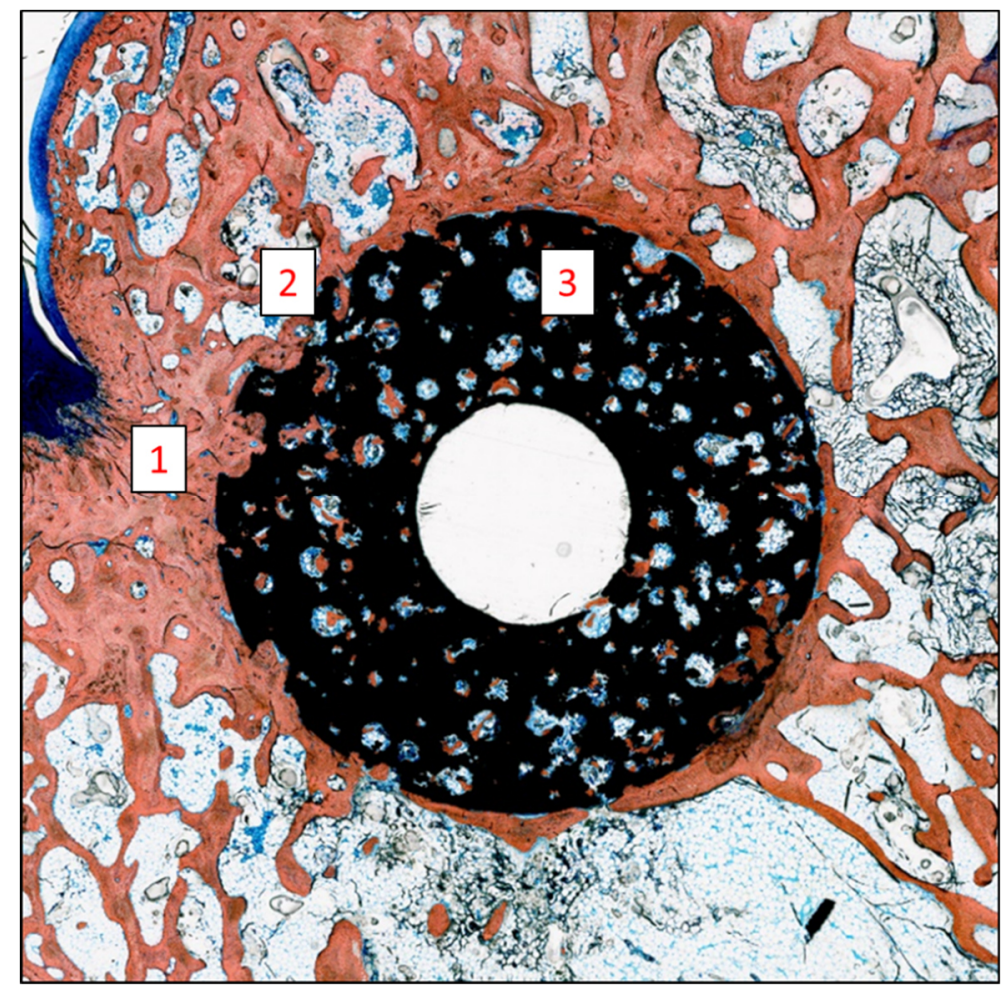

Abbildung 2.3.3-1 Histologisch gefärbtes Trenn-Dünnschliffpräparat. Knochen braun (1); Osteoid blau (2); Implantat schwarz (3).

\subsection{Digitalisierung}

Die Digitalisierung der histologischen Schnitte wurde mithilfe eines vollautomatisierten Mikroskops (Axiovert 200M, Firma Carl Zeiss, Oberkochen, Deutschland) und einer mit dem Mikroskop verbundenen Digitalkamera (Axiocam, Firma Carl Zeiss, Oberkochen, Deutschland) realisiert. Alle Präparate wurden mit einer fünffachen Vergrößerung digital aufgenommen.

\subsection{Histologische Auswertung}

Die Bestimmung der ossären Integration der Titanimplantate in das Knochengewebe wurde unter Berücksichtigung von histomorphologischen (qualitativen) und histomorphometrischen (quantitativen) Analysen durchgeführt. 


\subsubsection{Histomorphologische Analyse}

Die mikroskopische Evaluierung schloss die Beurteilung der allgemeinen Kriterienein. Dazu gehörte für Durchlichtmikroskopie ausreichende Schnittdicke und homogene Färbung: Eine Überfärbung der Präparate oder eventueller Farbverlauf sollte vermieden werden, da dies zu falschen Interpretationsergebnissen führen konnte. Sowie die Beachtung der rechtwinkligen Schnittführung zur Längsachse. Das Schneiden eines verkippt eingespannten Präparats hätte den Querschnitt des Implantats verfälschen und somit zu fehlerhaften Ergebnissen bei der histomorphometrischen Untersuchung führen können.

Alle Implantate ergaben einen einheitlichen Kreis bei Durchlichtmikroskopie.

Des Weiteren wurde auf die Implantatlage in situ mit Bezug zur anatomischen Lokalisation (Implantattiefe) geachtet. Aufgrund dessen konnte eine weitere Einteilung vorgenommen werden (Abbildung 2.11.1-1):

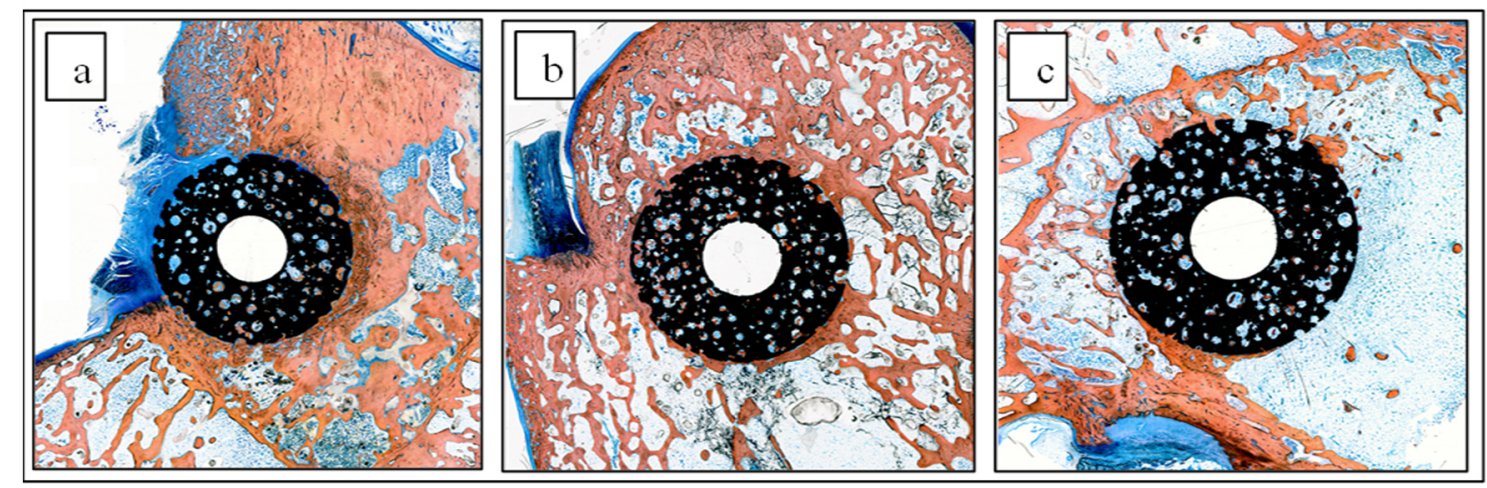

Abbildung 2.11.1-1 Poröses Implantat und die Implantattiefe im lateralen Femurkondylus: Schnittführung durch den kortikalen Knochen(a), Schnittführung durch den spongiösen Knochen(b), Schnittführung durch den Markraum(c).

Nach Testung der allgemeinen Eignungskriterien der Schliffpräparate für die histologische Auswertung folgte eine Beurteilung der stattgefundenen Osseointegration der Titanimplantate nach Branemark (Branemark 1983).

Weitere Kriterien der histologischen Untersuchung waren die Beurteilung der Knochenmenge sowie die Qualität und der Reifegrad des neugebildeten und mineralisierten Knochens um das Implantat herum und in den Poren des gesinterten Implantatmodells. In der Übersichtvergrößerung wurden der histologische Aufbau und die Qualität des neugebildeten Knochens mit dem alten bereits vorhandenen Knochen verglichen. Dabei lag das Augenmerk insbesondere auf dem Vergleich der Histomorphologie nach 4 und 12 Wochen. 
In den höheren Vergrößerungen wurden zunächst die zellulären Bestandteile wie Osteoblasten und Osteoklasten beurteilt. Als Qualitätskriterium der Aktivität der osteoblastären Zellen wurden das Vorhandensein und die Breite des gebildeten Osteoids sowie das Voranschreiten der Mineralisierung des gebildeten Osteoids herangezogen. Die Osteosynthese in den Poren der gesinterten Titanimplantate wurde histologisch untersucht und mit der Osteosynthese an der Oberfläche der gestrahlten Implantate verglichen.

Ferner wurde nach den allgemeinen histologischen Kriterien von Entzündungszeichen sowie Zeichen der Implantatabstoßung gesucht. Hierzu wurden die Präparate auf das Vorhandensein von Lymphozyten, Plasmazellen, eosinophilen und neutrophilen Granulozyten sowie Makrophagen untersucht.

\subsubsection{Histomorphometrische Analyse}

Ziel der vorliegenden Arbeit war es, das Ausmaß der periimplantären Knochenneubildung zu ermitteln. Um eine standardisierte Untersuchung zu ermöglichen, wurden einheitliche Areale außerhalb und innerhalb des Implantats definiert. Diese wurden als „,region of interest“ (ROI) bezeichnet und bilden durch konzentrische Kreise begrenzte Ringflächen (Abbildung 2.11.2-1). Die porösen Implantate erlauben durch die offenporige Struktur das Einwachsen des Knochens bis in das Implantatinnere. Um das gesamte Ausmaß der Knochenneubildung entsprechend zu erfassen, wurden weitere ROI (4-6) für die porösen Implantate definiert (Abbildung 2.11.2-1).

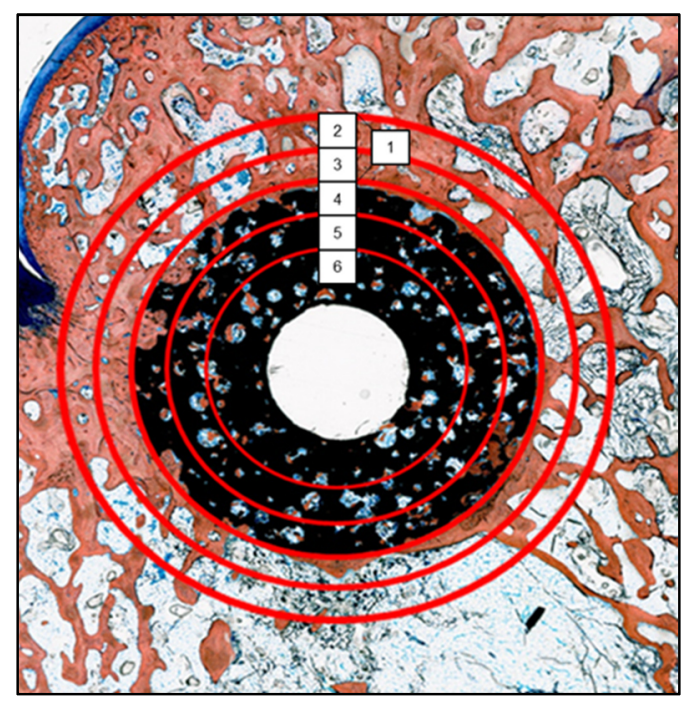

Abbildung 2.11.2-1 Region of interest periimplantär (ROI 1 = ROI 2 und 3) und intraimplantär (ROI 4-6)

Als Ausgangspunkt für die Festlegung der Kreisdurchmesser der verschiedenen ROI diente der Durchmesser der Prüfkörper (5,6 mm). Die Kreise der entsprechenden ROI wurden in 1-mm- 
Schritten periimplantär (außerhalb des Implantats) und intraimplantär (innerhalb des Implantats) angeordnet (Tabelle 2.11.2-1). Die Differenzen der im Durchmesser der Kreise erstandenen Zwischenräume beschreiben die ROI. So konnte eine zielscheibenartige Vorlage entwickelt und für alle Präparate angewandt werden.

Tabelle 2.11.2-1 Einteilung der Region of interest 1-6 peri- und intraimplantär

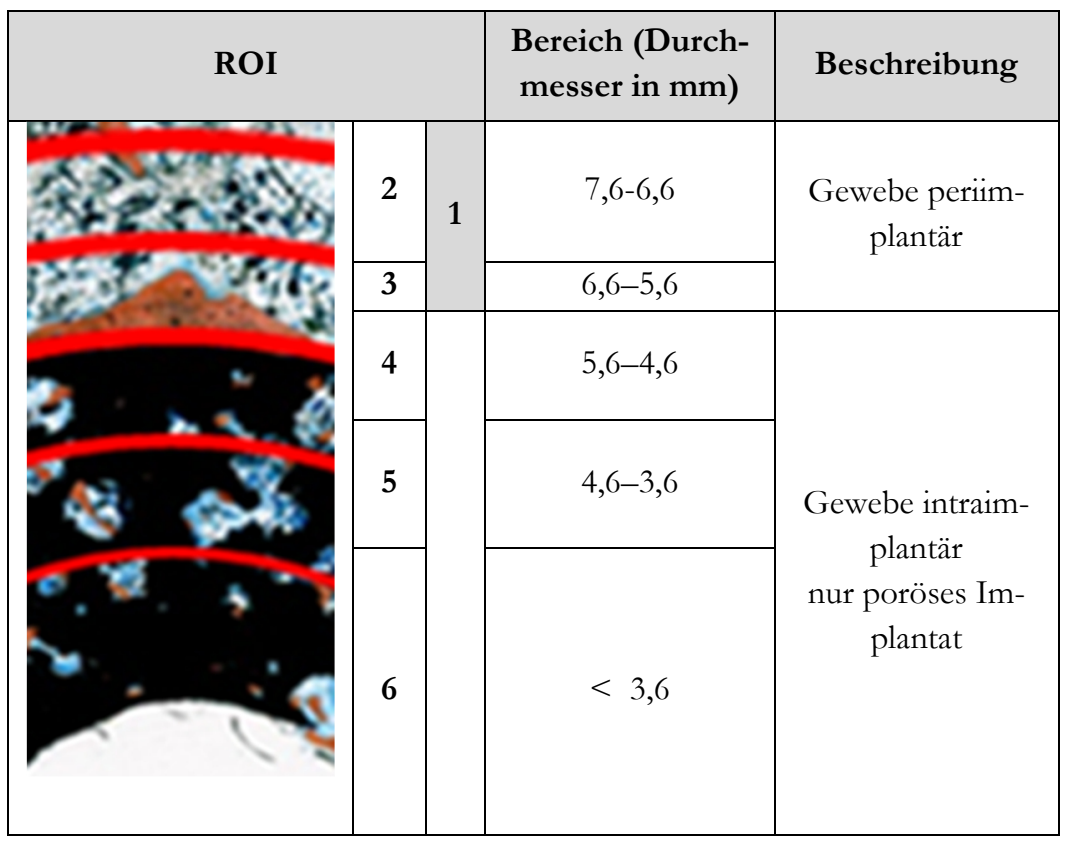

Das periimplantäre Areal wurde sowohl für das gestrahlte als auch für das poröse Implantat einheitlich ausgewertet. Mit Hilfe eines Vektorprogramms (Adobe Illustrator) wurden zwei Kreise mit den Durchmessern 6,6 mm (ROI 3 - unmittelbar periimplantär) und 7,6 mm (ROI 2 - implantatfern,) festgelegt (Tabelle 2.11.2-1). ROI 3 und ROI 2 sind in ROI 1 zusammengefasst. Da die offenporigen Implantate Knochenwachstum bis in das Innere der Implantate zulassen, wurden für diese Implantatmodelle ROI 4 bis 6 definiert. Dadurch wurde von oberflächennah (ROI 4) bis zentral (ROI 6) abgestuft eine intraimplantäre Evaluation der Knochenneubildung der porösen Implantate möglich (Tabelle 2.11.2-1).

Die digitalisierten Präparate wurden nun einzeln in das digitale Bildbearbeitungsprogramm Adobe Photoshop ${ }^{\circledR}$ Elements 7 eingefügt und bearbeitet. Vor Beginn der Messung musste die Messskala festgelegt werden. Beim Einrichten der Messskala wurde die bekannte Anzahl von Millimetern des Implantatdurchmessers (5,6 mm) gleichgesetzt mit einer bestimmten Anzahl von Pixeln im Bild.

Daraufhin erfolgte die eigentliche Quantifizierung des neugebildeten mineralisierten Knochens (braun). Das in das Programm eingefügte Bild des histologischen Schnittpräparats wurde zunächst 
mit der vorbereiteten und separat gespeicherten Vorlage der zielscheibenartigen Vorlage der vordefinierten ROI überlagert (Tabelle 2.11.2-1). Dazu wurde das schwarz dargestellte Titanimplantat mit Hilfe eines interaktiven Werkzeugs zur kontrastabhängigen Formelektion (,Zauberstab“) markiert. Das Programm zentrierte und legte die Kreise der Matrize automatisch über das markierte Titanimplantat. Dieser Schritt war für alle Präparate gleich. Jetzt musste zwischen porösen und nicht porösen Implantaten unterschieden werden, da sich die Anzahl der zu untersuchenden ROI hier unterschied (zusätzlich ROI 4-6). Die auf das Titanimplantat positionierte Matrize wurde lediglich als gestrichelte Linie dargestellt, sodass der Knochen und das Weichgewebe weiterhin sichtbar blieben. In diesem Zustand wurde mittels eines Spezialwerkzeugs des Programms, welches in einem vorherigen Schritt auf die Farbnuancen eingestellt wurde, der mineralisierte Knochenanteil markiert. Jedes der Präparate wurde nach diesem Schritt sorgfältig kontrolliert und die nicht erfassten mineralisierten Knochenareale manuell nachmarkiert. Im nächsten Schritt wurden die den entsprechenden Elementen zugewiesenen Farben durch Farbauswahl selektiert und mittels einer Histogrammfunktion als Pixelanzahlen dargestellt. Mittels einer Funktion („Pipette“) zur Farbselektion konnten die Farbnuancen der Knochenphase ausgewählt werden. Das Programm berechnete nach diesem Schritt automatisch feststehende Parameter und hielt sie in einem Messprotokoll fest.

Für den direkten Knochen-Implantat-Kontakt (bone to implant contact - BIC) wurde die Strecke des anliegenden Knochens mithilfe eines Spezialwerkzeugs „Zauberstab“ manuell markiert und ebenfalls berechnet. Das Programm unterschied bei der Berechnung den Umfang des in Schwarz dargestellten Prüfkörpers sowie den in Braun dargestellten und manuell markierten Knochen. Die Farbvorgabe der zu markierenden Farbnuance der Knochen-Phase erfolgte auch hier mittels „Pipette“. In der Histogrammfunktion wurden die ausgewählten Farbnuancen als Pixelanzahlen dargestellt. Die Ergebnisse konnten anschließend zueinander in Relation gesetzt und der prozentuale Wert ermittelt werden.

Zur Quantifizierung wurden folgende Messparameter verwendet:

I. Gesamtfläche des neugebildeten Knochens.

Errechnete Fläche in $\mathrm{mm}^{2}$ in ROI 1 (gestrahltes Implantat) und ROI 1-6 (poröses Implantat) bedeckt mit neugebildetem Knochen.

II. Verteilung der neugebildeten Knochenfläche.

Errechnete Fläche bedeckt mit neugebildetem Knochen in $\mathrm{mm}^{2}$ für jedes ROI im Einzelnen. 
III. Knochenanlagerung.

Direkter Knochen-Implantat-Kontakt an der Implantatoberfläche in mm.

IV. Schnittebene/Implantattiefe.

Lage des Implantats in situ mit Bezug zu den anatomischen/histologischen Abschnitten in der lateralen Femurkondyle. Kortikal - Spongiosa - Markraum. Schnittstufen wurden entlang des Implantats senkrecht zur Symmetrieachse angefertigt.

\subsection{Statistische Auswertung}

Die statistische Auswertung der Ergebnisse wurde in Zusammenarbeit mit dem Institut für medizinische Statistik der Universitätsmedizin Göttingen durchgeführt. Hierzu wurde die statistische Analyse mit Hilfe der statistischen Software R (Version 3.0.2, www.r-project.org) verwendet. Dabei kam das R-Package „Ime4“ und ImerTest“ zur Anwendung. Das Signifikanzlevel wurde für alle statistischen Tests auf $5 \%$ festgelegt. Da in der vorliegenden Arbeit mehrere Hypothesen untersucht werden, wurde die Signifikanz der multiplen Messergebnisse mit dem ANOVA-Test festgestellt. Die Irrtumswahrscheinlichkeit, das heißt die Wahrscheinlichkeit, mindestens eine falsch positive Aussage zu machen, steigt mit der Anzahl durchgeführter Tests und muss beschränkt werden. So kommt das Bonferroni-Holm-Verfahren zur Anwendung. Dabei wird das multiple Gesamtniveau durch die Anzahl der durchgeführten Tests geteilt. 


\section{Ergebnisse}

\subsection{Histologische Evaluation}

Alle Präparate erfüllten die makroskopischen und histologischen Kriterien einer erfolgreichen Osseointegration. Die Variation in der anatomischen Lage der Titanimplantate ergab sich aus der Implantationstechnik. Die ersten Schnittstufen der lateralen Femurkondyle mit Implantat erfolgten von lateral nach medial und damit von der Kortikalis über die Spongiosa zum Markraum (Abbildung 3.1-1). Alle histologischen Schliffpräparate zeigten eine für die Durchlichtmikroskopie ausreichend dünne und gleichmäßige Schliffdicke und eine dem Standard entsprechende Färbung nach Vorbehandlung der Präparate mit Methylenblau und Alizarin.

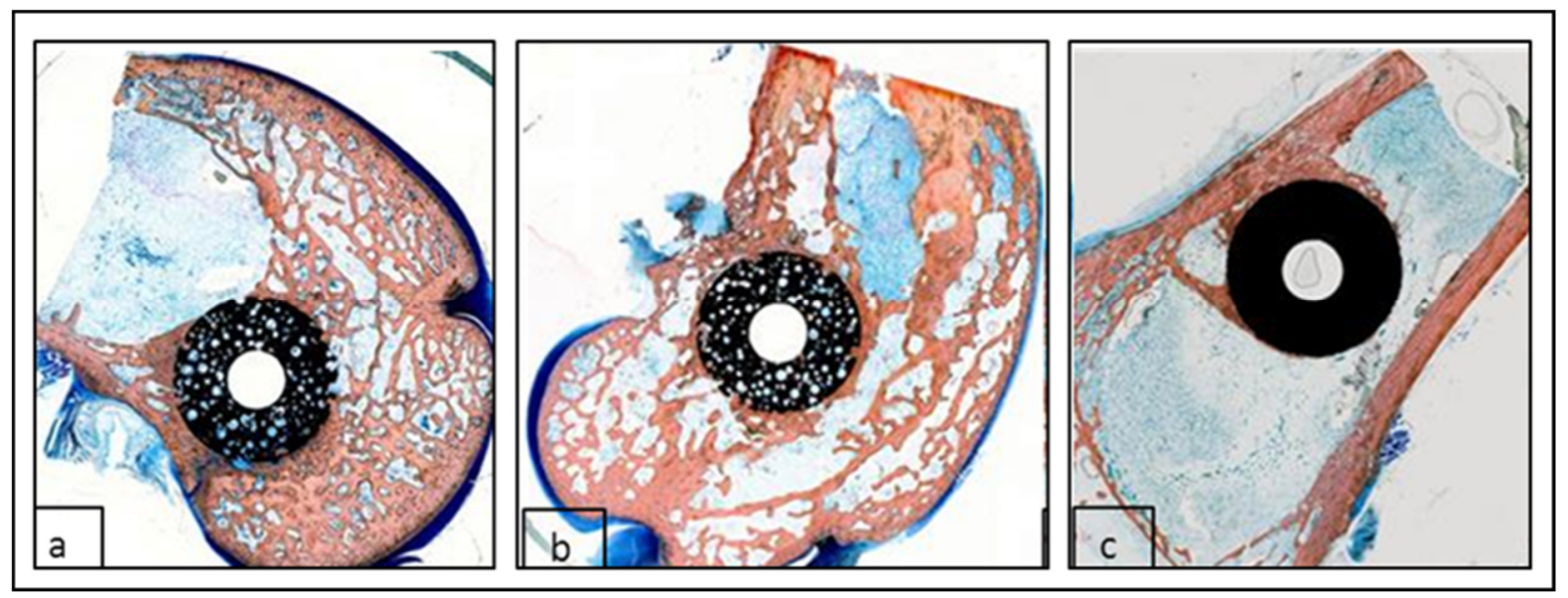

Abbildung 3.1-1 Laterale Femurkondyle des Kaninchens mit Titanimplantat und unterschiedlichen Lokalisationen. Kortikalis (a), Spongiosa (b), Markhöhle (c).

\subsubsection{4-Wochen-BZR}

Es lagen histologisch keine Unterschiede in der knöchernen Integration periimplantär (ROI 1) zwischen den Implantattypen P und G vor. Dies galt sowohl für die darzustellenden Gewebearten (mineralisierter und nichtmineralisierter Knochen) als auch für deren Differenzierungsgrad (Geflecht-, Lamellenknochen) und Verteilungsmuster (kortikal, spongiös, medullär). Am direkten Knochen-Implantat-Verbund bildete sich kein fibröses Bindegewebe.

\subsubsection{Implantate im kortikalen Knochen}

Histomorphologisch waren beide Titanimplantate P und G periimplantär (ROI 1) nahezu vollständig vom neugebildeten Knochen umschlossen. Die Grenzfläche war zwischen dem neugebildeten Geflechtknochen und dem außerhalb liegenden, ,alten“ Lamellenknochen deutlich erkennbar (Ab- 
bildung 3.1.1-1, Abbildung 3.1.1-2). Histologisch erfüllte der implantatfern gelegene Knochen (auBerhalb von ROI 1) die charakteristischen Kriterien des reifen Lamellenknochens der Substantia compacta der Kortikalis (Abbildung 3.1.1-1).

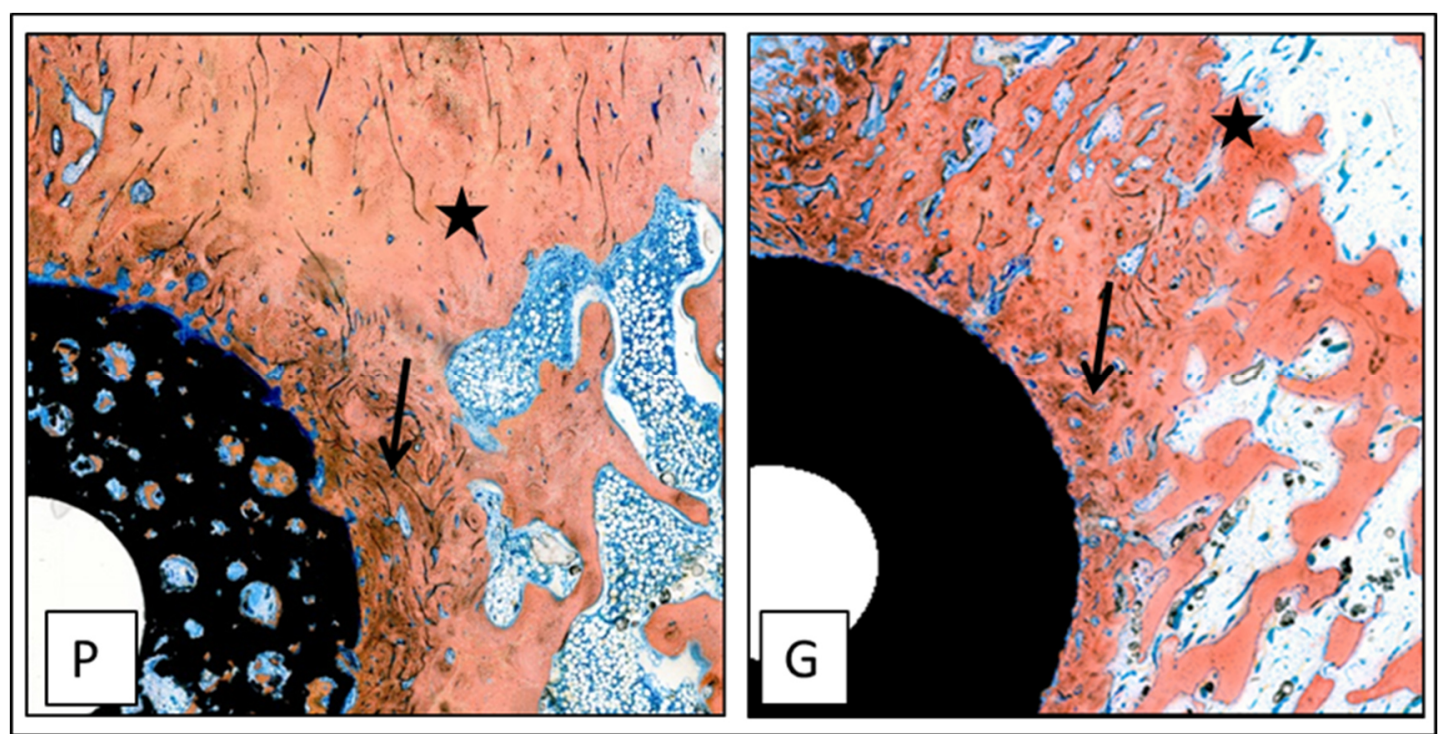

Abbildung 3.1.1-1 Poröses (P) und gestrahltes (G) Implantat nach 4-Wochen-BZR. Periimplantär deutliche dunkelbraune Färbung des zellreichen neugebildeten Knochens (Pfeil) und hellbraune Färbung des „,alten“

Lamellenknochen (Stern).

Um die Implantate wurde Geflechtknochen als Zeichen einer primären Knochenheilung neu gebildet (Abbildung 3.1.1-2). Das charakteristische Bild des neuentstandenen, unreifen Geflechtknochens war eine vermehrte, ungeordnete Zellularität. Kollagenfasern lagen als grobes, ungerichtete Bündel in der Knochenmatrix vor.

Die Osteoblasten umsäumten die neugebildete nichtmineralisierte Knochenmatrix, senkrecht zur Oberfläche aufgestellt, als kubische, epithelartig angeordnete Zellen. Gelegentlich waren Osteoklasten als Zeichen eines beginnenden Remodelingprozesses nachzuweisen. Die Osteozyten waren kurz nach dem Einschluss in die Knochenmatrix noch oval und besaßen größere Zellkörper als Ausdruck stärkerer Syntheseleistung der Knochengrundsubstanz. Interponiert waren zahlreiche kapillare Gefäßproliferate. Des Weiteren waren periimplantär bei beiden Implantamodellen keine Entzündungszeichen, keine Implantatabstoßung und keine bindegewebige Trennschicht zu erkennen. 


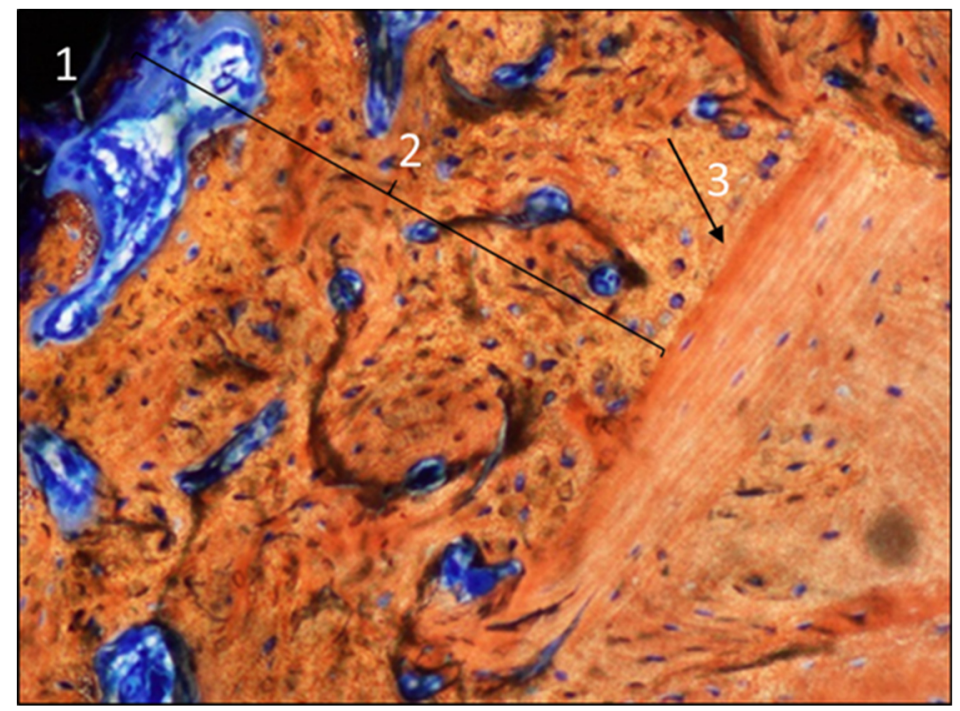

Abbildung 3.1.1-2 Periimplantäres Areal (1) mit neu gebildeten Geflechtknochen (2, schwarze Klammer). Übergang Geflechtknochen in ausgereiften (,alten“) Lamellenknochen (3, Pfeil).

Beim porösen Implantat setzte sich die Knochenneubildung von der Implantatoberfläche in die Poren fort. Der Differenzierungsgrad des Knochengewebes in den Poren entsprach dem der periimplantären Region. Die filigranen Knochentrabekel des Geflechtknochens waren an die Rauigkeit des Poreninneren angepasst (Abbildung 3.1.1-3).

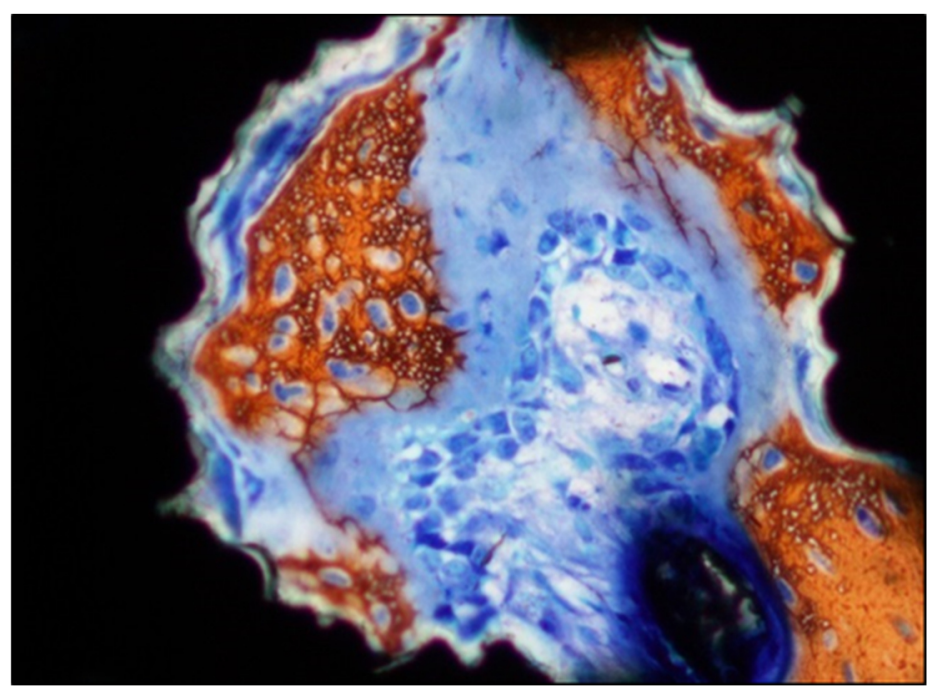

Abbildung 3.1.1-3 Poröses Implantat mit mineralisiertem Knochen (braun) und Osteoid (blau). Bereits eingemauerte Osteozyten in Osteoid. Der neugebildete Knochen passte sich der Rauigkeit der Poren an.

Das mineralisierte und nichtmineralisierte Knochengewebe war bis in die zentral liegenden Poren der ROI 6 nachweisbar. Auch ein Differenzierungsunterschied von äußeren Poren bis in die inneren Poren war zu beobachten. In ROI 4 bis 6 nahm der Anteil mineralisierten Knochens zum inneren des Implantats ab. Die Poren waren insbesondere in ROI 4 und 5 überwiegend mit Ge- 
flechtknochen und Osteoid mit Osteoblasten ausgefüllt. In ROI 6 war überwiegend nichtmineralisiertes Osteoid vorhanden. Es zeigte sich eine die Knochenneubildung begleitende Neovaskularisation in den Poren. An der Porenoberfläche bildeten sich kein interponiertes Bindegewebe und keine Entzündungs- und Abstoßungszeichen.

Zusammenfassend zeigten alle untersuchten Präparate eine gute ossäre Integration der Implantate in den Knochen. Es fand eine primäre Kontaktosteogenese statt. Die Implantate waren vom neugebildeten Knochen nahezu vollständig umgeben. Eine Abstoßungsreaktion fand nicht statt. Der neugebildete Knochen wies eine rege Osteosynthese mit stattfindendem Remodeling auf.

\subsubsection{Implantat im spongiösen Knochen}

Histomorphologisch fand in der ossären Integration kein Unterschied zwischen den Titanimplantaten P und G statt. Die Spongiosa entlang des Implantats zeigte weniger dichten Knochen im Vergleich zu den kortikalen Abschnitten. Im Gegensatz zu der flächendeckenden periimplantären Knochenneubildung in der Kortikalis waren in den spongiösen Schnittstufen periimplantär größere knochenfreie Aussparungen, die vom ortständigen Fettgewebe aufgefüllt waren, vorhanden (Abbildung 3.1.1-4). Das lockere Maschenwerk von Trabekeln periimplantär bestand, wie auch in den kortikalen Abschnitten, aus unreifen Geflechtknochen. Der Knochen war als Ausdruck einer primären überschießenden Knochenheilung dichter als die umliegende „reife“ Spongiosa (Abbildung 3.1.1-4). Die schwammartige, implantatferne Knochenstruktur bestand aus reifen Lamellenknochen.

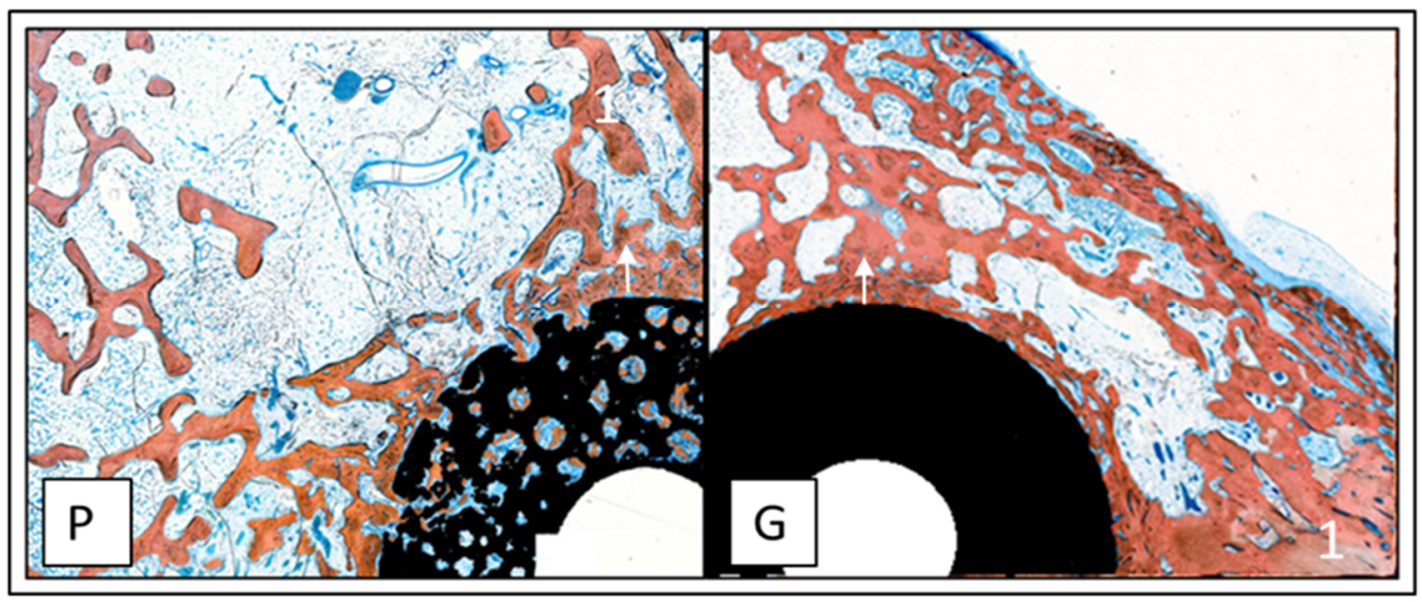

Abbildung 3.1.1-4 Poröses (P) und gestrahltes (G) Implantat nach 4-Wochen-BZR. Periimplantär neugebildeter Knochen (Pfeil) bei beiden Implantatmodellen. Im Vergleich zur kortikalen Schnittstufe geringere Knochendichte und trabekulärer Aufbau.

Die anfänglichen Auf- und Abbauprozesse fanden parallel zueinander statt. Diese unterschieden sich histomorphologisch nicht von den kortikalen Abschnitten. Ein breiter Osteoidsaum wies auch 
in den spongiösen Abschnitten eine aktive Syntheseleistung der knochenbildenden Zellen auf, sowohl periimplantär (Abbildung 3.1.1-5) als auch intraporös (Abbildung 3.1.1-6).

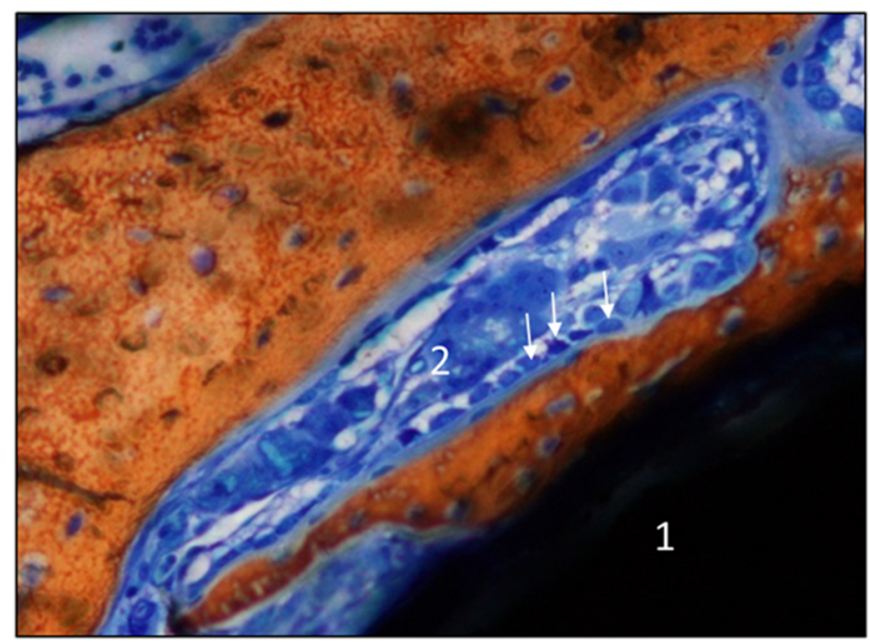

Abbildung 3.1.1-5 Gestrahltes Implantat (1). Periimplantäre Region. Lakunenartige Aussparungen gefüllt mit osteoidbildenden Osteoblasten (Pfeil) neben osteoklastären Riesenzellen (2). 60-fache Vergrößerung.

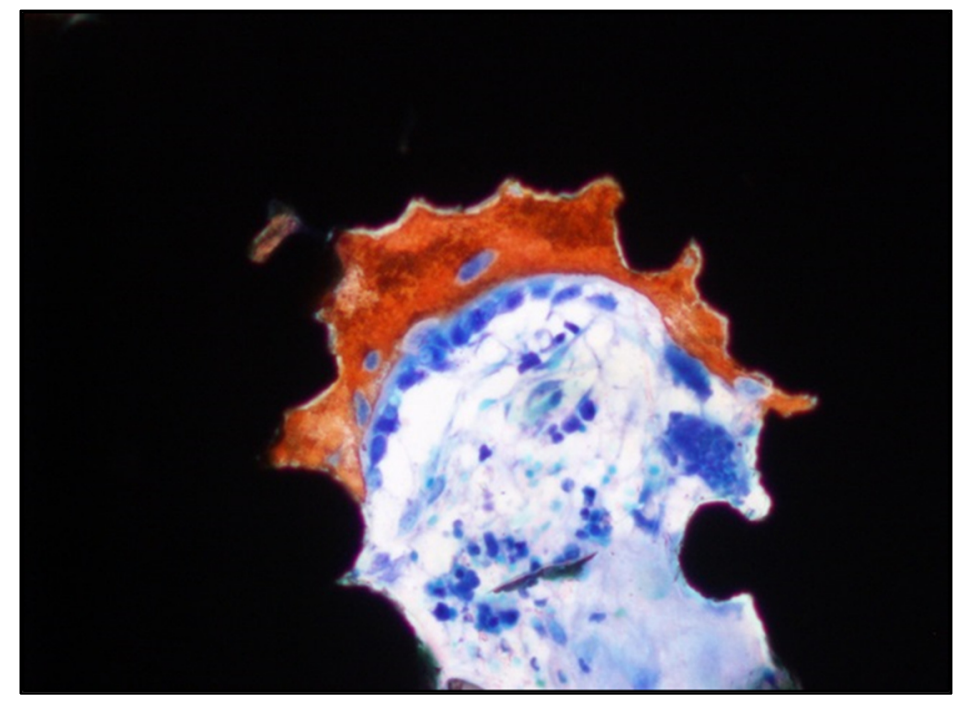

Abbildung 3.1.1-6 Poröses Implantat (schwarz). Rege Osteosynthese mit (braun) mineralisiertem Osteoid, nicht mineralisiertem Osteoid (blau) umsäumt von aktivierten Osteoblasten.

Wenige Osteoklasten lagen in muldenförmigen Resorptionslakunen (Howship'sche Lakunen) (Abbildung 3.1.1-5). Die Gefäße des lakunokanalikulären Systems waren stellenweise schwach als dünne Linien zu erkennen. Auch in der Spongiosa waren keine Zeichen einer Entzündung, Implantatabstoßung oder Ausbildung einer bindegewebigen Trennschicht zwischen Implantat und Knochen vorzufinden.

Der direkte Knochen-Implantat-Kontakt setzte sich ohne Unterbrechung von der Implantatoberfläche in die Poren fort (Abbildung 3.1.1-7). 


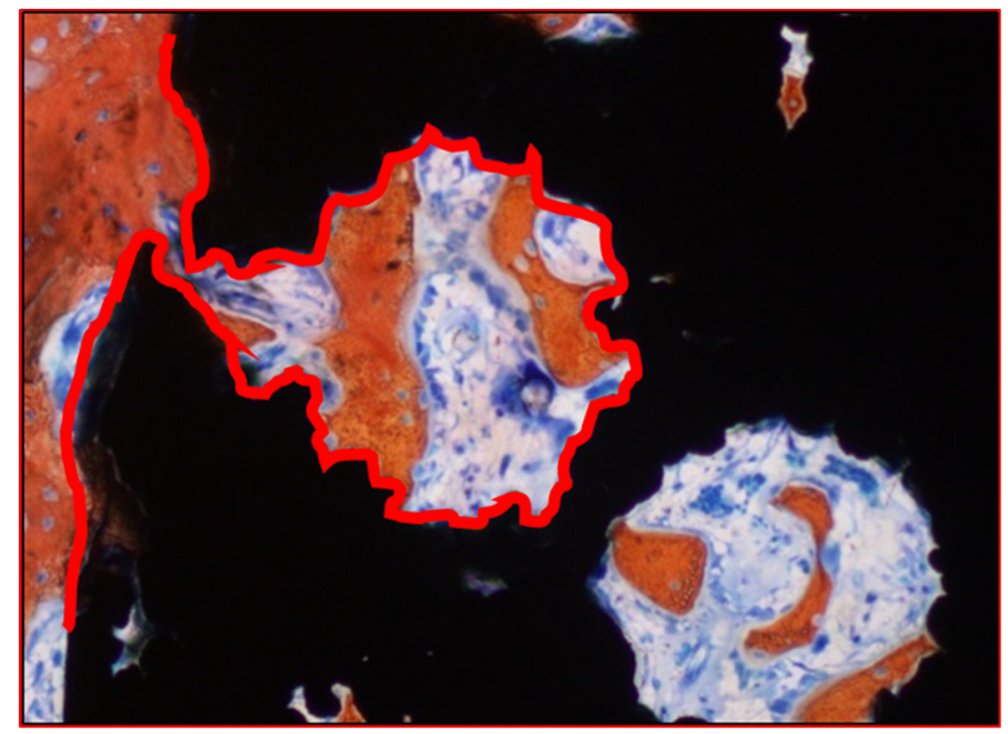

Abbildung 3.1.1-7 Poröses Implantat. Durch die offenporige Struktur setzt sich die Implantatoberfläche in den Poren fort (60-fache Vergrößerung)

Alle untersuchten Poren zeigten eine rege Osteosynthese mit zahlreichen osteoblastären Säumen um die Knocheninseln mit nichtmineralisiertem Osteoid. Eine Abhängigkeit des Knochenwachstums von der Porengröße war histomorphologisch nicht nachzuweisen. Das mineralisierte und nichtmineralisierte Knochengewebe war bis in die zentral liegenden Poren der ROI 6 nachweisbar. Der Differenzierungsgrad des Knochengewebes in den Poren entsprach dem der periimplantären Region. Die filigranen neugebildeten Spongiosabälkchen des Geflechtknochens waren an die inhomogene Porenstruktur angepasst (Abbildung 3.1.1-8).

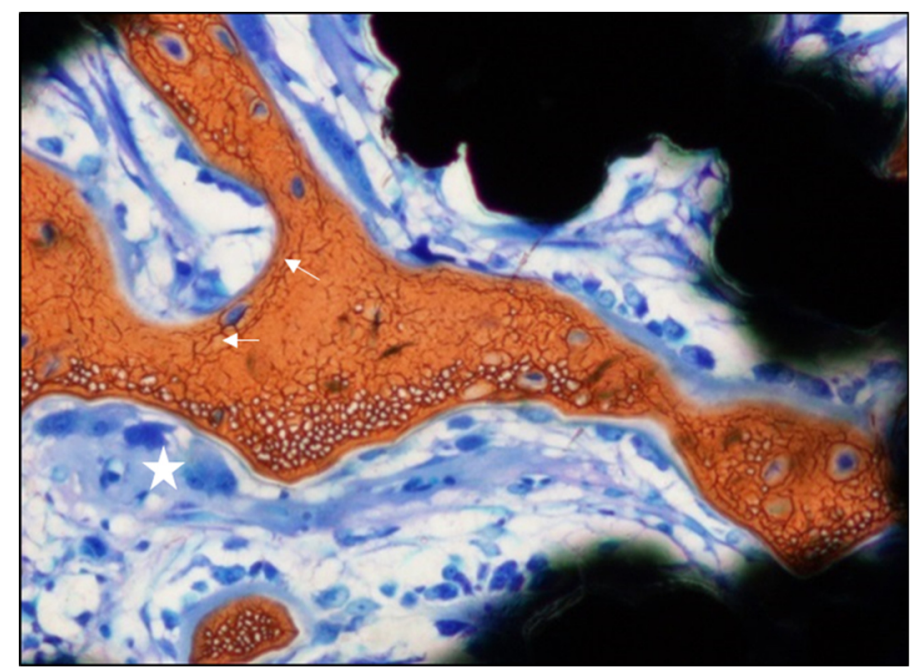

Abbildung 3.1.1-8 Poröses Implantat. Neugebildetes Spongiosabälkchen intraporös. Das lakunokanalikuläre System als feines Liniennetzwerk sichtbar (Pfeile). Nach 4-Wochen-BZR zahlreiche Osteoblastensäume und osteoklastäre Riesenzellen (Stern) als Zeichen eines Remodelingprozesses. 
Die Poren waren insbesondere in ROI 4 und 5 überwiegend mit mineralisiertem Geflechtknochen und Osteoid mit Osteoblasten ausgefüllt (Abbildung 3.1.1-9). Osteoklasten waren ebenfalls stellenweise vorhanden. Eine die Knochenneubildung begleitende Neovaskularisation in den Poren konnte beobachtet werden.

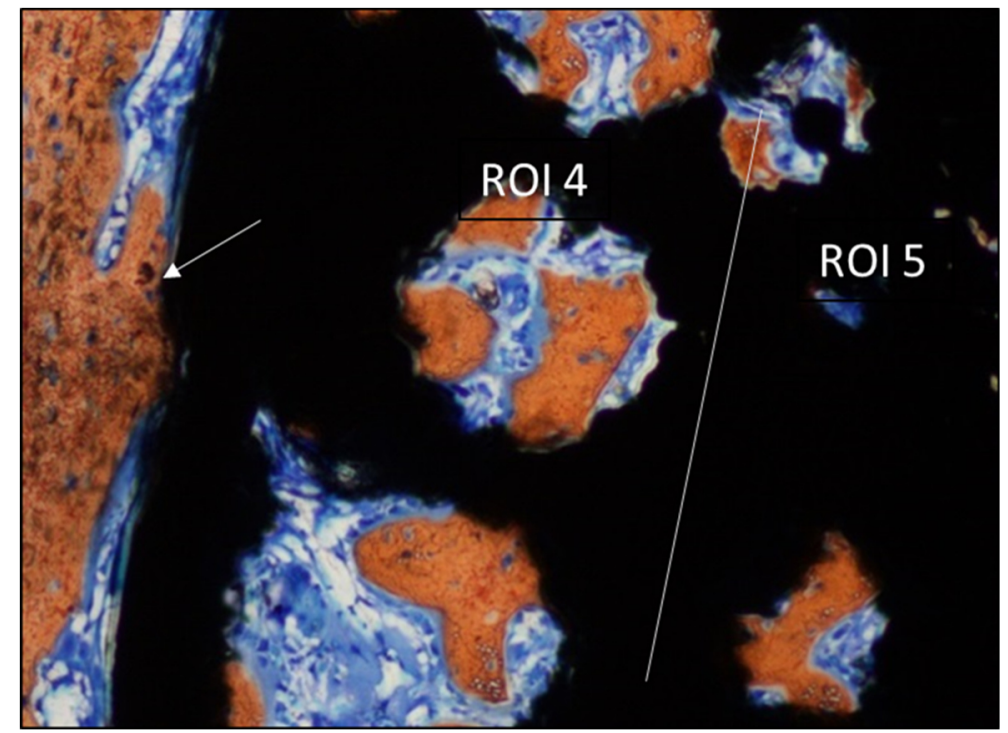

Abbildung 3.1.1-9 Poröses Implantat. Implantatoberfläche (Pfeil) sowie oberflächennahe ROI 4 und 5 gefüllt mit neugebildetem Knochen. Innerhalb der Poren fand weiterhin Osteosynthese statt. Die Poren wiesen zahlreiche osteoidbildende Osteoblasten auf (60-fache Vergrößerung)

Zusammenfassend kann auch in spongiösen Schnittstufen mit weniger dichten Knochen (Spongiosa) Osteoneogenese beobachten werden. Angepasst an den benachbarten Knochen fand hier eine Ausbildung neuer Spongiosabälkchen statt. Die Knochendichte des neugebildeten Knochens war ebenfalls geringer als in den kortikalen Abschnitten. Es wurde eine primäre Osteogenese (Kontaktosteogenese) beobachtet. Bindegewebe oder Knorpelzellen im periimplantären Spalt im Sinne einer Distanzosteogenese waren nicht nachzuweisen. Auch eine Abstoßungsreaktion war nicht feststellbar.

\subsubsection{Schnittführung durch den Markraum}

Die untersuchten Titanimplantate P und G zeigten histomorphologisch keine Unterschiede in der ossären Integration. Die letzten Schnittstufen entlang des Implantats erreichten den Markraum. In dieser Lokalisation war keine vollständige peri- und intraimplantäre Osseointegration vorzufinden. Die Implantate wurden, angepasst an die physiologischen Gegebenheiten des Markraums, nur teilweise vom neugebildeten Knochen umgeben. Zum großen Anteil umhüllte das ortständige Fettgewebe die Titanimplantate. Histomorphologisch handelte es sich auch in dieser Lokalisation um unreifen Geflechtknochen. Manschetten- und spanngenartige Knochenausläufer ausgehend von der Kortikalis des Röhrenknochens sowie einzelne filigrane Spongiosabälkchen als Fortsetzung der 
Spongiosa der Femurkondyle bildeten eine Verankerung der Implantate, unabhängig vom Implantattyp (Abbildung 3.1.1-10). Die zellulären Bestandteile des neugebildeten Knochens wiesen keine Unterschiede zu den zuvor untersuchten kortikalen und spongiösen Abschnitten auf.

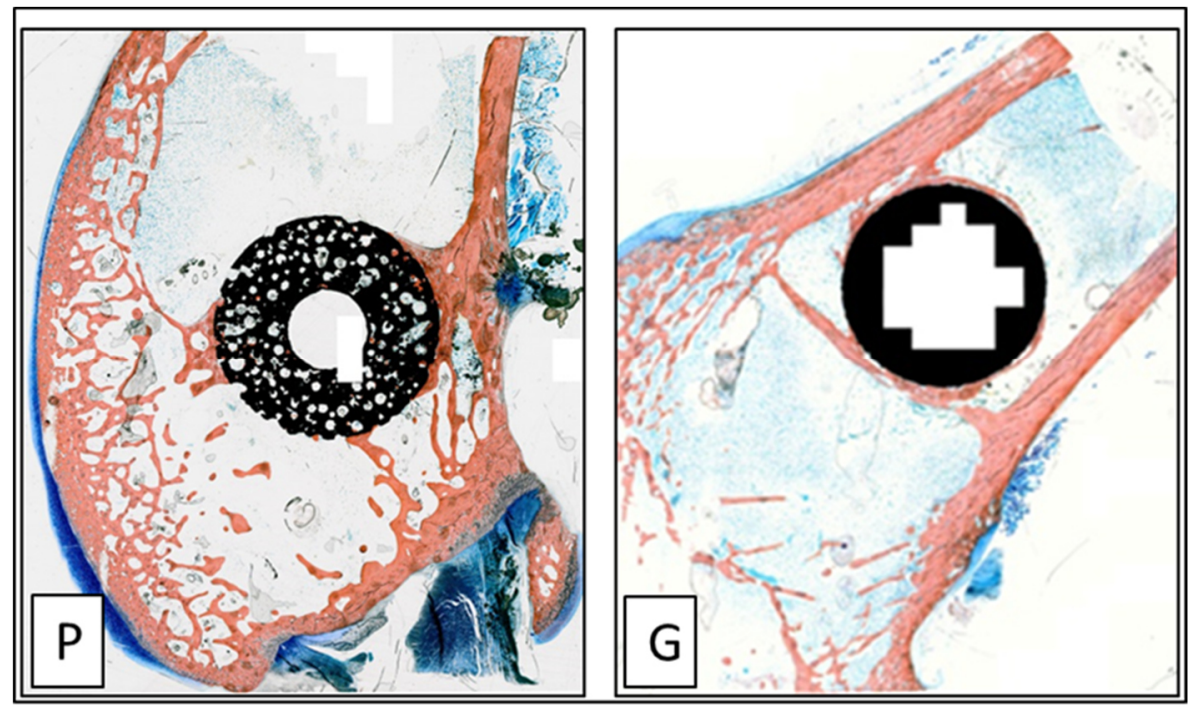

Abbildung 3.1.1-10 Poröses (P) und gestrahltes Implantat $(\mathrm{G})$ nach 4-Wochen-BZR. Ausbildung spangenartiger Knochenausläufer von der Kortikalis ausgehend von beiden Implantatmodellen.

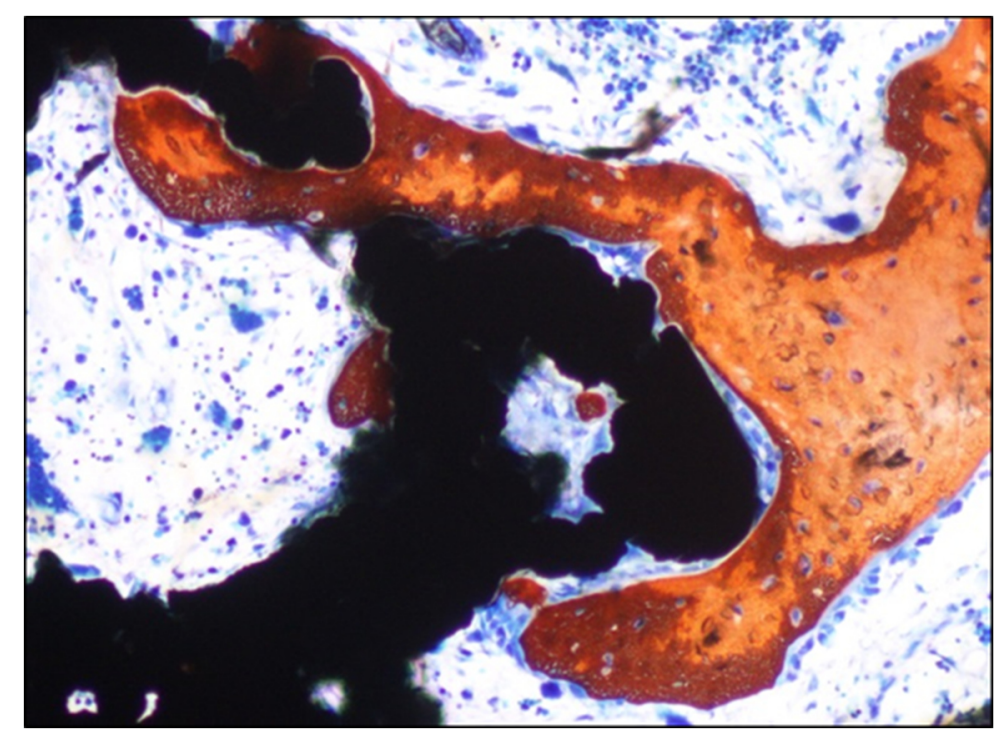

Abbildung 3.1.1-11 Poröses Implantat nach 4-Wochen-BZR. Angepasste, neugebildete Spongiosabälkchen im Poreninnenraum.

Die porösen Implantate wiesen eine Knochenneubildung von periimplantär (ROI 1) bis in die weitere Implantattiefe (ROI 4-6) auf. Im Vergleich zu spongiösen Schnittstufen enthielten die meisten Poren im Markraum Fettgewebe. Der histologische Aufbau sowie die Syntheseleistung der Osteoblasten glichen dem periimplantären Knochen (Abbildung 3.1.1-12). 


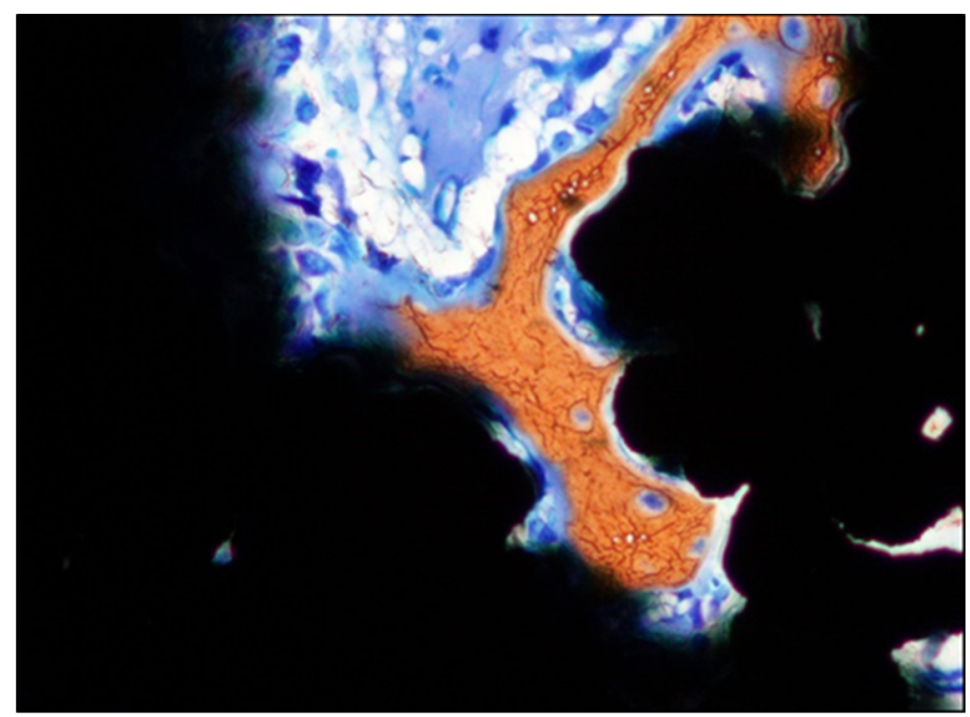

Abbildung 3.1.1-12 Ein neugebildetes Spongiosabälkchen intraporös in ROI 6.

Der neugebildete Knochen lag den Titanimplantaten ohne interponiertes Bindegewebe an. Eine Entzündungs- oder Abstoßungsreaktion fand nicht statt (Abbildung 3.1.1-12).

\subsubsection{2-Wochen-BZR}

Nach einem BZR von 12 Wochen zeigte sich der Knochen wesentlich zellärmer und im Faserverlauf geordneter. Beide Implantattypen wiesen histomorphologisch weiterhin eine gute Osseointegration auf. Einen Unterschied in der Qualität des neugebildeten Knochens gab es nicht. Es fanden sich jedoch vermehrt osteoklastäre Riesenzellen als Zeichen des stattfindenden Remodeling und einer funktionellen Anpassung.

\subsubsection{Implantat im kortikalen Knochen}

Die Implantate waren im für die ossäre Integration relevanten kortikalen Anteil zirkulär und flächendeckend von Knochengewebe umgeben und wiesen eine säulenartige Abstützung mit direktem Knochen-Implantat-Kontakt auf. Die primäre Ossifikation war mit der Bildung von mineralisiertem Lamellenknochen abgeschlossen. Der knöcherne Übergang zwischen dem neugebildeten Knochen und außerhalb liegendem ,altem“ Lamellenknochen war mikroskopisch nicht mehr zu unterscheiden (Abbildung 3.1.2-1). Im Vergleich zum 4-Wochen-BZR war nur noch wenig Osteoid nachzuweisen.

Die Remodelingprozesse der primären, überschießenden Knochenheilung wurden fortgesetzt. Als weiteres Zeichen für eine abgeschlossene primäre Ossifikation waren im Gegensatz zu dem 4Wochen-BZR vermehrt Osteoklasten in Resorptionslakunen als Hinweis auf eine stattgehabte funktionelle Anpassung an die physische Belastung zu erkennen. 


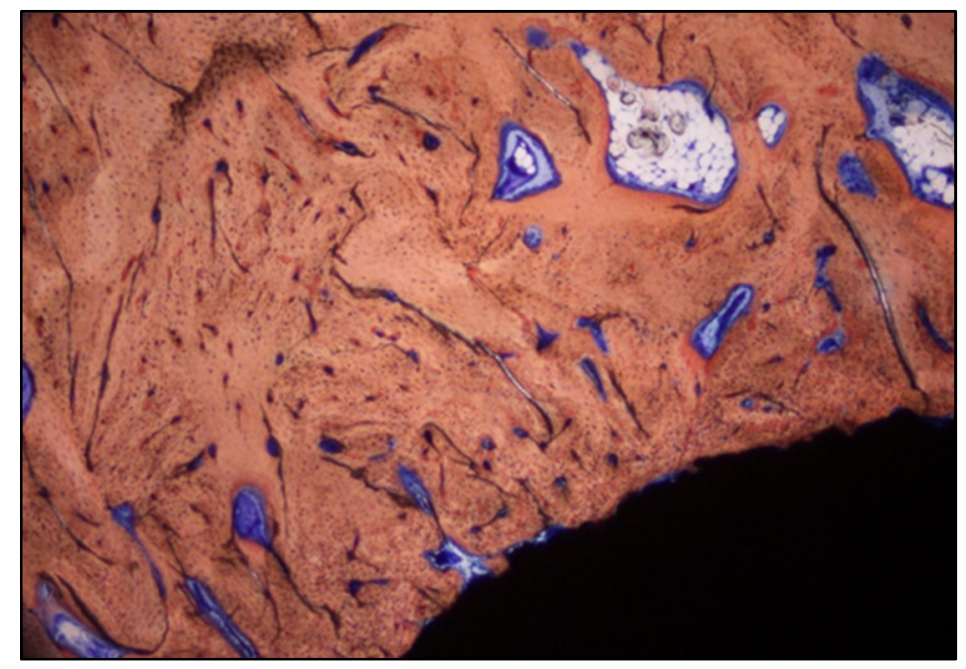

Abbildung 3.1.2-1 Titanimplantat nach 12-Wochen-BZR mit kortikaler Lage. „Reifer“ Lamellenknochen periimplantär ohne histomorphologischen Unterschied zum umliegenden Knochen.

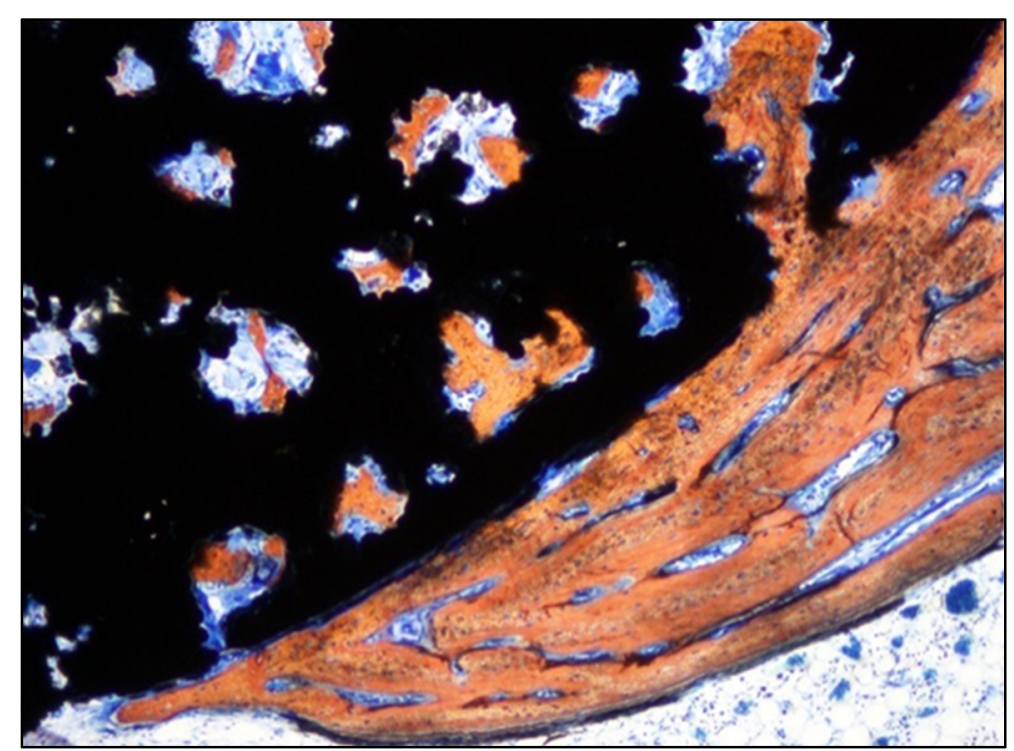

Abbildung 3.1.2-2 Poröses Implantat. 12-Wochen-BZR. Der Geflechtknochen periimplantär und in den Poren mit vollständiger Mineralisierung.

Die porösen Implantate zeigten nach einem BZR von 12 Wochen innerhalb der Poren ebenfalls eine regelhafte Ausreifung und Mineralisation des neugebildeten Knochens (Abbildung 3.1.2-2). Die meisten Poren in den kortikalen Schnittstufen wiesen reifen Lamellenknochen auf. Die histologische Zusammensetzung glich dem periimplantären Areal.

\subsubsection{Implantat im spongiösen Knochen}

Im spongiösen Knochen war der Anteil von nichtmineralisiertem Knochengewebe sowohl in der Gruppe mit porösen als auch mit gestrahlten Implantaten im Vergleich zur Kortikalis nach einem 12-Wochen-BZR deutlich reduziert (Abbildung 3.1.2-3). Osteoid wurde in geringerer Masse produziert (Abbildung 3.1.2-4). Um die neugebildeten Spongiosabälkchen außerhalb und innerhalb 
der Poren war eine geringere Osteoblastenaktivität zu verzeichnen. Des Weiteren fanden die gleichen Remodelingprozesse wie um die Implantate in den kortikalen Abschnitten statt. Der Anteil des mineralisierten Knochens war deutlich höher als nach 4 Wochen. Ein flächendeckender, knöcherner periimplantärer Umbau wie im kortikalen Abschnitt fand nicht statt. In den spongiösen Schnittstufen waren wie in den Schnittstufen nach 4 Wochen zahlreiche Aussparungen, aufgefüllt mit reifen Fettgeweben, zu verzeichnen. Die neugebildete Spongiosa zeigte die gleiche Morphologie wie die Spongiosa außerhalb des Bohrkanals.

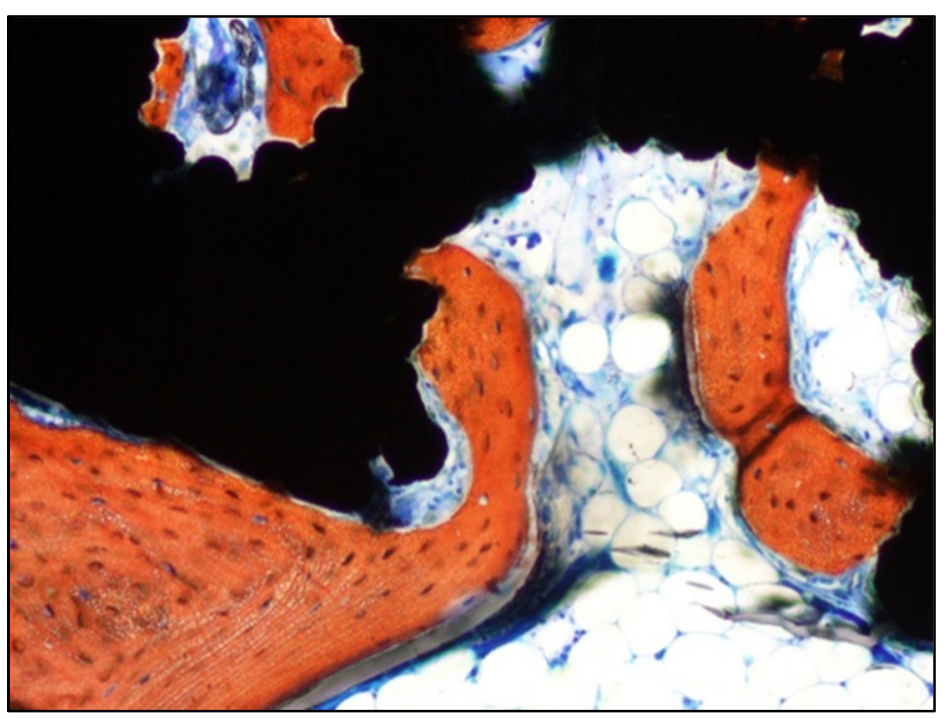

Abbildung 3.1.2-3 Poröses Implantat nach 12-Wochen-BZR. Ausgereifte Spongiosabälkchen verankern das Implantat im Knochen.

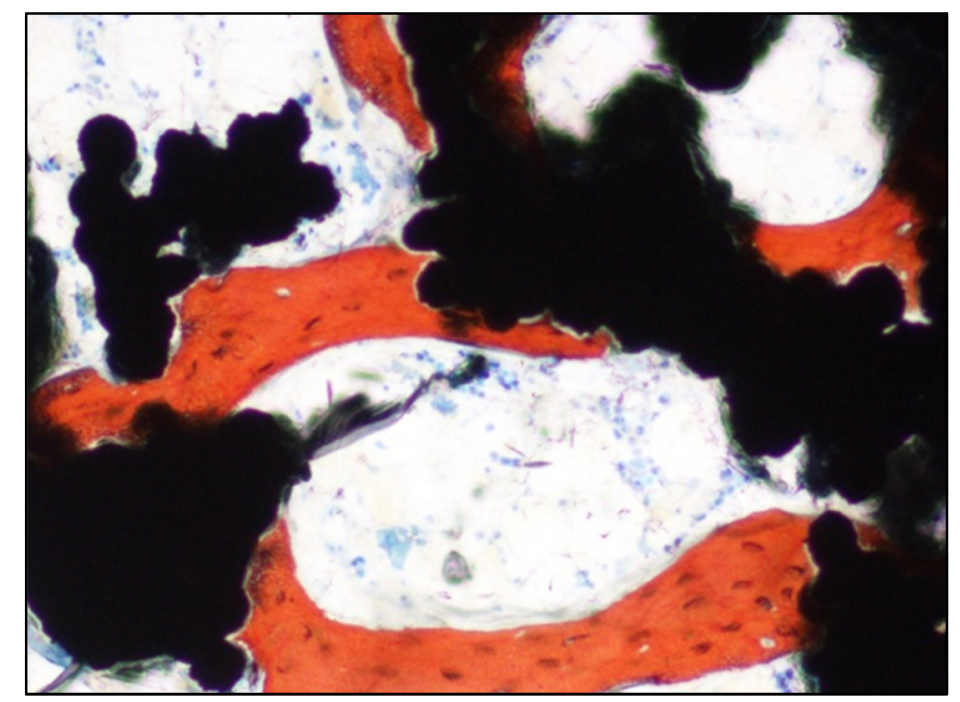

Abbildung 3.1.2-4 Poröses Implantat nach 12-Wochen-BZR. Spongiosabälkchen passen sich intraporös den Gegebenheiten der Pore an. 


\subsubsection{Implantat im Markraum}

Die Titanimplantate P und G zeigten histomorphologisch keine Unterschiede in der ossären Integration. Auch nach einem 12-wöchigen BZR zeigten beide Implantatmodelle eine der Umgebung angepasste Osseointegration. Eine vollständige peri- und intraimplantäre knöcherne Integration fand nicht statt. Die Implantate wurden nur teilweise vom neugebildeten Knochen umgeben. Zum großen Anteil umhüllte wie auch in dem 4-wöchigen BZR das ortständige Fettgewebe die Titanimplantate. Histomorphologisch handelte es sich auch in dieser Lokalisation um reifen Lamellenknochen. Ein morphologischer Unterschied in der Qualität zwischen porösem und gestrahltem Implantat des bereits mineralisierten Knochens gab es nicht. Histologisch zeigte sich das mineralisierte Knochengewebe deutlich zellärmer. Im Vergleich zum unreifen Geflechtknochen nach einem 4-wöchigen BZR lagen die eingemauerten Osteozyten geordneter in der mineralisierten Knochenmatrix und die Kollagenfasern nun parallel zueinander (Abbildung 3.1.2-5). Die Menge an nichtmineralisiertem Osteoid war deutlich reduziert und unterschied sich nicht von der kortikalen oder spongiösen Lage der Implantate.

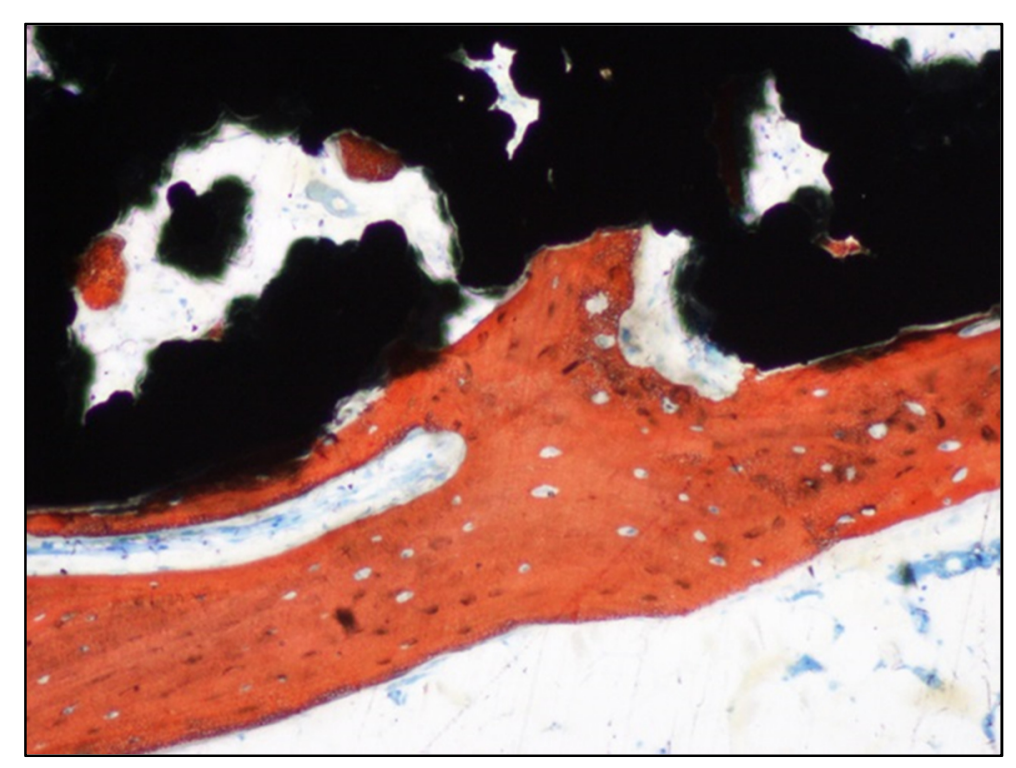

Abbildung 3.1.2-5 Poröses Implantat nach 12 Wochen. Ausgebildete Knochenspanngen umgeben das Implantat.

Im Markraum fand die knöcherne Integration über eine Vergrößerung der direkten Kontaktfläche von Knochen zu Implantat statt. Die sogenannte „elephantenfußartige“ Abstützung bestand aus einem zentralen Osteon, von dem aus sich flächenhaft Knochenmatrix an das Implantat anschmiegte und somit eine funktionelle Verankerung gewährleistete (Abbildung 3.1.2-6). Eine immunologische Reaktion blieb aus. 


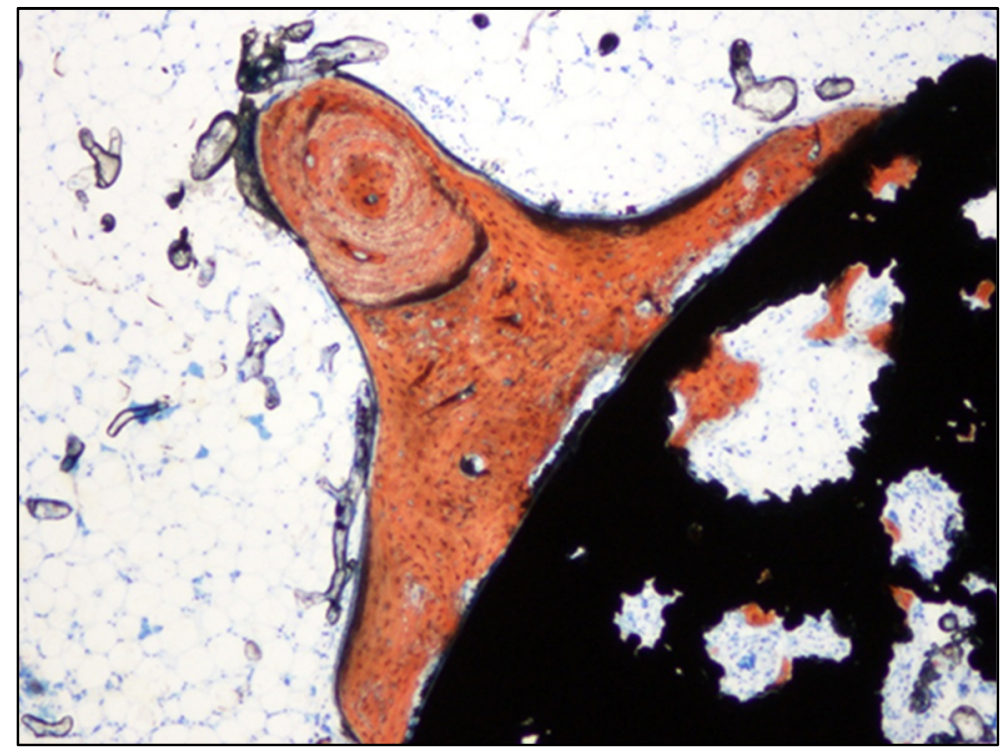

Abbildung 3.1.2-6 Poröses Implantat nach 12-wöchigem BZR. Reifer Lamellenknochen, elefantenfußartige Abstützung.

Zusammengefasst wiesen beide Implantatmodelle im zeitlichen Verlauf eine gute ossäre Integration auf. Als Zeichen einer primären Osseointegration bildete sich Geflechtknochen aus, der sich bereits nach einem 4-wöchigen BZR in Lamellenknochen umzuwandeln begann. Es fand eine rege Kontaktosteosynthese statt. Histologisch waren breite Osteoidsäume mit aufgestellten, aktiven osteoidbildenden Osteoblasten sowie osteoklastäre Riesenzellen nachzuweisen. Beim offenporigen Implantatmodell fand auch intraporös eine Osteoneogenese statt. Histologisch unterschied sich der intraporös ausgebildete Knochen nicht vom periimplantären. Die knöchernen Fragmente ähnelten in ihrer Gestalt Spongiosabälkchen und passten sich wie beim periimplantären Knochen gut der Rauigkeit der Poren an. Nach 12 Wochen waren die neuausgebildeten Knochenareale vollständig in Lamellenknochen umgewandelt und mineralisiert. Knöcherne auf- und Umbauvorgänge waren seltener oder kaum zu beobachten. Als Ausdruck funktioneller Anpassung im zeitlichen Verlauf traten lakunäre Aussparungen mit osteoklastären Riesenzellen auf. Neuausgebaute Knochenareale wurden remodelliert und die Belastung dem Kraftfluss angepasst. Der Knochen lag direkt an dem Implantat an. Eine bindegewebige Schicht im Sinne einer Distanzosteogenese blieb aus. Auch eine immunologische Reaktion auf das implantierte Gewebe im Sinne einer Implantatabstoßung war nicht festzustellen, was für die gute Biokompatibilität des Materials spricht. 


\subsection{Histomorphometrie}

\subsubsection{Materialkontrolle}

\subsubsection{Implantatumfang}

Der Umfang der Implantate wurde sowohl in der Gruppe 4-Wochen-BZR als auch 12-WochenBZR gemessen, um methodische Fehler zu überprüfen. Die Umfänge der gestrahlten Implantate aus den Versuchen nach 4 (20,31 +/- 0,31) und 12 Wochen $(20,08+/-0,25)$ BZR waren mit einer minimalen Variabilität fast identisch (Abb. 3.2.1.1/1). Dagegen war die Variabilität der Umfängen nach $4(27,73+/-3,51)$ und 12 Wochen $(28,43+/-3,45)$ BZR bei den porösen Implantaten stärker ausgeprägt (Abbildung 3.2.1-1, Anlage 6-1).

Im direkten Vergleich war der Umfang der porösen Implantate signifikant größer als bei den gestrahlten Implantaten $(\mathrm{p}<0,05)$ (Abbildung 3.2.1-1).

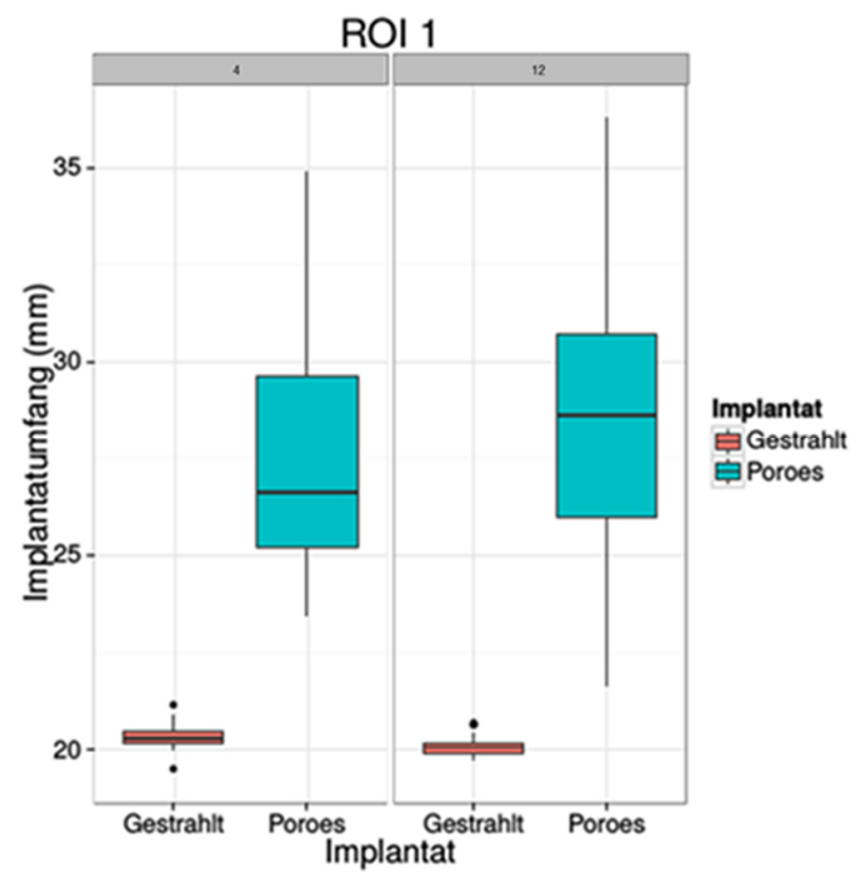

Abbildung 3.2.1-1 Umfänge für Implantate G und P im zeitlichen Verlauf eines 4- und 12-wöchigen BZR.

\subsubsection{Porositätsgrad}

Die Porosität war unabhängig von der Lage (ROI 4-6) nahezu gleich und zeigte keine signifikanten Unterschiede (Abbildung 3.2.1-2 und

Anlage 6-2). 

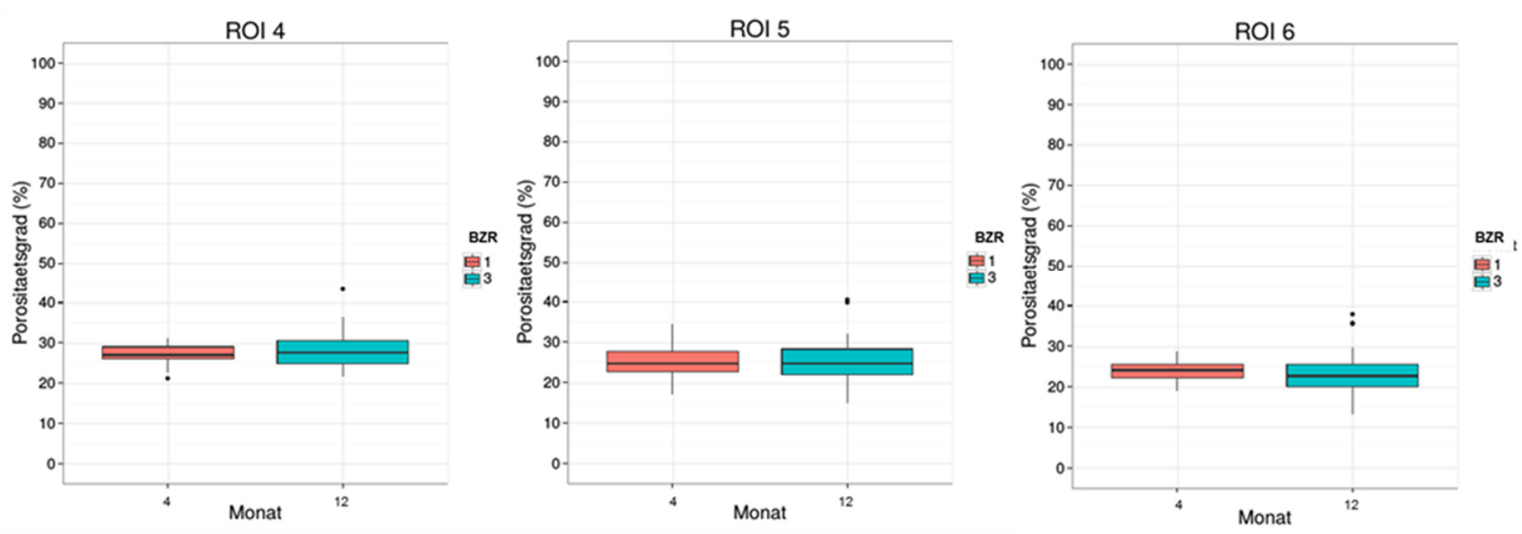

Abbildung 3.2.1-2 Porositätsgrad in ROI 4, 5 und 6.

\subsubsection{Interobserver Variabilität}

Um die Sensitivität der histomorphometrischen Untersuchungsverfahren zu validieren, wurden drei Untersucher eingesetzt, die jeweils die histomorphometrischen Messungen durchführten. Die Interobserver-Variabilität zeigte sowohl in dem 4- als auch dem 12-wöchiegen BZR keinen statistisch signifikanten Unterschied für die Knochendichte (

Anlage 6-3).

\subsubsection{Knochendichte}

\subsubsection{Periimplantär}

\section{4-wöchiger BZR}

Die neugebildete Gesamtknochendichte (\%) war periimplantär (ROI 1) bei beiden Implantattypen nahezu identisch $(\mathrm{p}=0,7036)$ (Tabelle 3.2.3-1).

Tabelle 3.2.3-1 Mittelwert und Standartabweichung für Knochendichte (\%) in ROI 1 nach 4-wöchigem BZR.

\begin{tabular}{|l|l|l|}
\hline Gestrahlt & Porös & p \\
\hline $40,03+/-15,54$ & $40,06+/-12,3$ & 0,7036 \\
\hline
\end{tabular}

Beide Implantattypen wiesen in ROI 1 eine statistisch signifikante negative Korrelation zwischen Knochendichte (\%) und Implantattiefe auf (Tabelle 3.2.3-2). Mit zunehmender Implantattiefe (Schnittstufen von 2 bis 10) konnte eine Abnahme der periimplantären Knochendichte (\%) beobachtet werden. In den oberflächlichen Implantatstufen (Schnitt 2 und 4) war die Knochendichte periimplantär (ROI 1) bei den porösen Implantaten größer als bei den gestrahlten Implantaten, ohne jedoch einen signifikanten Unterschied zu zeigen. Zu der größeren Implantattiefe hin (Schnitt 6-10) war die Knochendichte periimplantär (ROI 1) bei den gestrahlten Implantaten tendenziell größer als bei den porösen. 
Tabelle 3.2.3-2 Mittelwert und Standartabweichung für Knochendichte (\%) und Implantattiefe in ROI 1 nach 4 wöchigem BZR.

\begin{tabular}{|l|l|l|l|l|}
\hline Schnitt & Gestrahlt & Porös & p & p.Holm \\
\hline 2 & $47,97+/-8,4$ & $50,04+/-6,26$ & 0,2860 & 0,8580 \\
\hline 4 & $41,44+/-16,79$ & $44,96+/-9,3$ & 0,3373 & 0,8580 \\
\hline 6 & $39,68+/-18,04$ & $36,33+/-13,98$ & 0,5366 & 0,8580 \\
\hline 8 & $35,87+/-15,8$ & $30,79+/-8,4$ & 0,0620 & 0,0510 \\
\hline 10 & $35,35+/-15,26$ & $32,84+/-11,94$ & 0,1244 & 0,4976 \\
\hline
\end{tabular}

Die mittlere Gesamtknochendichte beim porösen Implantat war direkt am Implantat (ROI 3) gröBer als implantatfern (ROI 2) (Tabelle 3.2.3-3).

Tabelle 3.2.3-3 Mittelwert und Standartabweichung für Knochendichte (\%) in ROI 2-3 nach 4 Wochen.

\begin{tabular}{|l|l|l|l|}
\hline ROI & Gestrahlt & Porös & $\mathbf{p}$ \\
\hline 2 & $39,58+/-15,83$ & $37,12+/-11,57$ & 0,2110 \\
\hline 3 & $39,27+/-15,02$ & $41,31+/-11,67$ & 0,6577 \\
\hline
\end{tabular}

Tendenziell zeigte sich bei beiden Implantattypen eine negative Korrelation zwischen Knochendichte (\%) und Implantattiefe in ROI 2 und ROI 3 (Tabelle 3.2.3-4).

Tabelle 3.2.3-4 Mittelwert und Standartabweichung für Knochendichte (\%) periimplantär (ROI 2-3) und in der Implantattiefe (Schnitt 2-10) nach 4 Wochen.

\begin{tabular}{|l|l|l|l|l|l|}
\hline ROI & Implantattiefe & Gestrahlt & Porös & p & p.Holm \\
\hline 2 & 2 & $46,78+/-11,57$ & $48,94+/-5,75$ & 0,6052 & 1,0000 \\
\cline { 2 - 6 } & 4 & $41,84+/-18,34$ & $38,8+/-8,98$ & 0,5508 & 1,0000 \\
\cline { 2 - 6 } & 6 & $39,14+/-18,17$ & $33,14+/-13,1$ & 0,423 & 1,0000 \\
\cline { 2 - 6 } & 8 & $35,24+/-15,12$ & $28,9+/-7,35$ & 0,028 & 0,1120 \\
\cline { 2 - 6 } & 10 & $34,49+/-16,76$ & $31,35+/-11,96$ & 0,2534 & 0,8696 \\
\cline { 2 - 6 } & 2 & $50,03+/-6,1$ & $53,28+/-4,15$ & 0,1557 & 0,7785 \\
\cline { 2 - 6 } & 4 & $40,73+/-15,52$ & $46,25+/-7,21$ & 0,3539 & 1,0000 \\
\cline { 2 - 6 } & 6 & $39,63+/-18,42$ & $35,68+/-12,3$ & 0,6449 & 1,0000 \\
\cline { 2 - 6 } & 8 & $33,36+/-13,94$ & $31,41+/-3,83$ & 0,1833 & 0,7785 \\
\cline { 2 - 6 } & 10 & $32,08+/-15,38$ & $34,84+/-1496$ & 0,8127 & 1,0000 \\
\hline
\end{tabular}




\section{2-wöchiger BZR}

Die neugebildete Gesamtknochendichte (\%) war periimplantär (ROI 1) im gestrahlten und porösen Implantat vergleichbar (Tabelle 3.2.3-5).

Tabelle 3.2.3-5 Mittelwert und Standartabweichung für Knochendichte (\%) in ROI 1 nach 12 Wochen.

\begin{tabular}{|l|l|l|}
\hline Gestrahlt & Porös & $\mathbf{p}$ \\
\hline $34,38+/-9,02$ & $35,32+/-9,41$ & 0,5007 \\
\hline
\end{tabular}

Die neugebildete Gesamtknochendichte nahm periimplantär (ROI 1) bei beiden Implantattypen zur größeren Implantattiefe (Schnitt 2-8) hin ab (Tabelle 3.2.3-6 Mittelwert und Standardabweichung für die Knochendichte (\%) in ROI 1 nach der Implantattiefe und nach 12 Wochen In den oberflächlichen Implantatstufen (Schnitt 2 und 4) war die Knochendichte periimplantär (ROI 1) bei den gestrahlten Implantaten tendenziell größer als bei den porösen Implantaten. In den tieferen Schnittschichten (Schnitt 6-10) war die Knochendichte periimplantär (ROI 1) hingegen bei den porösen Implantaten größer. Signifikante Unterschiede konnten jeweils nicht festgestellt werden (Tabelle 3.2.3-6).

Tabelle 3.2.3-6 Mittelwert und Standardabweichung für die Knochendichte (\%) in ROI 1 nach der Implantattiefe und nach 12 Wochen.

\begin{tabular}{|l|l|l|l|l|}
\hline \multicolumn{1}{|c|}{ Schnitt } & \multicolumn{1}{|c|}{ Gestrahlt } & \multicolumn{1}{c|}{ Porös } & \multicolumn{1}{c|}{ p.Holm } \\
\hline 2 & $41,69+/-6,12$ & $40,04+/-7,4$ & 0,0755 & 0,3775 \\
\hline 4 & $38,48+/-9,54$ & $36,78+/-10,08$ & 0,6179 & 1,0000 \\
\hline 6 & $30,5+/-7,53$ & $33,19+/-7,61$ & 0,2780 & 1,0000 \\
\hline 8 & $30,13+/-7,06$ & $30,56+/-8,56$ & 0,8746 & 1,0000 \\
\hline 10 & $31,27+/-8,86$ & $36,25+/-11,88$ & 0,3096 & 1,0000 \\
\hline
\end{tabular}

Die mittlere Gesamtknochendichte war bei beiden Implantattypen direkt am Implantat (ROI 3) tendenziell größer als implantatfern (ROI 2) (Tabelle 3.2.3-7).

Tabelle 3.2.3-7 Mittelwert und Standardabweichung für die Knochendichte (\%) in ROI 2-3 nach 12 Wochen.

\begin{tabular}{|l|l|l|l|}
\hline \multicolumn{1}{|c|}{ ROI } & \multicolumn{1}{|c|}{ Gestrahlt } & \multicolumn{1}{c|}{ Porös } & \multicolumn{1}{c|}{ p } \\
\hline 2 & $27,13+/-9,02$ & $30,53+/-8,35$ & 0,0916 \\
\hline 3 & $41,02+/-10,65$ & $39,19+/-10,3$ & 0,4424 \\
\hline
\end{tabular}

Weiterhin lag bei beiden Implantattypen und in allen Implantatstufen (Schnitt 2-10) direkt am Implantat (ROI 3) eine höhere Knochendichte vor als implantatfern (ROI 2) vor (Tabelle 3.2.3-8). 
Tabelle 3.2.3-8 Mittelwert und Standardabweichung für Knochendichte (\%) in ROI 2-3 und Implantattiefe nach 12 Wochen.

\begin{tabular}{|l|l|l|l|l|l|}
\hline ROI & Schnitt & Gestrahlt & Porös & p & p.Holm \\
\hline 2 & 2 & $33,71+/-6.03$ & $34,27+/-5.21$ & 0,7853 & 1,0000 \\
\cline { 2 - 6 } & 4 & $30,55+/-8.38$ & $30,69+/-9.36$ & 0,9696 & 1,0000 \\
\cline { 2 - 6 } & 6 & $25,35+/-9.63$ & $29,0+/-7.52$ & 0,4499 & 1,0000 \\
\cline { 2 - 6 } & 8 & $23,47+/-7.25$ & $26,43+/-6.9$ & 0,4482 & 1,0000 \\
\hline \multirow{3}{*}{3} & 10 & $22,07+/-10.73$ & $32,92+/-12.8$ & 0,1846 & 0,9230 \\
\cline { 2 - 6 } & 2 & $48,9+/-10.27$ & $45,33+/-8.06$ & 0,0811 & 0,4055 \\
\cline { 2 - 6 } & 6 & $45,41+/-12.18$ & $41,69+/-11.07$ & 0,5603 & 1,0000 \\
\cline { 2 - 6 } & 8 & $35,04+/-8.4$ & $36,8+/-8.03$ & 0,6450 & 1,0000 \\
\cline { 2 - 6 } & 10 & $36,32+/-8.18$ & $33,68+/-9.43$ & 0,5860 & 1,0000 \\
\hline
\end{tabular}

\section{Vergleich 4- und 12-wöchiger BZR}

Die neugebildete Gesamtknochendichte (\%) nahm periimplantär (ROI 1) sowohl beim gestrahlten Implantat (40,03 +/- 15,54, bzw. 34,38 + / - 9,02) als auch beim porösen Implantat (40,06 +/- 12,3, bzw. 35,32 +/- 9,41) im zeitlichen Verlauf (4-wöchiger vs. 12-wöchiger BZR) deutlich ab (Abbildung 3.2.3-1).

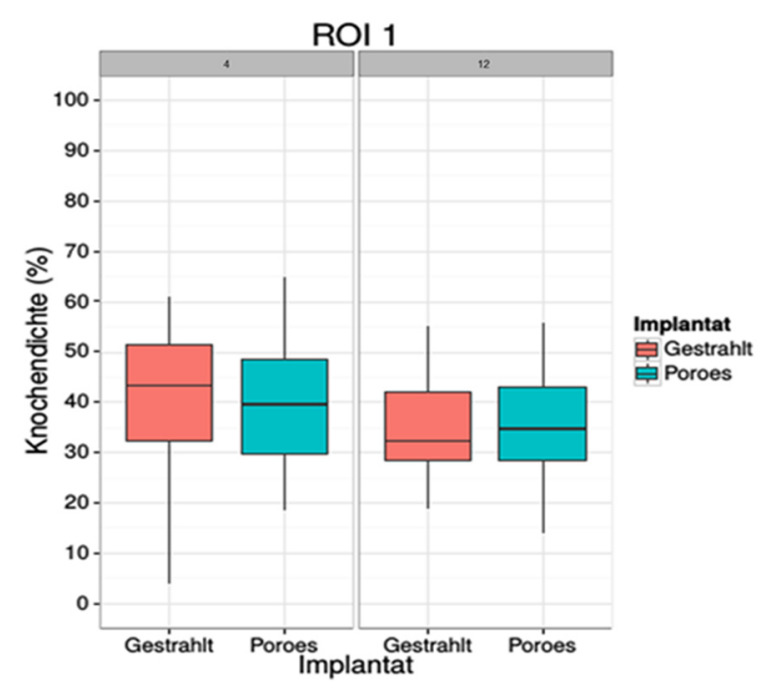

Abbildung 3.2.3-1 Periimplantäre Knochendichte (ROI 1) nach 4 und 12 Wochen.

Die neugebildete Gesamtknochendichte nahm periimplantär (ROI 1) bei beiden Implantattypen zur größeren Implantattiefe (Schnitt 2-8) hin mit dem zunehmenden BZR ab (Tabelle 3.2.3-9). 
Tabelle 3.2.3-9 Mittelwert und Standartabweichung für Knochendichte in ROI 1 zur Implantattiefe in den Implantaten G und P nach 4 und 12 Wochen.

\begin{tabular}{|c|c|c|c|c|c|}
\hline BZR & Implantattiefe & Gestrahlt & Porös & $\mathrm{p}$ & p.Holm \\
\hline \multirow[t]{5}{*}{4} & 2 & $47,97+/-8,4$ & $50,04+/-6,26$ & 0,2860 & 0.8580 \\
\hline & 4 & $41,44+/-16,79$ & $44,96+/-9,3$ & 0,3373 & 0.8580 \\
\hline & 6 & $39,68+/-18,04$ & $36,33+/-13,98$ & 0,5366 & 0.8580 \\
\hline & 8 & $35,87+/-15,8$ & $30,79+/-8,4$ & 0,0062 & 0.0310 \\
\hline & 10 & $35,35+/-15,26$ & $32,84+/-11,94$ & 0.1244 & 0.4976 \\
\hline \multirow[t]{5}{*}{12} & 2 & $41,69+/-6,12$ & $40,04+/-7,4$ & 0.0755 & 0.3775 \\
\hline & 4 & $38,48+/-9,54$ & $36,78+/-10,08$ & 0.6179 & 1.0000 \\
\hline & 6 & $30,5+/-7,53$ & $33,19+/-7,61$ & 0.2780 & 1.0000 \\
\hline & 8 & $30,13+/-7,06$ & $30,56+/-8,56$ & 0.8746 & 1.0000 \\
\hline & 10 & $31,27+/-8,86$ & $36,25+/-11,88$ & 0.3096 & 1.0000 \\
\hline
\end{tabular}

Die gemittelte Gesamtknochendichte über alle Schichten hinweg spiegelte die Tendenz zur Abnahme der Knochendichte von der implantatfernen ROI 2 zur implantatnahen ROI 3 unabhängig vom BZR wider (Abbildung 3.2.3-2, Tabelle 3.2.3-10).
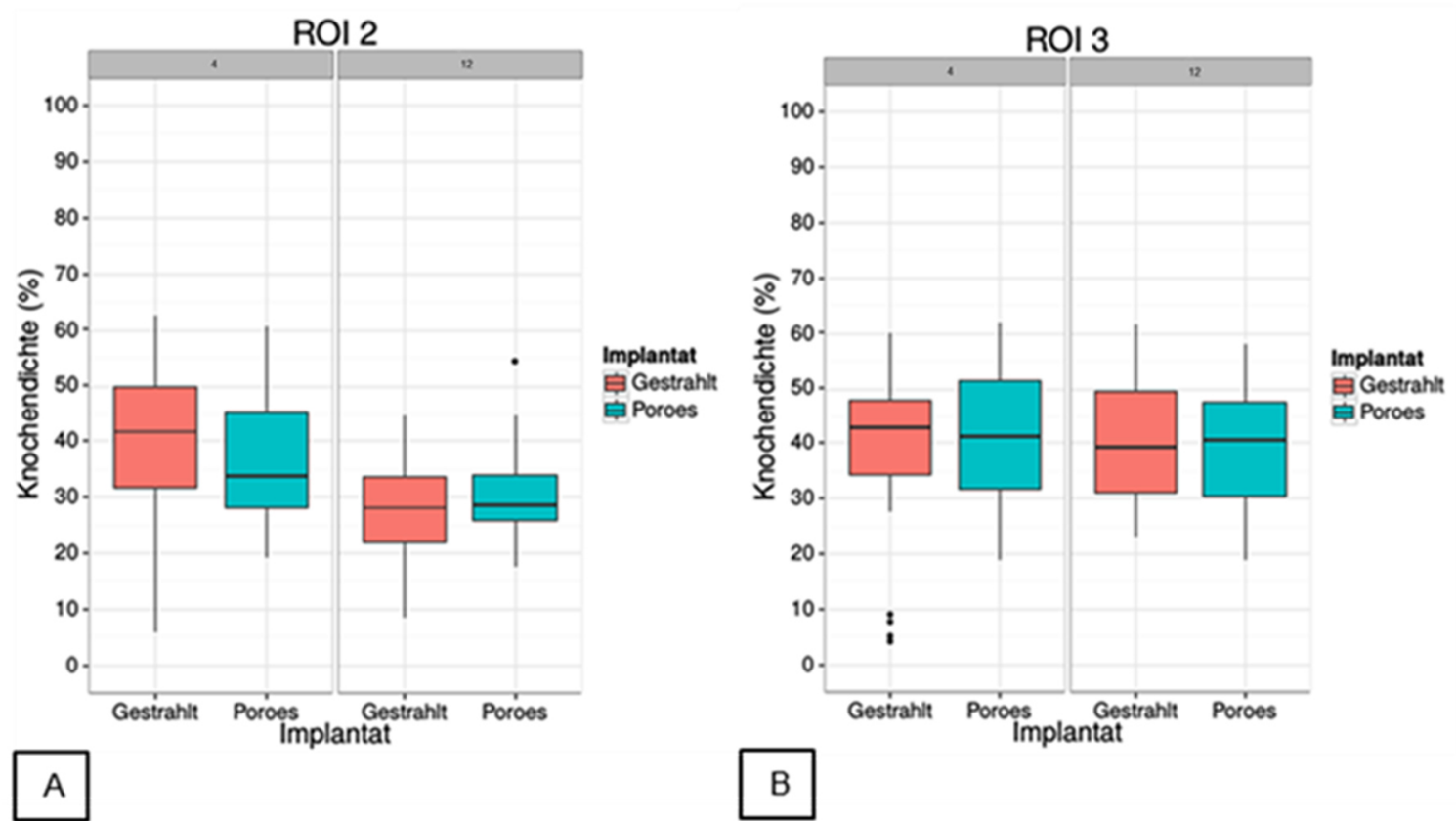

Abbildung 3.2.3-2 Implantatnahe (ROI 3) und -ferne (ROI 2) Knochendichte im zeitlichen Verlauf in beiden Implantaten.

Im zeitlichen Verlauf von 4 zu 12 Wochen wies die implantatnahe ROI 3 eher stabilere Knochendichtewerte auf als die implantatferne ROI 2, wobei es bei beiden Implantattypen zu einer deutlichen Reduktion der Knochendichte kam (Tabelle 3.2.3-10). 
Tabelle 3.2.3-10 Mittelwert und Standartabweichung für Knochendichte (\%) in ROI 2 und 3 für die Implantate G und P im zeitlichen Verlauf.

\begin{tabular}{|l|l|l|l|l|}
\hline BZR & ROI & Gestrahlt & Porös & p \\
\hline 4 & 2 & $39,58+/-15,83$ & $37,12+/-11,57$ & 0,2110 \\
\cline { 2 - 5 } & 3 & $39,27+/-15,02$ & $41,31+/-11,67$ & 0,6577 \\
\hline \multirow{2}{*}{12} & 2 & $27,13+/-9,02$ & $30,53+/-8,35$ & 00916 \\
\cline { 2 - 5 } & 3 & $41,02+/-10,65$ & $39,19+/-10,3$ & 0,4424 \\
\hline
\end{tabular}

Weiterhin lag bei beiden Implantaten und in allen Implantattiefen (2-10) direkt am Implantat (ROI 3) tendenziell eine höhere Knochendichte vor als implantatfern (ROI 2) (Tabelle 3.2.3-11). Diese Tendenz war bei den gestrahlten Implantaten stärker ausgeprägt.

Tabelle 3.2.3-11 Mittelwert und Standartabweichung für Knochendichte in ROI 2-3 zur Implantattiefe nach 4 und 12 Wochen.

\begin{tabular}{|c|c|c|c|c|c|c|}
\hline BZR & ROI & Implantattiefe & Gestrahlt & Porös & $\mathrm{p}$ & p.Holm \\
\hline \multirow[t]{10}{*}{4} & \multirow[t]{5}{*}{2} & 2 & $46,78+/-11,57$ & $48,94+/-5.75$ & 0,6052 & 1,0000 \\
\hline & & 4 & $41,84+/-18,34$ & $38,8+/-8.98$ & 0,5508 & 1,0000 \\
\hline & & 6 & $39,14+/-18,17$ & $33,14+/-13.1$ & 0,423 & 1,0000 \\
\hline & & 8 & $35,24+/-15,12$ & $28,9+/-7.35$ & 0,028 & 0,1120 \\
\hline & & 10 & $34,49+/-16,76$ & $31,35+/-11.96$ & 0,317 & 1,0000 \\
\hline & \multirow[t]{5}{*}{3} & 2 & $50,03+/-6,1$ & $53,28+/-4.15$ & 0,1557 & 0,7785 \\
\hline & & 4 & $40,73+/-15,52$ & $46,25+/-7.21$ & 0,3539 & 1,0000 \\
\hline & & 6 & $39,63+/-18,42$ & $35,68+/-12.3$ & 0,6449 & 1,0000 \\
\hline & & 8 & $33,36+/-13,94$ & $31,41+/-3.83$ & 0,1833 & 0,7785 \\
\hline & & 10 & $32,08+/-15,38$ & $34,84+/-14.96$ & 0,8127 & 1,0000 \\
\hline \multirow[t]{10}{*}{12} & \multirow[t]{5}{*}{2} & 2 & $33,71+/-6,03$ & $34,27+/-5.21$ & 0,7853 & 1,0000 \\
\hline & & 4 & $30,55+/-8,38$ & $30,69+/-9.36$ & 0,9696 & 1,0000 \\
\hline & & 6 & $25,35+/-9,63$ & $29+/-7.52$ & 0,4499 & 1,0000 \\
\hline & & 8 & $23,47+/-7,25$ & $26,43+/-6.9$ & 0,4482 & 1,0000 \\
\hline & & 10 & $22,07+/-10,73$ & $32,92+/-12.8$ & 0,1846 & 0,9230 \\
\hline & \multirow[t]{5}{*}{3} & 2 & $48,9+/-10,27$ & $45,33+/-8.06$ & 0,0811 & 0,4055 \\
\hline & & 4 & $45,41+/-12,18$ & $41,69+/-11.07$ & 0,5603 & 1,0000 \\
\hline & & 6 & $35,04+/-8,4$ & $36,8+/-8.03$ & 0,6450 & 1,0000 \\
\hline & & 8 & $36,32+/-8,18$ & $33,68+/-9.43$ & 0,5860 & 1,0000 \\
\hline & & 10 & $40,37+/-9,45$ & $38,17+/-14$ & 0,7791 & 1,0000 \\
\hline
\end{tabular}




\subsubsection{Intraporöse Knochendichte (Gruppe P)}

\section{4-wöchiger BZR}

Bei den porösen Implantaten konnte eine Tendenz zur Verringerung der Knochendichte mit zunehmender ROI (4 bis 6) beobachtet werden (Tabelle 3.2.3-12).

\section{2-wöchiger BZR}

Die Knochendichte wies keinen signifikanten Unterschied bezüglich der Implantattiefe und der Region of Interest (ROI 4-6) auf (Tabelle 3.2.3-12).

Tabelle 3.2.3-12 Mittelwert und Standardabweichung für Knochendichte (\%) in ROI 4-6 zur Implantattiefe nach 4 und 12 Wochen.

\begin{tabular}{|c|c|c|c|c|}
\hline ROI & Implantattiefe & 4-wöchiger BZR & 12-wöchiger BZR & $\mathrm{p}$ \\
\hline 4 & 2 & $22,06+/-15,43$ & $22,96+/-15,98$ & 0,8855 \\
\hline 4 & 4 & $20,09+/-13,58$ & $22,46+/-16,14$ & 0,6886 \\
\hline 4 & 6 & $16,51+/-12,88$ & $20,46+/-13,6$ & 0,4542 \\
\hline 4 & 8 & $14,38+/-10,58$ & $18,8+/-12,64$ & 0,3613 \\
\hline 4 & 10 & $15,55+/-10$ & $24,83+/-15,41$ & 0,1666 \\
\hline 5 & 2 & $20,5+/-4,45$ & $17,37+/-10,85$ & 0,5363 \\
\hline 5 & 4 & $20,31+/-3,6$ & $23,22+/-12,85$ & 0,6125 \\
\hline 5 & 6 & $17,9+/-6,77$ & $19,68+/-12,83$ & 0,7712 \\
\hline 5 & 8 & $15,92+/-3,36$ & $16,07+/-13,66$ & 0,9794 \\
\hline 5 & 10 & $11,11+/-0,63$ & $15,75+/-9,5$ & 0,3369 \\
\hline 6 & 2 & $18,61+/-6,61$ & $18,33+/-11,83$ & 0,9611 \\
\hline 6 & 4 & $15,54+/-7,42$ & $21,35+/-15,94$ & 0,4452 \\
\hline 6 & 6 & $16,84+/-6,55$ & $20,52+/-17,77$ & 0,6499 \\
\hline 6 & 8 & $13,97+/-2,9$ & $13,7+/-9,71$ & 0,9499 \\
\hline 6 & 10 & $14,38+/-4,53$ & $16,23+/-8,66$ & 0,7063 \\
\hline
\end{tabular}

\section{Vergleich 4- und 12-wöchiger BZR}

Eine signifikante Veränderung der intraporösen Knochendichte im zeitlichen Verlauf (4-wöchiger BZR vs. 12-wöchiger BZR) lag unabhängig von der Implantattiefe (2-10) nicht vor (Abbildung 3.2.3-3). 

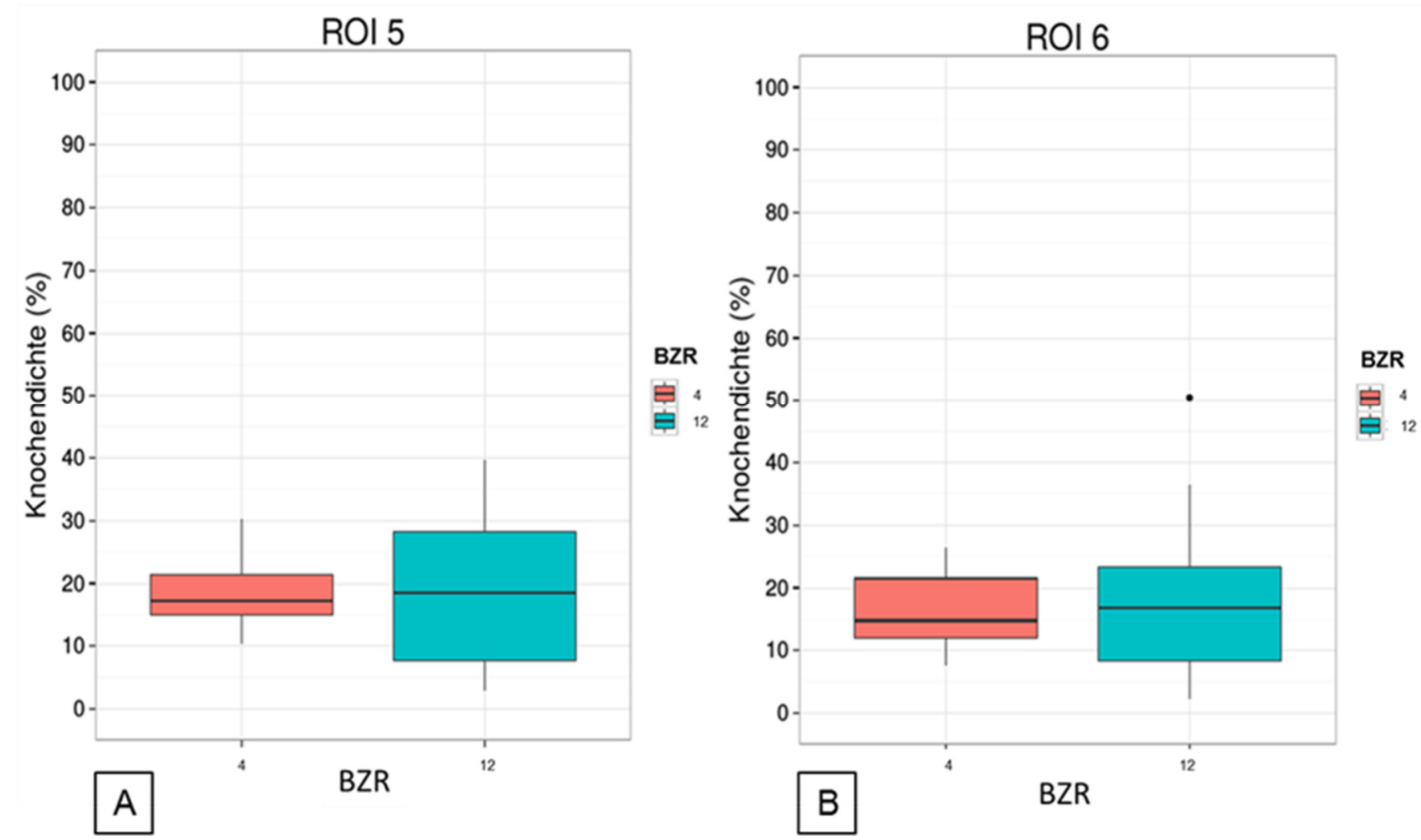

Abbildung 3.2.3-3 Knochendichte (\%) in ROI 5 (A) und ROI 6 (B) in beiden Implantattypen nach 4 und 12 Wochen.

\subsubsection{Knochenanlagerung Implantatoberfläche - Bone to Implant Contact (BIC)}

\section{4-wöchiger BZR}

Die Knochenanlagerung (mm) an der Implantatoberfläche ist im Mittelwert beim porösen Implantat signifikant höher als beim gestrahlten Implantat (7,46 mm vs. 5,72 mm; $\mathrm{p}<0,05)$ (Tabelle 3.2.4-1).

Tabelle 3.2.4-1 Mittelwert und Standardabweichung für Knochenanlagerung ( $\mathrm{mm}$ ) bei den gestrahlten und porösen Implantaten nach 4 und 12 Wochen.

\begin{tabular}{|l|l|l|l|l|}
\hline BZR & Gestrahlt (mm) & Porös (mm) & p & p.Holm \\
\hline 4 & $5,72+/-2,19$ & $7,46+/-2,58$ & $<0,05$ & $<0,05$ \\
\hline 12 & $9,52+/-1,5$ & $11,57+/-2,51$ & $<0,05$ & $<0,05$ \\
\hline
\end{tabular}

\section{2-wöchiger BZR}

Die direkte Knochenanlagerung an der Implantatoberfläche ist beim porösen Implantat signifikant größer als beim gestrahlten Implantat (Tabelle 3.2.4-1). 


\section{Vergleich 4- und 12-wöchiger BZR}

Bei beiden Implantattypen kam es im zeitlichen Verlauf zu einer signifikanten Zunahme des Knochen-ImplantatKontakts an der Oberfläche $(\mathrm{p}<0,05)$ (Tabelle 3.2.4-1, Abbildung 3.2.4-1,

\begin{tabular}{|l|l|l|}
\hline Effekt Knochendichte (\%) & 4-wöchiger BZR & 12-wöchiger BZR \\
\hline Implantattyp P & $\mathrm{p}=0,1362$ & $\mathrm{p}=0,0035$ \\
\hline Implantattyp G & $\mathrm{p}=0,2728$ & $\mathrm{p}=0,8546$ \\
\hline
\end{tabular}

Anlage 6-4,

Anlage 6-5).

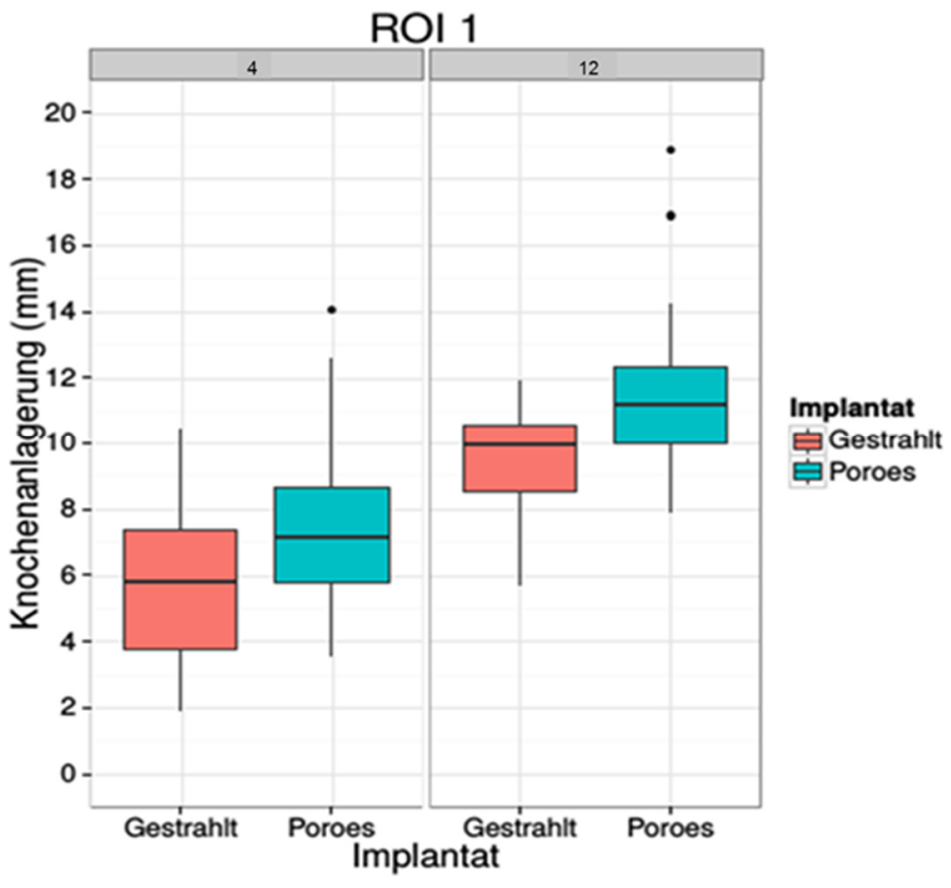

Abbildung 3.2.4-1 Verteilung des Parameters Knochenanlagerung (mm) für Implantat G und P im zeitlichen Verlauf. 


\section{Diskussion}

\subsection{Studiendesign}

Implantate aus einer Ti-6Al-4V-Legierung sind seit den achtziger Jahren in der Implantologie etabliert und gehören zu dem gängigsten Biomaterial in der orthopädischen Chirurgie (Delgado-Ruiz 2018; Simsek und Ozyurek 2019). Dies basiert auf exzellenten mechanischen Eigenschaften, ausgezeichneter Biokompatibilität (Head et al. 1995) sowie seiner guten Korrosionsbeständigkeit (Elias 2011). Andere verwendete Materialien im Bereich der lasttragenden Implantate wie z. B. rostfreier Stahl weisen häufig eine geringere Korrosionsbeständigkeit und damit eine geringere Bioverträglichkeit als Titan auf (Eliaz 2019). Die Wahrscheinlichkeit der Implantatlockerung bei lokalen oder systemischen Hypersensitivitätsreaktionen sind beim rostfreien Stahl höher (BaskoPlluska et al. 2011; Lin 2017). Eine weitere Möglichkeit ist die Verwendung von Implantaten aus Cobald-Chrom-Molybdän-Legierungen. Diese Implantate weisen jedoch ebenfalls eine geringere Bioverträglichkeit und somit eine höhere Rate an Implantatlockerung im Vergleich zum Titan auf (Jakobsen et al. 2007). Implantate aus Keramik haben eine hohe Korrosionsbeständigkeit und Osteokonduktivität sowie eine gute Biokompatibilität. Jedoch besteht bei diesen Implantaten ein höheres Risiko eines Implantatbruchs (Morlock und Jäger 2017). Zudem wird mit zunehmender Porosität des Keramikmaterials die Festigkeit zusätzlich reduziert (Gotzen 1992).

Trotz hervorragender Materialeigenschaften kann es auch bei Titanimplantaten zur Implantatlockerung kommen. Neben den Materialeigenschaften beeinflusst eine Vielzahl von Mechanismen die Osseointegration von Titanimplantaten, wie z. B. die Geometrie und Oberflächenbeschaffenheit, physische Belastung, die Implantationstechnik, der anatomische Implantationsort und die Art des umliegenden Knochens sowie das biologische Objekt (Botticelli und Lang 2017). Thomas et al. (1987) konnten belegen, dass Implantate mit aufgerauter Oberfläche eine höhere Festigkeit der Implantatverankerung sowie einen besseren Knochen-Implantat-Verbund aufweisen als glatt polierte Modelle (Thomas et al. 1987). Dadurch kann eine verbesserte mechanische Stabilität erreicht werden. Es besteht eine lineare Korrelation zwischen vermehrter Oberflächenrauigkeit bis hin zu Offenporigkeit und einer verbesserten Osseointegration (Buser et al. 1991; Wong et al. 1995).

Ziel der vorliegenden Arbeit war es, die ossäre Integration von zwei standardisierten Titanimplantaten mit unterschiedlichen Struktur- und Oberflächeneigenschaften dreidimensional sowohl histomorphologisch als auch histomorphometrisch zu untersuchen. Dabei handelte es sich zum einen um ein offenporiges, gesintertes Titanimplantat (Ti-6Al-4V) und zum anderen um ein solides Titanimplantat (Ti-6Al-4V) mit sandgestrahlter, aufgerauter Oberfläche als Kontrollgruppe. Die Ti- 
6Al-4V-Legierung der in dieser Arbeit verwendeten Implantate gehört zu den aktuell häufig verwenden Materialien in der Endoprothetik (Diehl 2010).

Die verwendeten offenporigen Implantate wurden im Platzhalterverfahren nach Bram in Zusammenarbeit mit dem Fraunhofer-Institut in Bremen hergestellt (Bram et al. 2004). Die Porosität der Testimplantate beträgt ca. 29 \%. Aufgrund dessen wird das Elastizitätsmodul im Vergleich zum massiven Implantat der Kontrollgruppe von 105 GPa auf ca. 30 GPa gesenkt und liegt somit deutlich näher am Elastizitätsmoduls des kortikalen Knochens (Bram et al. 2004; Long und Rack 1998). Dadurch wird ein übermäßiges Missverhältnis zwischen der Steifigkeit des Implantats und des umgebenden Knochens vermieden, sodass das Stress-Shielding reduziert und das Risiko einer Implantatlockerung gesenkt wird (Guden et al. 2008).

Neben der Elastizität ist auch die Porengröße ein Einflussfaktor für die Osseointegration poröser Implantate. Eine Porengröße zwischen 50 und $400 \mu \mathrm{m}$ scheint für das Einwachsen des Knochens optimal zu sein (Bobyn et al. 1980). In-vitro-Versuche bestätigen tendenziell diese Ergebnisse. Frosch et al. zeigten bei Versuchen mit humanen osteoblastenähnlichen Zellen ein schnelleres Einwachsverhalten in einen Titantestkörper mit einer Porengröße von 300-600 $\mu \mathrm{m}$ (Frosch et al. 2002). Laut Albrektsson und Johansson basiert das Einwachsen von Knochengewebe auf der Mikrostruktur der Poren (Albrektsson und Johansson 2001). Eine raue Strukturbeschaffenheit der Porenwand stimuliert Osteoblasten zur Migration und Adhäsion sowie Proliferation (Osteokonduktion).

Ein Nachteil bei der Verwendung von Titan und vielen anderen Metallen ist die Undurchlässigkeit für Röntgenstrahlen, was die Beurteilung postoperativer radiologischer Kontrollen erschweren kann (Ito et al. 2014). Dies betrifft insbesondere die Implantate aus einer homogenen Volllegierung. Poröse Titanimplantate erleichtern durch die poröse Struktur die radiologische Beurteilung und hinterlassen weniger Artefakte im CT (Ito et al. 2014). Ein weiterer potenzieller Nachteil von Titan als Implantationsmaterial ist die mögliche Toxizität von abgegebenen Titanionen in hohen Konzentrationen. Die Abgabe von Titanionen ist für alle Elemente der Legierung beschrieben, experimentelle oder epidemiologische Daten existieren diesbezüglich allerdings nicht (Head et al. 1995).

\subsection{Tiermodell}

Eine histologische Untersuchung des komplex aufgebauten Femurs mit implantiertem Titantestkörper ist nur mithilfe histologischer Schliffpräpate entlang des gesamten Implantats mit umliegendem Knochen möglich. Tiermodelle ermöglichen die Untersuchung der ossären Integration 
von Implantaten im Knochen aus biologischer, biochemischer und biomechanischer Sicht (Marsell und Einhorn 2011).

In der Literatur werden verschiedene Tiermodelle, wie zum Beispiel Hund, Kaninchen oder Ratte, für Studien der ossären Integration von Titanimplantaten vorgestellt (Botticelli und Lang 2017). Das Kaninchen erweist sich von allen vorgestellten Tiermodellen aus mehreren Gründen als am besten geeignet: Es hat einen ähnlichen histologischen Knochenaufbau und einen prinzipiell ähnlichen Ablauf der Frakturheilung verglichen mit dem Menschen, wobei die primäre Knochenheilung etwa doppelt so schnell abläuft (Botticelli und Lang 2017; Urist und Johnson 1943). Des Weiteren haben sich die Kaninchen unter Berücksichtigung des Tierschutzes als Versuchstiere bewährt, weil die Reproduzierbarkeit der Ergebnisse hinsichtlich des Einwachsens von Biomaterialien in experimentellen Studien nachgewiesen und auf den Menschen übertragbar ist (Wissing 1990).

Ein weiterer Grund für die Wahl der Kaninchen ist deren einfache Handhabung. Für die Untersuchung am Bewegungsapparat ist eine artgerechte Bodenhaltung mit ausreichender Bewegung wichtig. Die Tiere können zu größerer Anzahl in einem Raum unter gleichen Bedingungen gehalten werden. Somit besteht eine höhere Wahrscheinlichkeit, statistisch relevante Aussagen treffen zu können. Für diese Studie wurden ausgewachsene weibliche Kaninchen im Alter zwischen 11 und 12 Monaten der Rasse Chinchilla Bastard mit einem Mindestgewicht von $>3 \mathrm{~kg}$ ausgewählt. Laut Literatur gelten Kaninchen mit diesen Massen als ausgewachsen, da die Epiphysenfugen geschlossen sind (Jager et al. 1976). Des Weiteren wurden ausgewachsene Kaninchen ausgewählt, weil die Größe des distalen Femurs für die Maße der verwendeten Implantate ein ausreichend großes Implantatlager bietet.

Die angestrebte artgerechte Bewegungsfreiheit der Tiere bei der Haltung war in unserem Versuch wegen des daraus resultierenden Kraftflusses bei mechanischer Belastung auf die Implantationsregion (Roux Hypothese) von Bedeutung (Glatt et al. 2016). Dabei wurde während des gesamten Versuchsablaufs auf den physiologischen Zustand der Bewegungsabläufe des Kaninchens geachtet.

Die körperliche Belastung nimmt einen großen Einfluss auf die Entwicklung der Osteogenese. Allori und seine Arbeitsgruppe verwenden in diesem Zusammenhang den Begriff „Mechanotransduktion“ (Allori et al. 2008). Das bedeutet, dass mechanische Stimuli (physische Belastungen) in elektrochemische Aktivitäten konvertiert werden. Komplexe zelluläre und molekulare Mechanismen werden dadurch in Gang gebracht und nehmen Einfluss auf die Knochenmorphologie und das Remodeling. Dabei wird betont, dass eine hohe Frequenz der Belastung bei niedriger 
Amplitude sich positiv auf die Masse des spongiösen Knochens auswirkt. Hohe Belastungsspitzen oder Bewegungsmangel führen zum Knochenabbau. Ohne physische Belastung kommt es zur Implantatlockerung (Burr 2002).

Als Implantationsort der Titanzylinder eignete sich der laterale Rollhügel des Femurs, da er ausreichend großes und gut zugängliches Implantatlager bietet. So konnten mit großer Sicherheit Bohrlöcher platziert werden, ohne die angrenzende Kortikalis zu schwächen. Dadurch wurde die Gefahr einer postoperativen Fakturierung periimplantär minimiert und eine Vollbelastung der operierten Extremitäten direkt postoperativ ermöglicht. Periimplantäre Frakturen wurden im gesamten Versuchsverlauf nicht beobachtet.

Die Verweildauer der Implantate wurde entsprechend den physiologischen Aspekten des Kaninchens gewählt. Nach vier Wochen ist die primäre zum Teil überschießende Knochenheilung abgeschlossen und das anschließende Remodeling des neugebildeten Knochens, das dem Kraftfluss folgt, ist nach ca. 12 Wochen beendet (Wissing 1990). Dementsprechend wurden Beobachtungszeiträume (BZR) von 4 und 12 Wochen gewählt. Somit ließ sich im zeitlichen Verlauf nach initialer Osteogenese (4 Wochen) die funktionelle Beanspruchung des Knochens und die Integration der Implantate im Rahmen des Remodeling (12 Wochen) optimal untersuchen.

Für unsere Versuchszwecke wurden die Tiere doppelseitig behandelt. Entsprechend wurde randomisiert ein offenporiges und ein gestrahltes Implantat in je eines der Femora implantiert - zum einen, um die Anzahl der Versuchstiere zu halbieren, zum anderen, weil die doppelseitige Behandlung eine hohe und gute Vergleichbarkeit bietet (Frosch et al. 2006).

\subsection{Untersuchungsmethoden}

Um das Ausmaß der knöchernen Integration der Implantate zu untersuchen, stehen einige Verfahren zur Verfügung. Nichtinvasive physikalische Verfahren, wie die quantitative Computertomographie oder die Ultraschallmethode, sind die gängigsten (Klintström und Klintström 2016). Die gewählten Untersuchungsmethoden, die Histomorphologie und Histomorphometrie, werden in der Literatur als Goldstandard für die Untersuchung der Osseointegration von Implantaten beschrieben (Dalle Carbonare et al. 2005; Somanathan 2006). Die Histomorphometrie diente der Quantifizierung der Knochenneubildung. Die Vorteile der computergestützten Histomorphometrie liegen in der verwendeten Trenn- und Dünnschliff-Technik nach Donath und Breuner (Donath und Breuner 1982). Diese Methode ist verbreitet bei der Analyse der Pathogenese verschiedener meta- 
bolischer Erkrankungen des Knochens (Kulak und Dempster 2010). Weitere Vorteile der gewählten Methode ist die Möglichkeit einer Aussage über das dreidimensionale Verhalten der Knochenneubildung durch die Herstellung und Auswertung mehrerer Schliffe.

Die benötigten histologischen Schliffpräparate wurden entsprechend dem Herstellungsverfahren nach Donath und Breuner angefertigt (Kulak und Dempster 2010). Schliffdicke betrugt dabei 5 $\mu \mathrm{m}$. Stärkere Schichtdicken können aufgrund von Projektionseffekten die Auswertung erschweren und die Ergebnisse verzerren (Sumner et al. 1989). Die gewählte Schichtdicke minimiert Überlagerungsartefakte der Gewebeschichten und ermöglicht dadurch eine exakte lichtmikroskopische Untersuchung der feingeweblichen Strukturen (Donath und Breuner 1982). Die angewandte etablierte Färbemethode ermöglicht eine genaue mikroskopische Trennung zwischen mineralisiertem Knochen, neugebildetem Knochen mit mineralisierten Anteilen und dem nicht mineralisierten Osteoid (Smith und Karadgianes 1974).

\subsection{Interobserver-Unterschiede}

Bei der halbautomatisch durchgeführten computergestützten Histomorphometrie ist der Einfluss des Untersuchers ein wichtiger Faktor und kann nicht vollständig ausgeschlossen werden. Kulak und Dempster diskutieren (Kulak und Dempster 2010). Eine mögliche Abhängigkeit der Ergebnisse vom Untersucher wird als Nachteil der Untersuchung dargestellt (Kopp et al. 2012). Um die Interobserver-Variabilität und die Einflüsse einer Lernkurven zu minimieren, wurden die Messungen von der Verfasserin sowie von zwei weiteren Untersuchern durchgeführt. Die anfangs gewählten Kriterien der Auswertung waren ausreichend präzise festgelegt, so dass die Ergebnisse reproduzierbar waren.

\subsection{Operationsmethode}

Ein weiterer einflussreicher Faktor für eine erfolgreiche Osseointegration ist die angewandte Operationsmethode (Wong et al. 1995). Für eine sichere knöcherne Verankerung von zementfreien Endoprothesen bedarf es einer hohen initialen Stabilität und einer festen Verankerung des Implantats im Knochen, da Mikrobewegungen zu einer frühen aseptischen Lockerung führen können (Freeman und Railton 1987). Erreicht wird diese Primärstabilität durch das sogenannte Press-FitVerfahren, bei dem das Implantatlager im Vergleich zum verwendeten Implantat minimal unterdimensioniert ist (Galante et al. 1987). Um diese Press-Fit-Situation zu ermöglichen, wurde bei einem Implantatdurchmesser von 5,6 mm eine Hohlfräse mit einem Durchmesser von 5,4 mm zur Herstellung des Implantatlagers verwendet. Dieser direkte Knochenkontakt führt nach Schenk zu der 
angestrebten primären Knochenheilung (Schenk 1976). Bei Spaltbreiten größer $1 \mathrm{~mm}$ ist die primäre Knochenheilung gestört.

\subsection{Ergebnisse}

Im Rahmen der vorliegenden Studie „Anthrocells“ wurde der Verlauf der ossären Integration histomorphologisch und histomorphometrisch untersucht und eine Hypothese aufgestellt: Die neuartigen offenporigen Titanimplantate erfahren eine mindestens genauso gute ossäre Integration wie die bisher verwendeten, auf herkömmliche Weise hergestellten Implantate aus homogenen Titanlegierungen mit aufgerauter Oberfläche.

Die osteoinduktive Wirkung und die hervorragende Biokompatibilität des Titans, wie in der Literatur beschrieben, konnten in dieser Arbeit überzeugend nachgewiesen werden (Simsek und Ozyurek 2019). Histologisch bestätigte sich nicht nur eine organische, sondern auch eine funktionelle Osseointegration mit Ausbildung von trabekel- und spangenartigen Knochenausläufern vom Implantatlager bis zur Implantatoberfläche (Vasconcellos et al. 2010).

Beide Implantatmodelle (P und G) mit unterschiedlichen Oberflächenbeschaffenheiten wiesen einen direkten Knochen-Implantat-Kontakt auf. In beiden BZR lag eine regelhafte Anlagerung des neugebildeten Knochens periimplantär vor. Somit erfüllten beide Implantattypen die Kriterien einer erfolgreichen Osseointegration (Albrektsson et al. 1981; Albrektsson und Wennerberg 2019). Die Gruppe mit gestrahlten Implantaten zeigte eine Anpassung des neugebildeten Knochens an die raue Implantatoberfläche und die Gruppe mit porösen Implantaten zusätzlich ein Einwachsen des neugebildeten Knochens in die offenen Poren bis in das Implantatinnere (Rosa et al. 2009; Vasconcellos et al. 2010; Wazen et al. 2010).

Eine raue Oberfläche begünstigt im Vergleich zu einer glatten Oberfläche den direkten ImplantatKnochen-Kontakt ohne interponiertes Bindegewebe (Wennerberg et al. 2018). Die glatte Oberfläche bringt den biologischen Nachteil mit sich, dass die Zellen, die in Kontakt mit glatten Oberflächen treten, sich in Fibroblasten und im Falle eines oralen Implantats in Epithelzellen der Mundschleimhaut differenzieren (Wong et al. 1995). Eine Bindegewebsschicht verhindert den KnochenImplantat-Kontakt und führt zugleich zur erhöhten Instabilität bis hin zur Lockerung des Implantats (Long und Rack 1998). Dagegen löst eine moderate Rauigkeit der Implantatoberfläche eine vollständige Osseointegration mit einer Osteoblastendifferenzierung und Kollagensynthese aus (Albrektsson und Wennerberg 2019). 
Buser und seine Arbeitsgruppe bewiesen eine positive Korrelation mit steigernder Oberflächenrauhigkeit des Implantats und dem Ausmaß des Knochen-Implantat-Verbunds im Interface (Buser et al. 1991). Der Vorteil der porösen Implantate liegt in ihren offenen und untereinander korrespondierenden Poren. Dadurch wird eine biologische Verankerung zwischen umliegendem Knochen und Implantat ermöglicht und ein besserer Knochen-Implantat-Verbund gewährleistet (Vasconcellos et al. 2010).

Einer vollständigen Osseointegration bis in das Implantatinnere der Poren bewies zum einen die Interkonnektivität der Poren und zum anderen die osteokonduktive Eigenschaft des Titangerüsts. Diese Eigenschaften tragen zur zusätzlichen Implantatstabilität bei. Aus der Sicht der Biotechnik zeigen die porösen Implantate, dass die auch in dieser Arbeit angestrebte Porengröße von $400 \mu \mathrm{m}$ und die Mikroarchitektur der Poren eine optimale Umgebung für Zelladhäsion, Proliferation und organoide Differenzierung ergeben (Bobyn et al. 1980; Itala et al. 2001). Zusätzlich erlauben die knochengefüllten Poren eine bessere Kraftübertragung bis in den Kern des Implantats (TorresSanchez et al. 2017).

Der Ablauf der ossären Integration der Titanimplantate entspricht dem biologischen Modell der Frakturheilung. Auch in dieser Arbeit, insbesondere unter Berücksichtigung der gewählten Zeiträume von vier und zwölf Wochen, lässt sich histologisch der physiologische Ablauf der Frakturheilung beobachten. Nach einem 4-wöchigem BZR war die primäre Osseointegration vollzogen. Sowohl periimplantär als auch in den Poren konnte reichlich Osteoidbildung und Übergang in den überwiegen mineralisierten, osteozytenreichen Geflechtknochen beobachtet werden. Diese histologischen Beobachtungen bestätigen eine erfolgreiche Osseointegration.

Im zeitlichen Verlauf (12-wöchiger BZR) fand eine Umstrukturierung der initialen überschießenden Knochenheilung von peripher zu implantatnah sowie eine Ausreifung des neugebildeten Knochens statt. Es konnte eine Reduktion der Menge des Osteoids beobachtet werden. Der osteozytenreiche Geflechtknochen wurde zu osteozytenärmerem, reifem und mineralisiertem Lamellenknochen umgebaut. Es lag nicht nur die anfängliche und vollständige Osseointegration (4-wöchiger BZR) vor, sondern auch ein anschließendes, funktionelles Remodeling (12-wöchiger BZR). Zu dem 12-wöchigen BZR hin war ein organoides Remodeling offenkundig. Zwischen den neugebildeten Knochenlamellen nahmen die Adipozyten sowohl an der Implantatoberfläche als auch in den Poren zu. Zellen der Hämatopoese waren, wie erwartet, implantatnah nicht vorzufinden. Mit der Zeit verdrängten die Fettzellen das rote Mark und ersetzten dieses. Dies wird bei offenporigen Implantaten häufig beobachtet. Es ist also davon auszugehen, dass das Titangerüst die Funktion des spongiösen Knochens ersetzt (Albrektsson und Wennerberg 2019; Barrère 2003). 
Die offenporige Struktur der Testimplantate senkt laut Literatur das Infektionsrisiko (Bonsignore et al. 2011). Es ist davon auszugehen, dass der offenporige dreidimensionale Aufbau den Transport von Flüssigkeiten, Blutbestandteilen, Stammzellen, mesenchymalen Stammzellen, Osteoblasten und Osteoklasten sowie Blutgefäßen in das Implantatinnere gewährleistet ist. Die dadurch verbesserte Vaskularisation des Implantats geht mit einer geringeren Infektionsrate einher (Ito et al. 2014).

Die neugebildete Knochendichte (\%) war bei beiden Implantatmodellen periimplantär (ROI 1) identisch und zeigte im zeitlichen Verlauf eine ähnliche abnehmende Tendenz. Zum einen ist dies durch eine erfolgreiche Osseointegration beider Titanimplantate in das Knochenlager begründet, zum anderen deutet die Tendenz der Abnahme der Knochendichte im zeitlichen Verlauf sowie die Verlagerung der Knochenmasse von ROI 2 (implantatfern) zu ROI 3 (implantatnah) auf Remodelingvorgänge hin.

Die initiale überschießende Knochenheilung unter Ausbildung von Kallus wird unter physischer Belastung reorganisiert und im Kraftfluss umstrukturiert. Interessanterweise zeigte die absolute Knochendichte bemessen in $\mathrm{mm}^{2}$ signifikant höhere Werte für das poröse Implantat. Diese Beobachtung basiert auf der vergrößerten Oberfläche und intraporöse Knochenbildung der porösen Implantate. Die Offenporigkeit ermöglicht den Implantaten eine Fortführung des Knochens von der Oberfläche bis in das Zentrum der Implantate und verbessert die Verankerung im Knochen.

Bei Implantaten aus homogener Volllegierung mit sandgestrahlter Oberfläche wird die Belastung vom Knochenlager auf das Implantat übertragen und umgekehrt. Bei offenporigen Implantaten gilt dies auch. Zudem ermöglicht ein interkonnektierendes Porensystem, dass der Knochen in die Poren einwachsen kann und somit das Implantatinnere mit dem Implantatlager verbindet. Die Knochendichte intraporös nahm zur Implantatmitte (ROI 6) hin ab.

Das Verteilungsmuster des neugebildeten Knochens innerhalb der Poren der porösen Implantate erklärt das Wolffsche Gesetz, bei dem eine Knochenneubildung nur bei einer von außen wirkenden Belastung entsteht (Wolff 1892). Der prozentuale Knochenanteil ist dementsprechend in den oberflächennahen Poren am stärksten ausgebildet und sinkt in den oberflächenfernen Poren signifikant ab. Auch der zeitliche Verlauf spricht für eine funktionelle Beanspruchung im Kraftfluss des Knochens innerhalb der Poren, da sich nach einer möglicherweise initial überschießenden Knochenneubildung (nach 4 Wochen) im Verlauf des Remodeling (nach 12 Wochen) eher mehr Knochen in den oberflächennahen Poren bildete und in den oberflächenfernen Poren die Knochenfläche konstant blieb. Eine Änderung im zeitlichen Verlauf konnte nicht beobachtet werden. 
Die negative Korrelation zwischen Knochendichte $\left(\%\right.$ und $\left.\mathrm{mm}^{2}\right)$ und Implantattiefe (4- und 12wöchiger BZR) ergab sich aus der biologischen Gegebenheit des Knochens. Die histomorphometrische Untersuchung zeigte, dass die Schnittstufe 2 und 4 überwiegend im kortikalen Knochen periostnah liegen und die weiteren tieferen Schnittstufen sich im metaphysären und partiell intramedulären Abschnitt des Femurs befinden.

Die abnehmende Knochendichte ist auf die unterschiedliche osteogene Aktivität der verschiedenen Knochenstrukturen zurückzuführen. Periostal und endostal besteht ein höheres Knochenwachstumspotential als metaphysär und intramedulär (Eschenroeder et al. 1987). Chang et al. untersuchten die Osseointegration von Implantaten bezüglich ihrer Positionierung innerhalb des Knochens. Sie belegten dabei, dass die osteogene Aktivität des Knochenmarks im Vergleich zu periostalen kortikalen Lagen niedriger ist (Chang et al. 1994).

Die verwendeten Titanimplantate unterscheiden sich im Herstellungsverfahren und dadurch in ihrer Oberflächenmorphologie. Die Testkörper sind jedoch gleich dimensioniert und weisen einen Implantatdurchmesser von 5,6 $\mathrm{mm}$ und eine Länge von $7 \mathrm{~mm}$ auf. Trotz dessen weisen die porösen Implantate $(\mathrm{P})$ aufgrund der porösen Oberflächenbeschaffenheit einen signifikant größeren Implantatumfang als die gestrahlten Implantate auf $(G=20,08+/-0,25 \mathrm{~mm} ; \mathrm{P}=28,44$ + /- 3,71 mm; $\mathrm{p}<0,05)$. Aufgrund des größeren Implantatumfangs kann mehr Knochen an die porösen Implantate angelagert werden und ein besserer Knochen-Implantat-Verbund wird ermöglicht (Wazen et al. 2010).

In der histomorphometrischen Untersuchung der direkten Knochenanlagerung an die Implantatoberfläche spielt aufgrund der unterschiedlichen Implantatumfänge weniger der prozentuale (\%) als vielmehr der abolute Wert (mm) die entscheidende Rolle. Es zeigte sich eine signifikant erhöhte direkte Knochenanlagerung des porösen Implantats im Vergleich zum gestrahlten Implantat (G= 5,72 +/- 2,19 $\mathrm{mm}$ und $\mathrm{P}=7,46+/-2,58 \mathrm{~mm}$ nach vier Wochen BZR; $\mathrm{p}<0,05)$. Nach zwölf Wochen ergab sich histomorphometrisch ebenfalls ein signifikant höheres Ergebnis $(p<0,05)$ für das poröse Implantat mit durchschnittlich $11,57 \mathrm{~mm}$ im Vergleich zum gestrahlten Implantat mit 9,52 mm. Somit erweist sich die poröse Oberflächenstruktur bezüglich der direkten Knochenanlagerung als ein Indikator für die erfolgreiche Osseointegration, da ein besserer Knochen-ImplantatKontakt für eine bessere Langzeitverankerung der Implantate spricht (Wennerberg et al. 1995). Der zeitliche Aspekt dabei untermauert die These einer besseren osteokonduktiven und osteoinduktiven Funktion des porösen Titangerüsts. 


\section{$5 \quad$ Zusammenfassung}

In der Endoprothetik und Implantologie ist die dauerhafte und sichere Implantatverankerung ein entscheidenderer Faktor für eine erfolgreiche Behandlung. Das verwendete Material muss einer dauerhaften Belastung standhalten, ohne dass es zur Verformung oder zum Materialbruch kommt. Titan und seine Legierungen sind aufgrund ihrer guten Biokompatibilität, biomechanischen Eigenschaften sowie exzellenten Korrosionsbeständigkeit weit verbreitet. Ein zu großer Unterschied des Elastizitätsmoduls zwischen Knochen und Implantatmaterial wie z. B. bei soliden Titanimplantaten kann jedoch zur frühzeitigen Lockerung führen.

Poröse Titanimplantate bieten sowohl eine adäquate Materialstabilität als auch aufgrund der Mikrostruktur ein dem Knochen angepasstes Elastizitätsmodul. Zudem fördert die raue Oberfläche der offenporigen Struktur das Einwachsverhalten im Vergleich zu glatt polierten Oberflächen.

In der vorliegenden Arbeit wurde histomorphologisch und histomorphometrisch das knöcherne Einwachsverhalten eines porösen zylinderförmigen Titanimplantats (Ti-6Al-4V), das in einem neuartigen Sinterungsprozess hergestellt wurde, in einem Tierversuch untersucht. Als Kontrollgruppe wurden herkömmliche solide Titantestzylinder (Ti-6Al-4V) mit aufgerauter Oberfläche eingesetzt.

Folgende Hypothesen wurden aufgestellt:

die neuen offenporigen Titanimplantate werden zumindest eine gleich gute knöcherne Integration erfahren wie gleichdimensionierte Titanzylinder mit grobgestrahlter Oberfläche einer Kontrollgruppe sowie

die neuen offenporigen Titanimplantate werden in den Kraftfluss integriert und das Knochengewebe wird in die Poren der Implantate einwachsen.

Bei 15 Kaninchen wurde pro Seite je ein poröses oder ein sandgestrahltes Implantat in die lateralen Femurkondyle eingesetzt. Die Tiere wurden entweder nach vier oder zwölf Wochen euthanasiert. Anschließend wurden Schliffpäparate der Knochen mit einliegendem Implantat hergestellt und eine histologische Färbung mit Methylenblau und Alizarinrot durchgeführt. Nach der Digitalisierung der Schnitte mittels eines vollautomatisierten Mikroskops erfolgten die deskriptive histomorphologische Untersuchung sowie die histomorphometrische Messung.

In der histomorphologischen Untersuchung zeigte sich sowohl für das poröse Implantat als auch für die Kontrollgruppe eine erfolgreiche Osseointegration. Nach vier Wochen waren die Implantate periimplantär vollständig vom Osteoid oder mineralisierten Geflechtknochen sowie weniger 
vom Lamellenknochen umgeben. Nach zwölf Wochen war ein deutliches Remodeling nachweisbar. Es war mehr mineralisierter Lamellenkonchen, aber weniger Geflechtknochen und kaum Osteoid mehr vorhanden. Zwischen den Knochenbälkchen lag zunehmend reifes Fettgewebe vor. Am direkten Kontakt zum Implantat entstand kein interponierendes Bindegewebe, das die Stabilität des Implantats hätte verringern können. Die periimplantäre und intraimplantäre Knochenneubildung waren vergleichbar, was für die funktionelle Beanspruchung des Knochens in den Poren spricht. Histomorphometrisch unterschied sich die neugebildete Knochenmasse periimplantär nicht signifikant zwischen den beiden Implantattypen. Entsprechend den geometrischen Gegebenheiten der porösen Implantate mit einer größeren Implantatoberfläche aufgrund der offenporigen Struktur war die direkte Implantat-Kochen-Kontaktfläche signifikant größer als bei der sandgestrahlten Kontrollgruppe.

Die histomorphologischen sowie histomorphometrischen Ergebnisse bestätigen die Hypothese, dass das neuartige offenporige Titanimplantat eine mindestens gleich gute Osseointegration im Vergleich zu dem sandgestrahlten Titanimplantat aufweisen würde. Der größere Knochen-Implantat-Kontakt sowie der Nachweis von neugebildetem, funktionellem Knochen in den Poren sprechen für eine überlegene Verankerungskraft der porösen Titanimplantate. Der Nachweis hierfür muss jedoch in einem biomechanischen Ausstoßversuch erbracht werden. 


\section{Anlage}

Anlage 6-1 ANOVA-Test Ergebnisse (p-Wert) des Vergleiches der Umfänge (mm) zwischen beiden Implantattypen (P und G).

\begin{tabular}{|l|l|}
\hline Effect & $\mathbf{p}$ \\
\hline Implantat & $<0,05$ \\
\hline BZR & 0,6873 \\
\hline Implantattiefe & 0,4511 \\
\hline Implantat x Monat & 0,3220 \\
\hline
\end{tabular}

Anlage 6-2 Mittelwert und Standardabweichung des Porositätsgrades (\%.) im Vergleich von ROI 4-6 und im zeitlichen Verlauf (4 und 12 Wochen BZR).

\begin{tabular}{|l|l|l|l|}
\hline ROI & 4-wöchiger BZR & 12-wöchiger BZR & $\mathbf{p}$ \\
\hline 4 & $27,2+/-2,35$ & $28,25+/-4,75$ & 0,2976 \\
\hline 5 & $25,78+/-4,3$ & $25,19+/-5,66$ & 0,6645 \\
\hline 6 & $23,93+/-2,51$ & $23,65+/-5,67$ & 0,8093 \\
\hline
\end{tabular}

Anlage 6-3 ANOVA Test Ergebnisse (p-Wert). Interobserver-Variabilität der Knochendichte (\%) unterteilt in Implantattyp und BZR.

\begin{tabular}{|l|l|l|}
\hline Effekt Knochendichte (\%) & 4-wöchiger BZR & 12-wöchiger BZR \\
\hline Implantattyp P & $\mathrm{p}=0,1362$ & $\mathrm{p}=0,0035$ \\
\hline Implantattyp G & $\mathrm{p}=0,2728$ & $\mathrm{p}=0,8546$ \\
\hline
\end{tabular}

Anlage 6-4 Mittelwert und Standardabweichung der Knochenanlagerung im zeitlichen Verlauf.

\begin{tabular}{|l|l|l|l|l|l|}
\hline Parameter & BZR & Gestrahlt & Porös & p & p.Holm \\
\hline Knochenanlagerung (\%) & 4 & $28,22+/-10,87$ & $27,17+/-8.86$ & 0,5054 & 0,5054 \\
& & & & & \\
\hline
\end{tabular}




\begin{tabular}{|c|c|c|c|c|c|}
\hline Parameter & BZR & Gestrahlt & Porös & $\mathrm{p}$ & p.Holm \\
\hline & 12 & $47,48+/-7,67$ & $41.35+/-9.67$ & $<0,05$ & $<0,05$ \\
\hline \multirow[t]{2}{*}{ Knochenanlagerung (mm) } & 4 & $5.72+/-2.19$ & $7.46+/-2.58$ & $<0,05$ & $<0,05$ \\
\hline & 12 & $9.52+/-1.5$ & $11.57+/-2.51$ & $<0,05$ & $<0,05$ \\
\hline
\end{tabular}

Anlage 6-5 ANOVA-Testergebnisse für den Effekt des Implantats, Implantattiefe und Implantat-Monat Interaktion.

\begin{tabular}{|l|l|l|}
\hline Parameter & Effect & $\mathbf{p}$ \\
\hline Knochenanlagerung (\%) & Implantat & $<0,05$ \\
\cline { 2 - 3 } & BZR & $<0,05$ \\
\cline { 2 - 3 } & Implantattiefe & 0,2015 \\
\cline { 2 - 3 } & Implantat x BZR & 0,1014 \\
\hline
\end{tabular}




\section{Literaturverzeichnis}

Albrektsson T, Zarb GA (1993): Current interpretations of the osseointegrated response: clinical significance. Int J Prosthodont $\underline{6}, 95-105$

Albrektsson T, Albrektsson B (1987): Osseointegration of bone implants. A review of an alternative mode of fixation Acta Orthop Scand. $\underline{58}, 567-577$

Albrektsson T, Branemark PI, Hansson HA, Lindstrom J (1981): Osseointegrated titanium implants. Requirements for ensuring a long-lasting, direct bone-to-implant anchorage in man. Acta Orthop Scand $\underline{52}, 155-170$

Albrektsson T, Johansson C (2001): Osteoinduction, osteoconduction and osseointegration. Eur Spine J, 96-101

Albrektsson T, Wennerberg A (2019): On osseointegration in relation to implant surfaces. Clin Implant Dent Relat Res, 4-7

Allori AC, Sailon AM, Pan JH, Warren SM (2008): Biological basis of bone formation, remodeling, and repair-part III: biomechanical forces. Tissue Eng Part B Rev 14, 285-293

Aparicio C, Gil FJ, Fonseca C, Barbosa M, Planell JA (2003): Corrosion behaviour of commercially pure titanium shot blasted with different materials and sizes of shot particles for dental implant applications. Biomaterials 24, 263-273

Barrère F, van der Valk CM, Dalmeijer Remco AJ, Meijer G, van Blitterswijk CA, de Groot K, Layrolle P (2003): Osteogenecity of octacalcium phosphate coatings applied on porous metal implants. Journal of Biomedical Materials Research Part A 66, 779-788

Basko-Plluska JL, Thyssen JP, Schalock PC (2011): Cutaneous and systemic hypersensitivity reactions to metallic implants. Dermatitis $\underline{22}, 65-79$

Bobyn JD, Pilliar RM, Cameron HU, Weatherly GC (1980): The optimum pore size for the fixation of porous-surfaced metal implants by the ingrowth of bone. Clin Orthop Relat Res $\underline{150}$, 263-270

Bobyn JD, Wilson GJ, MacGregor DC, Pilliar RM, Weatherly GC (1982): Effect of pore size on the peel strength of attachment of fibrous tissue to porous-surfaced implants. J Biomed Mater Res $\underline{16}$, $571-584$

Bonsignore LA, Colbrunn RW, Tatro JM, Messerschmitt PJ, Hernandez CJ, Goldberg VM, Stewart MC, Greenfield EM (2011): Surface contaminants inhibit osseointegration in a novel murine model. Bone $\underline{49}$, 923-930

Botticelli D, Lang NP (2017): Dynamics of osseointegration in various human and animal models a comparative analysis. Clin Oral Implants Res $\underline{28}, 742-748$

Boyan BD, Hummert TW, Dean DD, Schwartz Z (1996): Role of material surfaces in regulating bone and cartilage cell response. Biomaterials $\underline{17}, 137-146$ 
Bram M, Laptev A, Buchkremer HP, Stöver D (2004): Herstellung von hochporösen, endkoturnahen Titan-Formkörpern für biomedizinische Anwendung. Mater Sci Eng Technol $\underline{35}$, 213-218

Bram M: (2013) Pulvermetallurgische Herstellung von porösem Titan und von NiTi-Legierungen für biomedizinische Anwendungen. Schriften des Forschungszentrum Jülich $\underline{171}$

Branemark PI (1983): Osseointegration and its experimental background. J Prosthet Dent $\underline{50}$, 399410

Burr DB (2002): Targeted and nontargeted remodeling. Bone $\underline{30}, 2-4$

Burr DB, Robling AG, Turner CH (2002): Effects of biomechanical stress on bones in animals. Bone $\underline{30}, 781-786$

Buser D, Schenk RK, Steinemann S, Fiorellini JP, Fox CH, Stich H (1991): Influence of surface characteristics on bone integration of titanium implants. A histomorphometric study in miniature pigs. J Biomed Mater Res $\underline{25}$, 889-902

Cameron HU, Macnab I, Pilliar RM (1978): A porous metal system for joint replacement surgery. Int J Artif Organs 1, 104-109

Carter DR, Giori NJ: Effect of mechanical stress on tissue differentation in the bony implant bed. In: Davies JE, The biomaterial interface, Toronto Press, Toronto 1991, 367-379

Chang YS, Oka M, Kobayashi M, Gu HO, Li ZL, Kitsugi T, Nakamura T (1994): Bone formation and remodeling around implanted materials under load-bearing conditions. Clin Mater $\underline{17}, 181-187$

Dahl LK (1952): A simple and sensitive histochemical method for calcium. Proc Soc Exp Biol Med. 80, 474-479

Dalle Carbonare L, Valenti MT, Bertoldo F, Zanatta M, Zenari S, Realdi G, Lo Cascio V, Giannini S (2005): Bone microarchitecture evaluated by histomorphometry. Micron $\underline{36}$, 609-616

Delgado-Ruiz RGR (2018): Potential Causes of Titanium Particle and Ion Releasein Implant Dentistry: A Systematic Review. Int J Mol Sci $\underline{19}$

Diehl P. HM, Bergschmidt P., Gollwitzer H., Schauwecker J, Bader R., Mittelmeier W. (2010): Zementfreie Huftendoprothetik: eine aktuelle Übersicht. Biomed Tech 55, 251-264

Donath K, Breuner G (1982): A method for the study of undecalcified bones and teeth with attached soft tissues. The Sage-Schliff (sawing and grinding) technique J Oral Pathol 11, 318-326

Elias CN (2011): Factors affecting the success of dental implants, Implant dentistry - a rapidly evolvving practice. Rijeka InTech open, 319-364

Eliaz N (2019): Corrosion of Metallic Biomaterials: A Review Materials (Basel) 12

Eschenroeder HC, Jr., McLaughlin RE, Reger SI (1987): Enhanced stabilization of porous-coated metal implants with tricalcium phosphate granules. Clin Orthop Relat Res, 234-246

Freeman MA, Railton GT (1987): [Cementless fixation in endoprosthetics] Orthopade 16, 206-219 
Frosch KH, Barvencik F, Lohmann CH, Viereck V, Siggelkow H, Breme J, Dresing K, Sturmer KM (2002): Migration, matrix production and lamellar bone formation of human osteoblast-like cells in porous titanium implants. Cells Tissues Organs $\underline{170}$, 214-227

Frosch KH, Drengk A, Krause P, Viereck V, Miosge N, Werner C, Schild D, Sturmer EK, Sturmer KM (2006): Stem cell-coated titanium implants for the partial joint resurfacing of the knee. Biomaterials 27, 2542-2549

Galante J, Sumner DR, Gachter A (1987): [Surface structures and bone ingrowth in cement-free fixed prostheses] Orthopade $\underline{16}, 197-205$

Glatt V, Evans CH, Tetsworth K (2016): A Concert between Biology and Biomechanics: The Influence of Mechanical Environment on Bone Healing. Front Physiol 1, 678

Gotzen G, Hofmann CH (1992): Knochenersatz Aktueller Stand und Perspektiven Allgemeine Behandlungsgebiete, Teil II

Guden M, Celik E, Hizal A, Altindis M, Cetiner S (2008): Effects of compaction pressure and particle shape on the porosity and compression mechanical properties of sintered Ti6Al4V powder compacts for hard tissue implantation. J Biomed Mater Res B Appl Biomater 모, 547-555

Hartmann M: Ein Beitrag zur zellulären Bauweise von Implantatwerkstoffen nach dem Vorbild der Natur. hrsg. v.: Naturwissenschaftliche - Technische Fakultät III C, Pharmazie, Bio- und Werkstoffwissenschaften der Universität des Saarlandes. 2012

Head WC, Bauk DJ, Emerson RH, Jr. (1995): Titanium as the material of choice for cementless femoral components in total hip arthroplasty. Clin Orthop Relat Res $\underline{311}$, 85-90

Itala AI, Ylanen HO, Ekholm C, Karlsson KH, Aro HT (2001): Pore diameter of more than 100 microm is not requisite for bone ingrowth in rabbits. J Biomed Mater Res $\underline{58}, 679-683$

Ito K, Horiuchi T, Arai Y, Kawahara I, Hongo K (2014): Histological, mechanical, and radiological study of osteoformation in titanium foam implants. Acta Neurochir (Wien) 156, 2165-2172

Jager M, Gordes W, Kossyk W, Ungethum M (1976): [Flexural strength testing in conservatively (cast fixation and medullary splinting) and operatively (stable plate osteosynthesis) treated osteotomies of rabbit tibiae (author's transl)]. Unfallheilkunde 79, 193-201

Jakobsen SS, Larsen A, Stoltenberg M, Bruun JM, K. S (2007): Effects of as-cast and wrought CobaltChrome-Molybdenum and Titanium-Aluminium-Vanadium alloys on cytokine gene expression and protein secretion in J774A.1 macrophages. Eur Cell Mater. 14, 45-55

Klintström E, Klintström B (2016): Predicting Trabecular Bone Stiffness from Clinical Cone-Beam CT and HR-pQCT Data; an In Vitro Study Using Finite Element Analysis. 11

Knoch H: Knochenbruchheilung mit Ultraschall. Springer, Berlin Heidelberg New York 1990

Kopp S, Warkentin M, Ori F, Ottl P, Kundt G, Frerich B (2012): Section plane selection influences the results of histomorphometric studies: the example of dental implants. Biomed Tech (Berl) $\underline{57}$, $365-370$

Kulak CA, Dempster DW (2010): Bone histomorphometry: a concise review for endocrinologists and clinicians. Arq Bras Endocrinol Metabol 또, 87-98 
Lexer E (1924): Die freien Transplantationen. Neue Deutsche Chir. Bd. 26b Teil II

Lin X LT, Wu G, Zheng Y, Wismeijer D, Liu Y (2017): Peri-implantitis Induced by Stainless Steel Ligature in Beagle Dogs. Int J Periodontics Restorative Dent 37, e170-e179

Long M, Rack HJ (1998): Titanium alloys in total joint replacement--a materials science perspective. Biomaterials 19, 1621-1639

Marsell R, Einhorn TA (2011): The biology of fracture healing. Injury $\underline{42}$, 551-555

Morlock MM, Jäger M (2017 ): Endoprothetik des älteren Menschen. Orthopäde 46, 4-17

Murray GA, Semple JC (1981): Transfer of tensile loads from a prosthesis to bone using porous titanium. J Bone Joint Surg Br $\underline{63-B}, 138-141$

Nachtigall W: Bionik. Springer-Verlag Berlin Heidelberg 2002

Pauwels F (1973): [Short survey of mechanical stress of bone and its importance for the functional adaptation (author's transl)]. Z Orthop Ihre Grenzgeb 111, 681-705

Remes A, Williams DF (1992): Immune response in biocompatibility. Biomaterials $\underline{13}$, 731-743

Rosa AL, Crippa GE, Oliveira PT, Taba Jr M, Lefebvre L-P, Beloti MM (2009): Human alveolar bone cell proliferation, expression of osteoblastic phenotype, and matrix mineralization on porous titanium produced by powder metallurgy. Clin Oral Implants Res $\underline{5}, 472-481$

Rubin C, Turner AS, Bain S, Mallinckrodt C, McLeod K (2001): Anabolism. Low mechanical signals strengthen long bones. Nature $\underline{412}$, 603-604

Rubin CT, Lanyon LE (1985): Regulation of bone mass by mechanical strain magnitude. Calcif Tissue Int $\underline{37}, 411-417$

Ryan G, Pandit A, Apatsidis DP (2006): Fabrication methods of porous metals for use in orthopaedic applications. Biomaterials $\underline{27}, 2651-2670$

Schenk R, Willenegger H (1976): Histologie der primären Knochenheilung. Arch Klin Chir 19: 593

Schmidt M (1992): Spezifische Absorption organischer Moleküle auf oxidiertem Titan: Bioaktivität auf molekularen Niveau. Osteologie Band 1, 222-235

Schmit-Neuenburg KP, Stuermer KM (eds): Die Tibiaschaftfraktur des Erwachsenen. SpringerVerlag Berlin Heidelberg New York 1987

Simancik F: Introduction: the strange World of Cellular Metals. In Handbook of Cellular Metals. Wiley-VCH Verlag GmbH\& Co. KGaA 2002

Simsek I, Ozyurek D (2019): Investigation of the wear and corrosion behaviors of Ti5 Al2.5Fe and Ti6Al4V alloys produced by mechanical alloying method in simulated body fluid environment. Mater Sci Eng C Mater Biol Appl 94, 357-363

Smith LG, Karadgianes MT (1974): Histological preparation of bone to study ingrowth into implanted materials. Calcif Tissue Res, 333-337

Soldner E (1999): Knorpel-Knochen-Transplantation. Trauma Berufskrankh, 204-208 
Somanathan RV. SA (2006): Evaluation of the success of beta-tricalciumphosphate and deproteinized bovine bone in maxillary sinus augmentation using histomorphometry: a review. Acta Medica (Hradec Kralove) 2, 87-89

Sumner DR, Olson CL, Freeman PM, Lobick JJ, Andriacchi TP (1989): Computed tomographic measurement of cortical bone geometry. J Biomech 22, 649-653

Tengvall P, Lundstrom I (1992): Physico-chemical considerations of titanium as a biomaterial. Clin Mater $\underline{9}, 115-134$

Thomas KA, Kay JF, Cook SD, Jarcho M (1987): The effect of surface macrotexture and hydroxylapatite coating on the mechanical strengths and histologic profiles of titanium implant materials. J Biomed Mater Res 21, 1395-1414

Torres-Sanchez C, Al Mushref FRA, Norrito M, Yendall K, Liu Y, Conway PP (2017): The effect of pore size and porosity on mechanical properties and biological response of porous titanium scaffolds. Mater Sci Eng C Mater Biol Appl 77, 219-228

Urist MR, Johnson RWJ (1943): Calcification and ossification: IV. The healing of fractures in man under clinical conditions JBJS $\underline{25}, 375-426$

Vasconcellos LM, Leite DO, Olivera FN, Cairo CA (2010): Evaluation of bone ingrowth into porous titanium implant: histomorphometric analysis in rabbits. Implantology

Wazen RM, Lefebvre LP, Baril E, Nanci A (2010): Initial evaluation of bone ingrowth into a novel porous titanium coating. J Biomed Mater Res B Appl Biomater 94, 64-71

Wennerberg A, Albrektsson T, Anderson B (1995): An animal study of c.p. titanium screw with different surface topographies. Journal of Materials science: Materials in Medicine $\underline{6}, 302-309$

Wennerberg A, Albrektsson T, Chrcanovic B (2018): Long-term clinical outcome of implants with different surface modifications. Int J Oral Implantol 11, S123-s136

White RA, Weber JN, White EW (1972): Replamineform: a new process for preparing porous ceramic, metal, and polymer prosthetic materials. Science 176, 922-924

Wissing H, Stürmer, K. M. und Breidenstein, G. (1990): Die Wertigkeit verschiedener Versuchstierspecies für experimentelle Untersuchungen am Knochen. Hefte Unfallheilkd, 479-488

Wolff J (1892): Das Gesetz der Transformation der Knochen. Hirschwald, Berlin

Wong M, Eulenberger J, Schenk R, Hunziker E (1995): Effect of surface topology on the osseointegration of implant materials in trabecular bone. J Biomed Mater Res $\underline{29}$, 1567-1575 


\section{Danksagung}

Mein besonderer Dank gilt Dipl.Ing. Gottfried Buchhorn für seine kompetente Betreuung und gedultsame Korrekturphase. Ohne seinen großen Wissens- und Erfahrungsschatz wäre die Umsetzung dieser Dissertationarbeit nicht möglich gewesen.

Meinem Doktorvater Prof. Dr. med. László Fuzesi bin ich für seine unglaubliche Unterstützung, seine Inspiation und Begeisterungsfähigkeit, nicht nur während dieser Arbeit, sondern auch während meiner studentischen und beruflichen Laufbahn, überaus dankbar. 
$\longrightarrow$ 